NEON ISOTOPE SEPARATION BY GASEOUS DIFFUSION TRANSPORT IN THE TRANSITION FLOW REGIME WITH REGULAR GEOMETRIES

AUTHORS:

D. E. Fain

W. K. Brown

\title{
OAK RIDGE GASEOUS DIFFUSION PLANT
}

\section{OAK RIDGE, TENNESSEE}

prepared for the U.S. ATOMIC ENERGY COMMISSION

under U.S. GOVERNMENT Contract W.7405 eng 26 


\section{DISCLAIMER}

This report was prepared as an account of work sponsored by an agency of the United States Government. Neither the United States Government nor any agency Thereof, nor any of their employees, makes any warranty, express or implied, or assumes any legal liability or responsibility for the accuracy, completeness, or usefulness of any information, apparatus, product, or process disclosed, or represents that its use would not infringe privately owned rights. Reference herein to any specific commercial product, process, or service by trade name, trademark, manufacturer, or otherwise does not necessarily constitute or imply its endorsement, recommendation, or favoring by the United States Government or any agency thereof. The views and opinions of authors expressed herein do not necessarily state or reflect those of the United States Government or any agency thereof. 


\section{DISCLAIMER}

Portions of this document may be illegible in electronic image products. Images are produced from the best available original document. 
Printed in the United States of America. Available from

National Technical Information Service

U.S. Department of Commerce

5285 Port Royal Road, Springfield, Virginia 22151

Price: Printed Copy $\$ 5.45$; Microfiche $\$ 1.45$

This report was prepared as an account of work sponsored by the United States Government. Neither the United States nor the United States Atomic Energy Commission, nor any of their employees, nor any of their contractors, subcontractors, or their employees, makes any warranty, express or implied, or assumes any legal liability or responsibility for the accuracy, completeness or usefulness of any information, apparatus, product or process disclosed, or represents that its use would not infringe privately owned rights. 


\section{Date of Issue: September 13, 1974 Report Number: K-1863 \\ Subject Category: UC-22, Isotope Separation}

\section{NEON ISOTOPE SEPARATION BY GASEOUS DIFFUSION TRANSPORT IN THE TRANSITION FLOW REGIME WITH REGULAR GEOMETRIES}

D. E. Fain and W. K. Brown

Experimental Barrier Development Department

Gaseous Diffusion Development Division

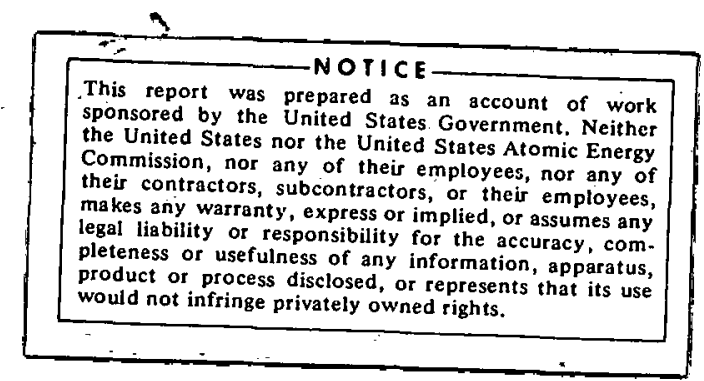

\section{UNION CARBIDE CORPORATION NUCLEAR DIVISION}

Oak Ridge Gaseous Diffusion Plant

nak Ridge, Tennessee 


\section{THIS PAGE}

\section{WAS INTENTIONALLY \\ LEFT BLANK}




\section{$\underline{\text { ABSTRACT }}$}

A comprehensive study of the pressure dependence of the transport and transport ratio of neon isotopes by gaseous diffusion through regular geometries has been made. The pressure range was such that the knudsen number or the ratio of capillary radius to gas mean free path varied from about 0.05 to 10 . The measurements were made using paralle1 plates and capillaries with radii from $5 \mu$ to $25 \mu$, length-to-radius ratios from 4 to 900 , and materials of construction including glass, plastic, and gold. The results are compared with available theories and an interpolation formula for the data is given, which is an empirical modification of the Present and deBethune theory to include effects of flow anomalies and real gas flow pressure dependence. Both the flow and transport ratio measurements clearly show anomalies which are probably caused by deviations from cosine 1 aw wall scattering, but they are not completely consistent with each other. 
THIS PAGE

\section{WAS INTENTIONALLY LEFT BLANK}


TABLE OF CONTENTS

$\underline{\text { Page }}$

LIST OF TABLES • • • • • • • • • • • • • • • • • • 7

LIST OF FIGURES. • • • • • • • • • • • • • • • • • . • 9

INTRODUCTION. • • • • • • • • • • • • • • • • •

SUMMARY • • • • • • • • • • • • • • • • • • •

REVIEW OF THE FLOW AND SEPARATION PHENOMENA $•$ • • • • • • • • 16

TRANSPORT PROCESSES • . . . . . . . . • . . . . . 16

Poiseuille and Knudsen Flow . . . . . . . . . . . 16

Slip Flow . . . . . . . . • . . • . . . . . 16

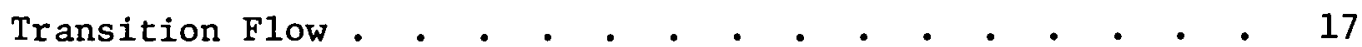

BINARY SEPARATION. • . • • . . • . • • • . • • . 24

Experimental Design. • • . . • . • • • • • . . 25

MATHEMATICAL MODELS • • • • • • • • • • • • • • • 27

PRESENT AND deBETHUNE MODEL (PBM) • • • • • • • • • • • 27

MODIFIED PRESENT AND deBETHUNE MODEL (PBFM) • • • • • • • • 31

GENERAL CAPILLARY MODEL (GCM) • • • • • • • • • • • • 32

EXPERIMENTAL TEST SAMPLES • • • • • • • • • • . • • • • . 34

SAMPLE SELECTION • • • • • • • • • • • • • • • • • • 34

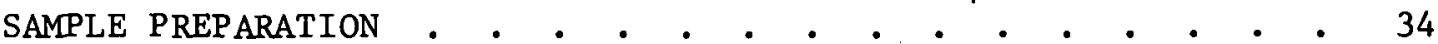

Capillary Samples . • • . • • . • • • • • . 36

Short Capillary Sample. . . . . . . . . . . . . 43

Parallel Plate Samples. . . . . . . . . . . . . 43

FLOW MEASUUKEMENT S. • • • • • • • • • • • . • • 43

SEPARATION MEASUREMENTS. • • • • • • • • • • • • • • • • 48

SEPARATION EFFICIENCY CALCULATION METHOD . • • • • • • • 56

DISCUSSION OF RESULTS. • • • • • • • • • • • • • • • • • • 60

CONCLUSIONS • • • • • • • • • • • • • • • • • • • • 97

ACKNOWLEDGMENTS. . . • . . . . . . . . . . . . . . 101

BIBLIOGRAPHY. • • • • • • • • • • • • • • • • . . 1n2

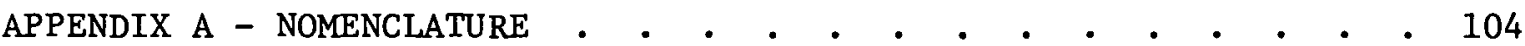

APPENDIX B - COMPLLATION OF DATA • . • . • • • . . . . 106

APPENDIX C - ACCURACY AND PRECISION • • • • • • • • • . • .

MASS SPECTROMETER MEASUREMENTS • . . • . • . . . • . 131

FLOW MEASUREMENTS. • • • • • • • • • • • • • • • 131 


\section{THIS PAGE}

\section{WAS INTENTIONALLY LEFT BLANK}


LIST OF TABLES

Table

$\underline{\text { Page }}$

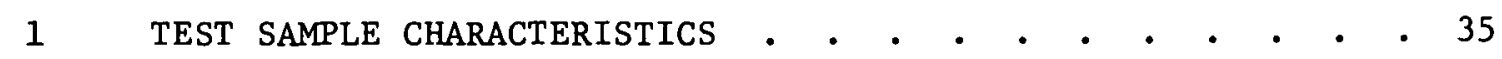

2 FLOW MEASUREMENT PARAMETERS • • • • • • • • • • • . . 49

3 CONSTANTS FOR THE MODIFIED PRESENT AND deBETHUNE MODEL • • 69

4 MEASURES OF CAPILLARY RADIUS . • • • • • • • • • • • 73

5 DEVIATION FROM DIFFUSE WALL SCATTERING IMPLIED BY MEASUREMENTS • • • • • • • • • • • • • • • • 74

6 VARIATION IN FLOW PARAMETERS FOR SMALLEST GLASS CAPILLARIES. 75

7 COMPARISON OF GCM PARAMETERS OBTAINED FROM FLOW MEASUREMENTS WITH THOSE NEEDED TO FIT THE SEPARATION DATA. . • 78

8 SEPARATION EFFICIENCY INITIAL SLOPE RATIOS COMPARED WITH

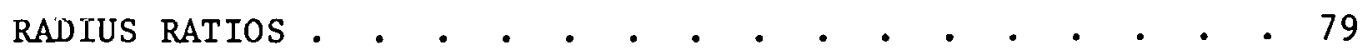

9 COMPARISON OF THE STANDARD DEVIATION OF THE EXPERIMENTAL DATA OBTAINED WITH THE DIFFERENT MODELS.$\quad \cdot \quad \cdot \quad \cdot \quad \cdot \quad \cdot 83$

10 THE MODIFICATION CONSTANT $K$ FOR THE PRESENT AND deBETHUNE MODEL FOR DIFFERENT GEOMETRIES AND CALCULATION METHODS • • 93

C-1 COMPARISON OF FLOW MEASUREMENTS FROM A VOLUMETRIC SYSTEM WITH THOSE FROM A GRAVIMETRIC SYSTEM • • • • • • • • 132

C-2 COMPARISON OF MEASURED AND THEORETICAL VALUES FOR DIFFERENT GASES • • • : • • • • • • • • • • • • • 133 
THIS PAGE

WAS INTENTIONALLY

LEFT BLANK 
LIST OF FIGURES

$\underline{\text { Figure }}$

$\underline{\text { Page }}$

1 LOW PRESSURE NITROGEN FLOW DATA FOR A 25.97-MICRON-RADIUS ORIFICE SAMPLE. • • • • • • • • • • • • • • • • • 18

2 HIGH PRESSURE NITROGEN FLOW DATA FOR A 25.97-MICRON-RADIUS ORIFICE SAMPLE. • • • • • • • • • • • • • • • • • • • 19

3 LOW PRESSURE NITROGEN FLOW DATA FOR A 4.907-MICRON-RADIUS GLASS CAPILLARY • • • • • • • • • • • • • . • 20

4 HIGH PRESSURE NITROGEN FLOW DATA FOR A 4.907-MICRON-RADIUS GLASS CAPILLARY • • • • • • • • • • • • • • • 21

5 LOW PRESSURE NITROGEN FLOW DATA FOR A 10.29-MICRON PARALLEL PLATE SAMPLE • • • • • • • • • • • • • • • • 22

6 HIGH PRESSURE NITROGEN FLOW DATA FOR A 10.29-MICRON PARALlEL PLATE SAMPLE • • • • • • • • • • • . . 23

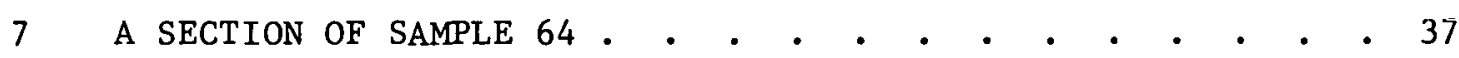

8 GLASS CAPILLARY FROM SAMPLE 64 .

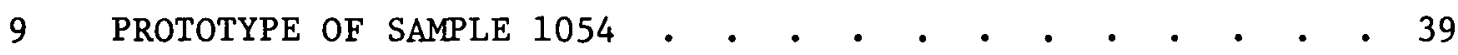

10 SAMPLE 1054. . . . . . . . . . . . . . . . . . 40

11 GLASS CAPILLARY USED IN SAMPLE 1054. • • • • • • • • 41

12 STAINLESS STEEL WIRE ON METAL FRAME. • • • • • • • • 41

13 METAL FRAMES WITH STAINLESS STEEL WIRE CAST IN PLASTIC • • 42

14 CAPILlaries in Plastic SAMPle. • • • • • • • • • • 42

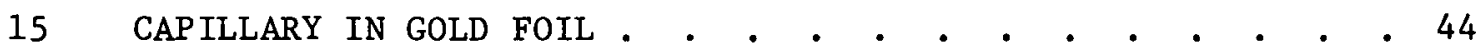

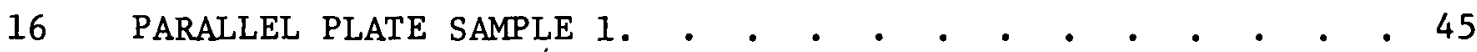

17 INERT GAS SEPARATION SYSTEM • • • • • • • • • • • . . 50

18 HIGH PRESSURE SIDE OF SAMPLE HOTIDER. - • • • • • • . 52

19 LOW PRESSURE SIDE OF SAMPLE HOLDER • • • • • • • •

20 COMPLETE HOLDER ASSEMBLY • • • • • • • • • • • • 54

21 INERT GAS SEPARATION SYSTEM • • • • • • • • • • • • 57 
LIST OF FIGURES (cont'd.)

Figure

$\underline{\text { Page }}$

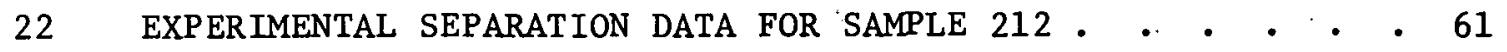

23 EXPERIMENTAL SEPARATION DATA FOR SAMPLE 838 . • • • • • • 62

24 EXPERIMENTAL SEPARATION DATA FOR SAMPLE 924 . • • • • • 63

25 EXPERIMENTAL SEPARATION DATA FOR SAMPLE 1054. • • • • . 64

26 EXPERIMENTAL SEPARATION DATA FOR SAMPLE 64 • • • • • • 65

27 EXPERIMENTAL SEPARATION DATA FOR SAMPLE 2. • • • • • • 66

28 EXPERIMENTAL SEPARATION DATA FOR SAMPLE 1. • . • • • • • 67

29 EXPERIMENTAL SEPARATION DATA FOR SAMPLE 5. • • • • • • 68

30 EFFECTIVE PRESSURE PARAMETER FOR SEPARATION • • • • • • 71

31 SEPARATION EFFICIENCY OF 4.907-MICRON-RADIUS GLASS

CAPILLARY SAMPLE • • • • • • • • • • • • • • • 72

32. BEST AGREEMENT BETWEEN EXPERIMENTAL DATA AND THEORETICAL

CURVES USING ADJUSTED PARAMETERS. • • • • • • • • 76

33 SEPARATION EFFICIENCY OF 12.91-MICRON-RADIUS PLASTIC

CAPILLARY SAMPLE • • • • • • • • • • • • • • 80

34 SEPARATION EFFICIENCY OF A 12.65-MICRON-RADIUS PLASTIC

CAPILLARY SAMPLE • . • • • • . • • • • . • • 81

35 SEPARATION EFFICIENCY OF 22.01-MICRON-RADIUS GLASS

CAPILLARY SAMPLE • • • • • • • • • • • • • • 82

36 CUT CURVE FOR A 12.65-MICRON-RADIUS CAPILLARY SAMPLE • • • 85

37 CUT CURVE FOR A 4.907-MICRON-RADIUS CAPILLARY SAMPLE • • • 86

38 LOW PRESSURE SEPARATION EFFICIENCY DATA FOR 4.907-MICRONRADIUS GLASS CAPILLARY SAMPLE. • . • • • • • • . 88

39 LOW PRESSURE SEPARATION EFFICIENCY DATA FOR 12.65-MICRON-

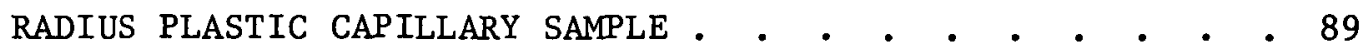

40 COMPARISON OF GLASS LONG CAPILLARY, ORIFICE, AND PARALLEL PLATE DATA IN LOW PRESSURE REGION . . . . . . . . . 90

41 COMPARISON OF SEPARATION EFFICIENCY OF LONG CAPILLARY, ORIFICE, AND PARALLEL PLATE • • • • • • • • • • • 91 
11

LIST OF FIGURES (cont'd.)

Figure

$\underline{\text { Page }}$

42 SEPARATION EFFICIENCY OF 25.97-MICRON-RADIUS GOLD ORIFICE SAMPLE • • • • • • • • • • • • • • • • • • • • 92

43 SEPARATION EFFICIENCY OF STEEL PARALLEL PLATE SAMPLE WITH PLATE SPACING OF 25.58 MICRONS . . . • . • . . . . 94

44 SEPARATION EFFICIENCY OF STEEL PARALLEL PLATE SAMPLE WITH PLATE SPACING OF 10.29 MICRONS • • • • • • • • • • . 95 
THIS PAGE

WAS INTENTIONALLY

LEFT BLANK 
NEON ISOTOPE SEPARATION BY GASEOUS DIFFUSION TRANSPORT IN THE TRANSITION FLOW REGIME WITH REGULAR GEOMETRIES

\section{INTRODUCTION}

It has been known for over one hundred years that the different gas species in a mixture can be partially separated by passing the gas mixture through a porous material if the dimensions of the openings in the material are small in comparison to the mean free path of the gas molecules. About 25 years ago, R. D. Present and A. J. deBethune [1] developed a theory for the separation of a binary gas mixture flowing through circular capillaries. Until now, there has been no definitive data which could be used to check the theory of Present and deBethune. The purpose of this study has been to obtain accurate data for the separation of a binary isotopic mixture flowing through well-defined regular geometries. These data are needed to define the effect of geometry on the pressure dependence of the separation phenomena and provide the information needed to check the theory of Present and deBethune or any other theory which may become available.

A comprehensive study of the pressure dependence of the separation of neon isotopes by gaseous diffusion through regular geometries has been made and the results are given in this report. Separation measurements have been made with capillaries with different length-to-radius ratios and with parallel plate geometries. The results are compared with available theories and an interpolation formula is also given.

The results of this study will be presented as follows. First, a summary of the report is given to indicate the general results which have been found. A discussion of the theories available is presented along with how they affect sample selections and define the experimental data which are needed. Some points of historical interest in the development of this subject are also given. The techniques of sample preparation are discussed next. A discussion of the flow measurement apparatus and the differences in details of the flow data obtained with different geometries are given. The separation apparatus, the measurement technique, and the data reduction are discussed. The results of the flow and the separation measurements are presented and their comparison with theory is discussed. In addition, an interpolation formula for the data and its possible physical significance is discussed. Finally, the conclusions reached as a result of this study and recommendations for further work are indicated.

Several appendices are included. Appendix A gives a listing of all symbols used and their definitions. Appendix B gives a listing of the separation data which were obtained. Appendix $C$ gives information relative to the precision and accuracy of measurements. 


\section{SUMMARY}

A listing of all the separation data which were obtained is given in Appendix B. Separation measurements were made with glass capillaries with radii of nominally $5 \mu$ and $25 \mu$ and length-to-radius ratios of nominally 900 and 450; with plastic capillaries with radii of nominally $12 \mu$ and $25 \mu$ and length-to-radius ratios of nominally 600 and 200; with gold capillaries with radii of nominally $25 \mu$ and a length-to-radius ratio of about 4; and with metal parallel plates with spacing of nominally $10 \mu$ and $25 \mu$ and length-to-spacing ratios of nominally 900 and 350 . An accurate determination of the capillary radii and the plate spacing was made by flow measurements.

When the experimental separation data are first examined on a broad scale, there appears to be no fundamental difference in the pressure dependence of the separation efficiency in these different geometries in contrast to the large differences in the pressure dependence of the flow in these same geometries. This result would appear to be consistent with the Present and deBethune theory using the hydraulic radius concept, and is probably due to the fact that most of the differences in the pressure dependence of the flows occur in the pressure region where the separation efficiency is above about 0.90. These differences in the pressure dependence of the flow do produce differences in the initial slope of the separation efficiency ratio curves, but these differences are not as dramatic as the differences in the flow curves. Apparently, below separation efficiencies of about 0.90 , the separation curves are influenced more by slip flow than by free molecule flow. Since slip flow depends only on the hydraulic radius and not other details of geometry, the pressure dependence of separation appears to be essentially independent of geometry other than hydraulic radius below a separation efficiency of about 0.90 .

Of the separation theories presently available, the Present and deBethune theory [1] generally predicts separation results somewhat lower than those which are measured. A calculation method by Malling [2], which is based on the flow equations of Lund and Berman [3] and is called the general capillary separation theory, generally predicts separation results higher than those of the Present and deBethune theory. Although closer to the measured values, they are still too low particularly in the region of separation efficiencies below about 0.60. An empirical modification of the Present and deBethune theory has been made to give a better approximation to the experimental data. This modification accounts for the change in flow velocity from the free molecule value to the slip value and in-. cludes a parameter to account for deviations from ideal free molecule flow. This empirical modification has resulted in calculations of separation efficiency ratios which agree most closely with the measured values and is considered the best interpolation formula for the data.

A closer inspection of the data reveals that deviations from diffuse scattering of molecules from the capillary walls were observed with these samples and that these deviations which affect the flow rates also affect 
the slopes of the separation curves. The geometry of the flow channel also affects the relationship between the initial slopes of the separation curves and the channel dimension. In the modified Present and deBethune theory, the differences observed due to deviations in the wall scattering 1 aw and differences due to geometry appear in terms of the constants required to represent the experimental data. The constants indicating deviations in wall scattering are generally in about the same ratio as those obtained from the flow measurements. However, the constants relating to differences in geometry do not seem to be consistent with what would be predicted from the Clausing calculation of free molecule flow.

It is observed that in addition to this modification of the Present and deBethune theory, some apparently arbitrary changes in the Lund and Berman flow parameters can result in significantly better agreement with the experimental data obtained with the general capillary separation theory. This could imply that the Lund and Berman flow parameters were not appropriately determined. In fact, it is shown that the Lund and Berman flow equations result in significantly better agreement with the separation data when they are used as differential equations rather than an integrated equations as they were originally presented.

One change in the flow constants which results in better agreement with the separation data is a simple translation of the specific flow or transmission ratio with respect to the theoretical value as calculated by Clausing. However, the changes with respect to scattering law deviations are such as to. indicate that the difficulties with the Malling calculation are of a more fundamental nature. The fact that both models indicate that the Clausing transmission probability may not be the best estimate of the flow velocity for predicting the pressure dependence of the separation efficiency ratios is probably sufficient reason to question the accuracy of the Clausing calculation. The accuracy is particularly questionable for the parallel plate geometries. It is relatively difficult to extrapolate the transmission ratio curves to zero pressure to determine accurately the free molecule transmission ratios for comparison with calculations. However, the differences between the measured and calculated separation efficiency ratio curves are clearly distinguishable and indicate a serious discrepancy between theory and measurement.

Further separation efficiency studies, particularly with parallel plate geometries, should be very helpful. These studies should include plates with different surfaces such as glass and a stable metal such as gold. The studies should also include parallel plates with an order of magnitude or greater difference in length-to-spacing ratio. 
REVIEW OF THE FLOW AND SEPARATION PHENOMENA

The kinetic theory of gases is most important in any study of the detailed motion of a gas. The major developments in the kinetic theory of gases occurred between about 1857 and 1880 by Clausius [4], Maxwe11 [5], and Boltzmann [6]. But even before the development of kinetic theory, Graham [7] in 1829 showed that the effusion rate of a gas through a small orifice was proportional to the square root of the gas density and therefore could be used as a means of partially separating the components of a gas mixture. However, it was almost 100 years before Aston [8], in 1920, made practical use of this phenomenon to separate the isotopes of neon.

\section{TRANSPORT PROCESSES}

Before discussing the separation phenomena, some aspects of the transport process should be discussed. Kinetic theory accounts for the properties of a gas by treating the gas as an ensemble of molecules with random motions but with a definite distribution of velocities. The equilibrium velocity distribution, which was first determined by Maxwell, defines an average kinetic energy for the molecules which is proportional to the temperature of the gas. In its simplest form, the molecules are treated as billiard balls bouncing around at random colliding with each other. The average distance moved between a collision with another molecule is the mean free path and the number of collisions per unit time is the collision frequency.

\section{Poiseuille and Knudsen Flow}

When a gas flows through a channel under pressure and temperature conditions such that the mean free path is small compared to the smallest dimension of the flow channel, then there is a thorough exchange of momentum among the colliding molecules and the gas flows as a viscous continuum mass and is of ten called Poiseuille flow. When the mean free path is large compared to the characteristic channel dimension, then the molecules collide with the walls of the channel much more frequently than with each other, and therefore they tend to flow through the channel with their own characteristic thermal velocities. In the limit where there are no collisions between molecules, the flow is known as free molecule or Knudsen flow. The transport process results in a maximum separation of the components of a gas mixture when the flow is free molecule and no separation occurs when the flow is entirely viscous.

\section{Slip Flow}

In 1875, while studying the viscous damping of a vibrating disk by a surrounding gas, Kundt and Warburg [9] found that at low pressures the damping decreased. They attributed this effect to a slipping of the gas over the surface of the disk. In 1879 Maxwell developed an approximate theory to account for the slip effect. This effect is always observed when a gas flows past a stationary surface. In the early 1900's Knudsen [10] studied the flow of gases through capillaries at low pressures. He 
showed that, as is indicated by Maxwell's slip theory, at high pressures slip flow is directly proportional to the pressure difference and independent of the pressure level, but at a sufficiently low pressure slip flow per unit pressure difference increases and extrapolates to a higher value at zero pressure. Knudsen explained the zero pressure limit in terms of a free molecule flow. This effect can best be observed by plotting the specific flow (mass or molar flow per unit pressure difference) as a function of the average pressure. At high pressures, the curve is linear with average pressure and extrapolates to a finite value at zero average pressure. The extrapolated value at zero pressure is due to the constant slip flow per unit pressure drop at the high pressures. At sufficiently low pressures, such that the gas mean free path is comparable to the capillary radius, a minimum is observed in the specific flow curve. At very low pressures the curve extrapolates to the higher free molecule value. Free molecule flow is similar to slip flow but larger in magnitude. These features in the specific flow curves can be seen in figures 1 through 6 . Other experimental investigations of significance were performed during this period by Gaede [11] and Adzumi [12]. Gaede performed experiments with a parallel plate channel and showed that the minimum in the specific flow curve was much deeper than it was with a capillary.

\section{$\underline{\text { Transition Flow }}$}

It has only been in recent years that a reasonable explanation for the minimum in the specific flow curve has been given. In 1948 Pollard and Present [13] developed a theory for the variation with pressure of the self-diffusion coefficient of a gas in a capillary. While this theory was applicable only to the diffusion of a gas with no net pressure difference across the capillary, it did give a qualitative explanation for the Knudsen minimum in terms of a decrease in the diffusion coefficient. They suggested that, at least at low pressures, the total flow might be described by the superposition of a diffusive flow as computed in their paper and a viscous drift component. In 1951 visner [14], using xenon isotopes, showed that the Pollard and Present theory could accurately account for the variation with pressure of the self-diffusion coefficient. In 1952 Hiby and Pah1 [15] used the same approach as Pollard and Present to describe the self-diffusion of a gas between infinite parallel plates. They showed that for the parallel plate, the decrease in the diffusion coefficient with pressure was more rapid than with a capillary and therefore qualitatively accounts for the difference in depth of the Knudsen minimum for these two geometries.

In 1954 Weber [16] applied the idea of the superposition of a diffusive and drift component to describe Knudsen's flow data quantitatively. He assumed that the total gas transport in a long capillary is given at all pressures by the addition of (1) a diffusive component as obtained from the Pollard and Present calculation, (2) a slip component which is zero at zero pressure and rises to a constant value at large pressure, and (3) a viscous component, which rises linearly from zero at zero pressure. In 1965 Lund and Berman [3] extended the superposition idea to include 
DWG. NO. G-72-1155

(U)

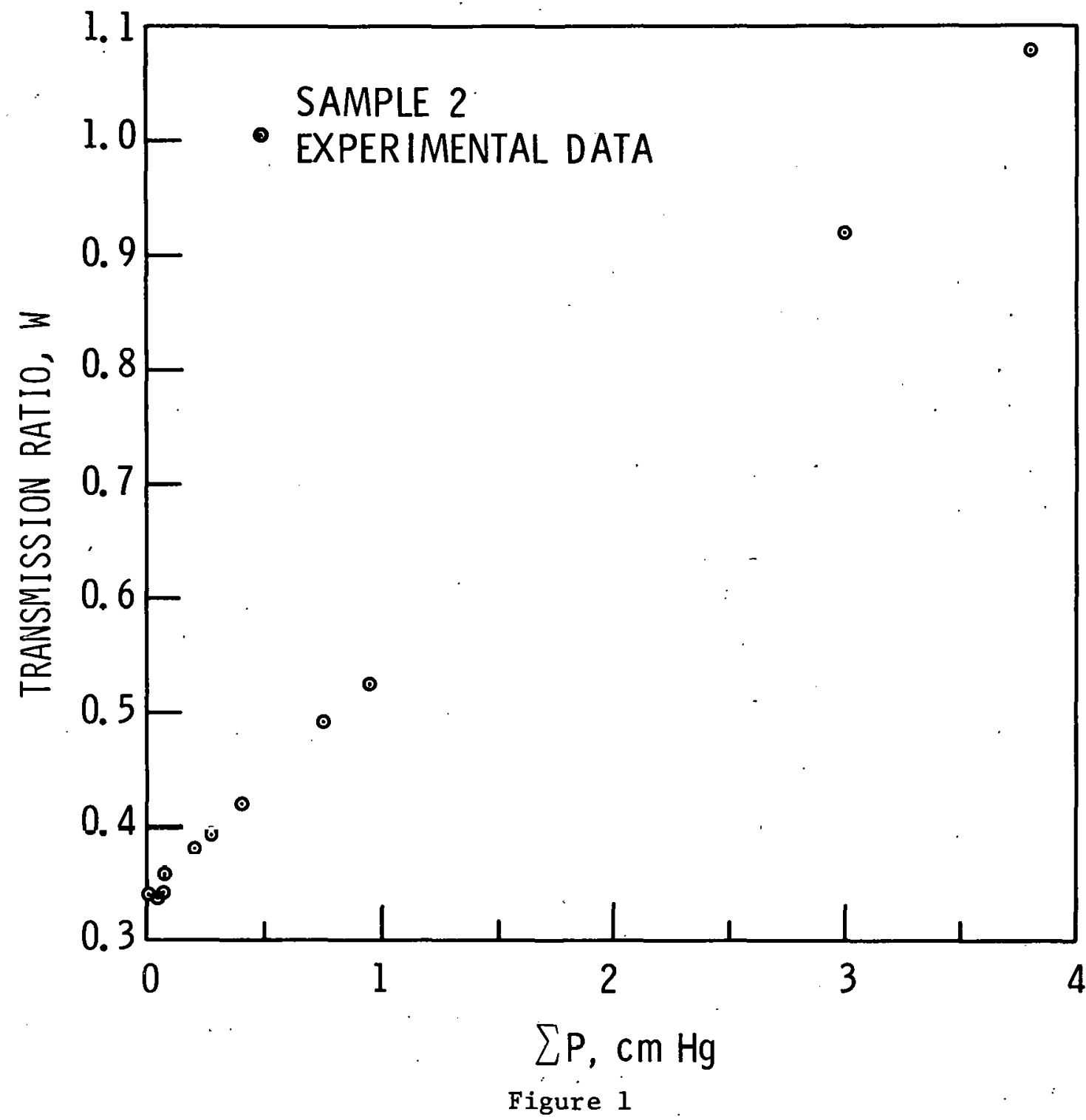

LOW PRESSURE NITROGEN FLOW DATA FOR

A 25. 97-MICRON-RADIUS ORIFICE SAMPLE 
DWG. NO. G-72-1154

(U)

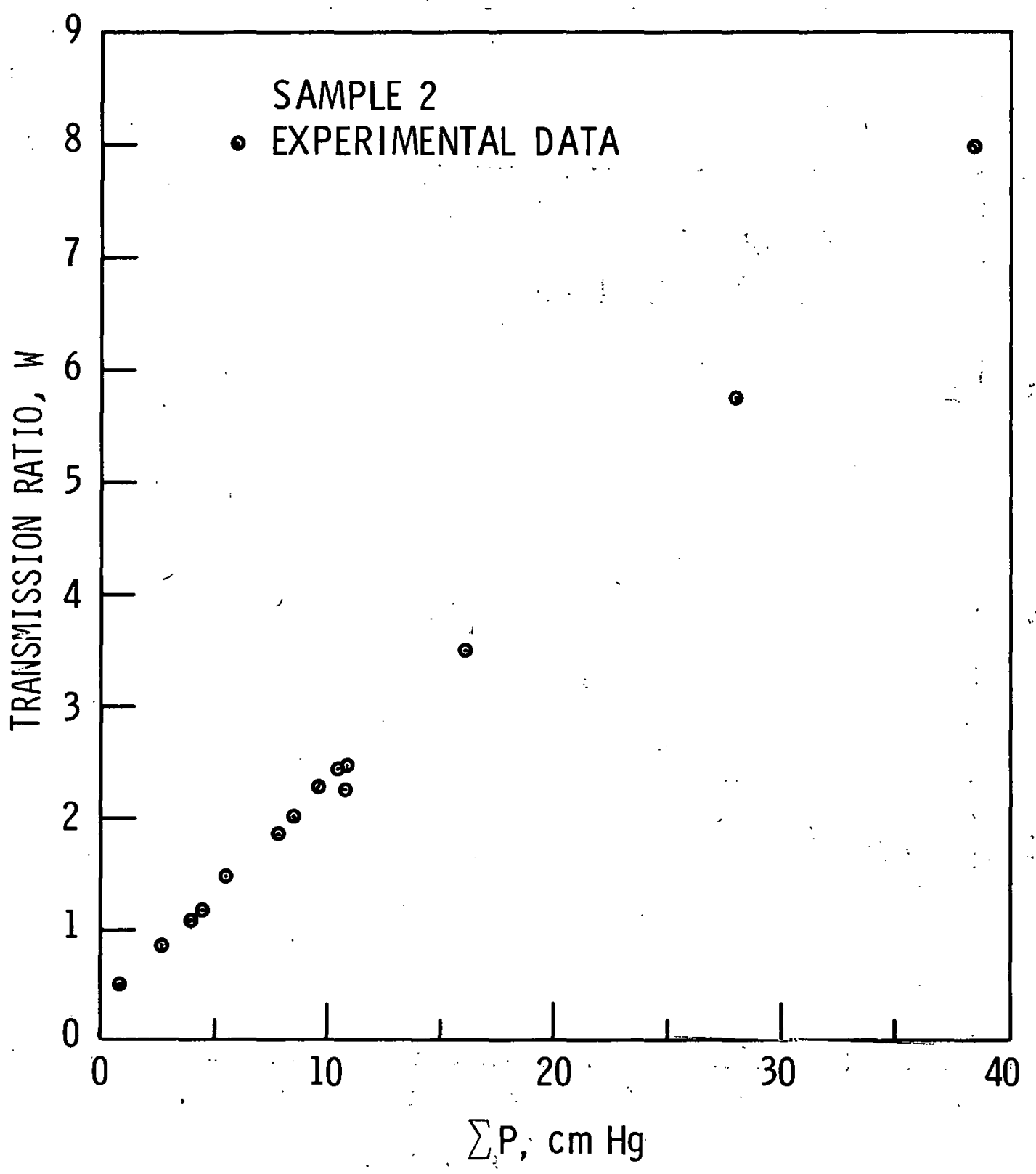

Figure 2

HIGH PRESSURE NITROGEN FLOW DATA FOR

A 25.97-MICRON-RADIUS ORIFICE SAMPLE 


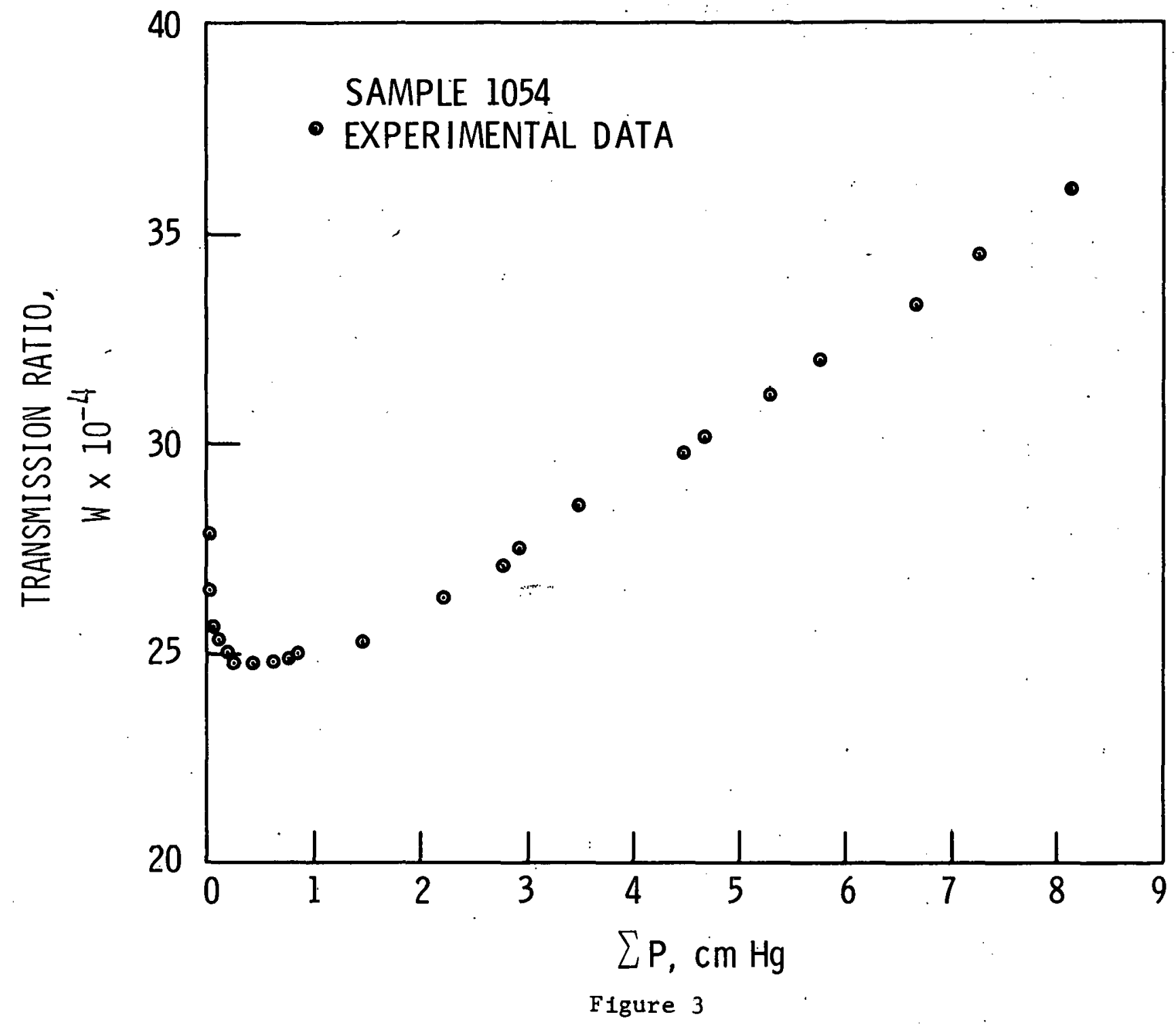

LOW PRESSURE NITROGEN FLOW DATA FOR A 4.907-MICRON-RADIUS GLASS CAPILLARY 


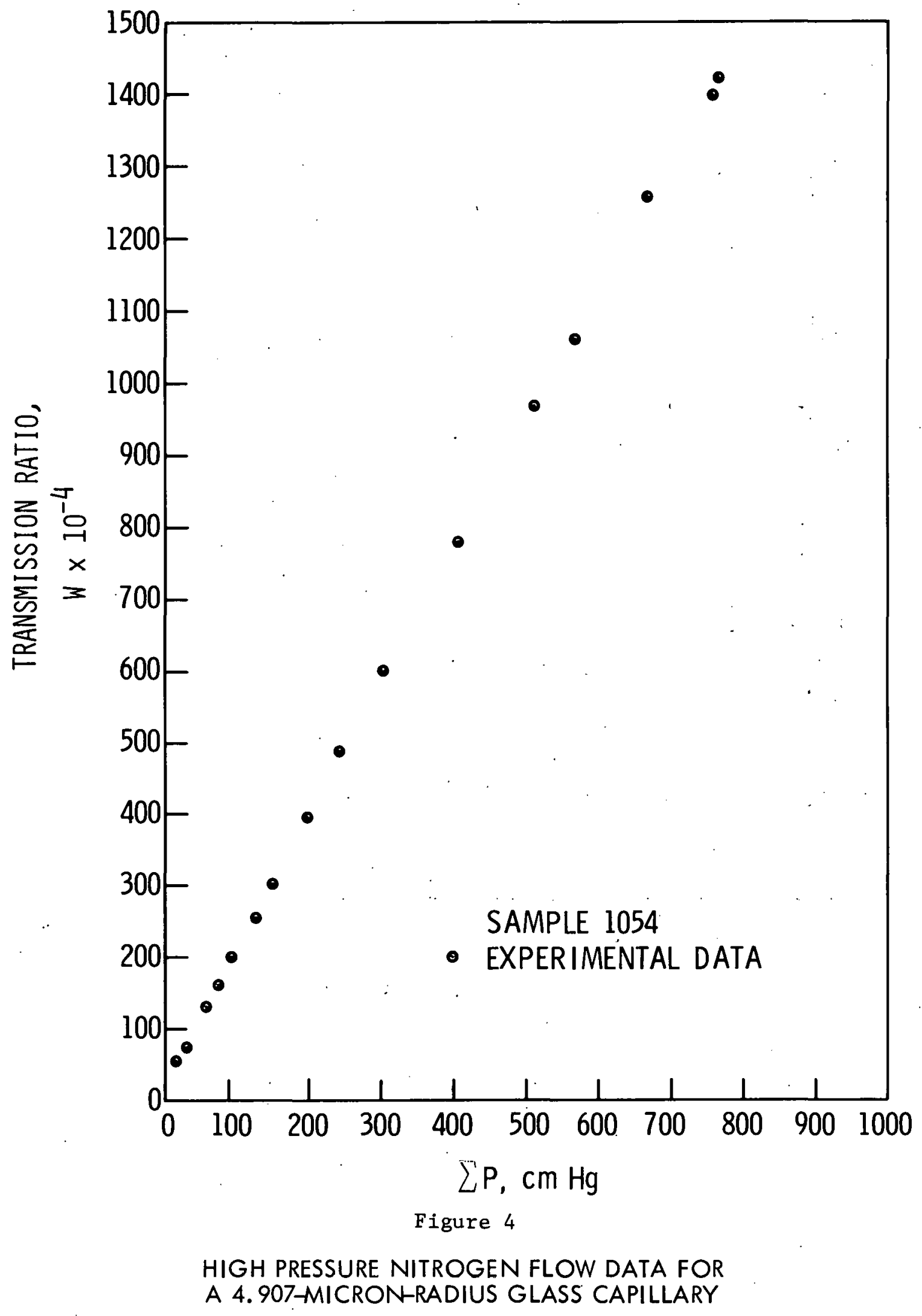


DWG. NO. G-72-1158

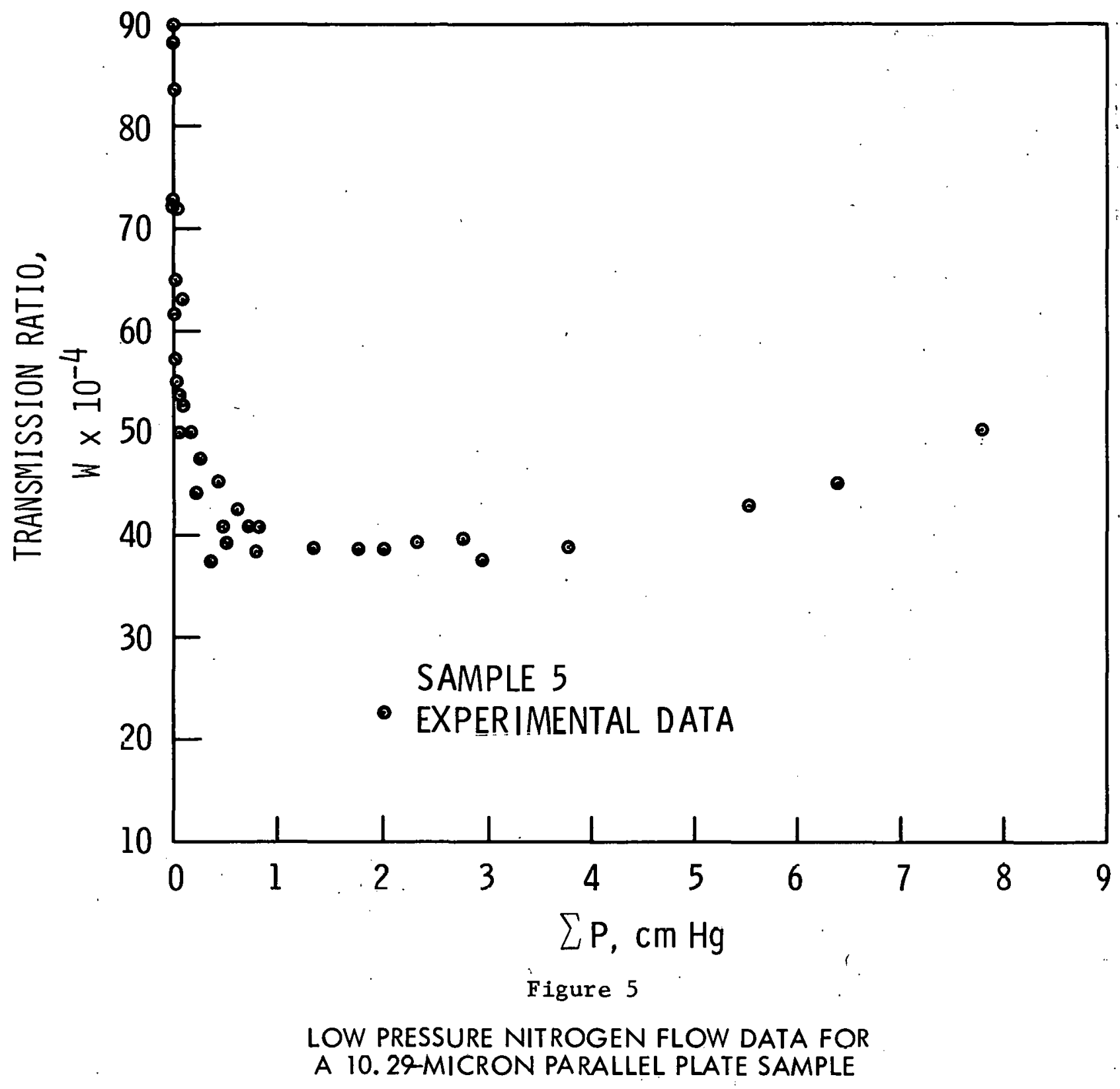


DWG. NO. G-72-1156

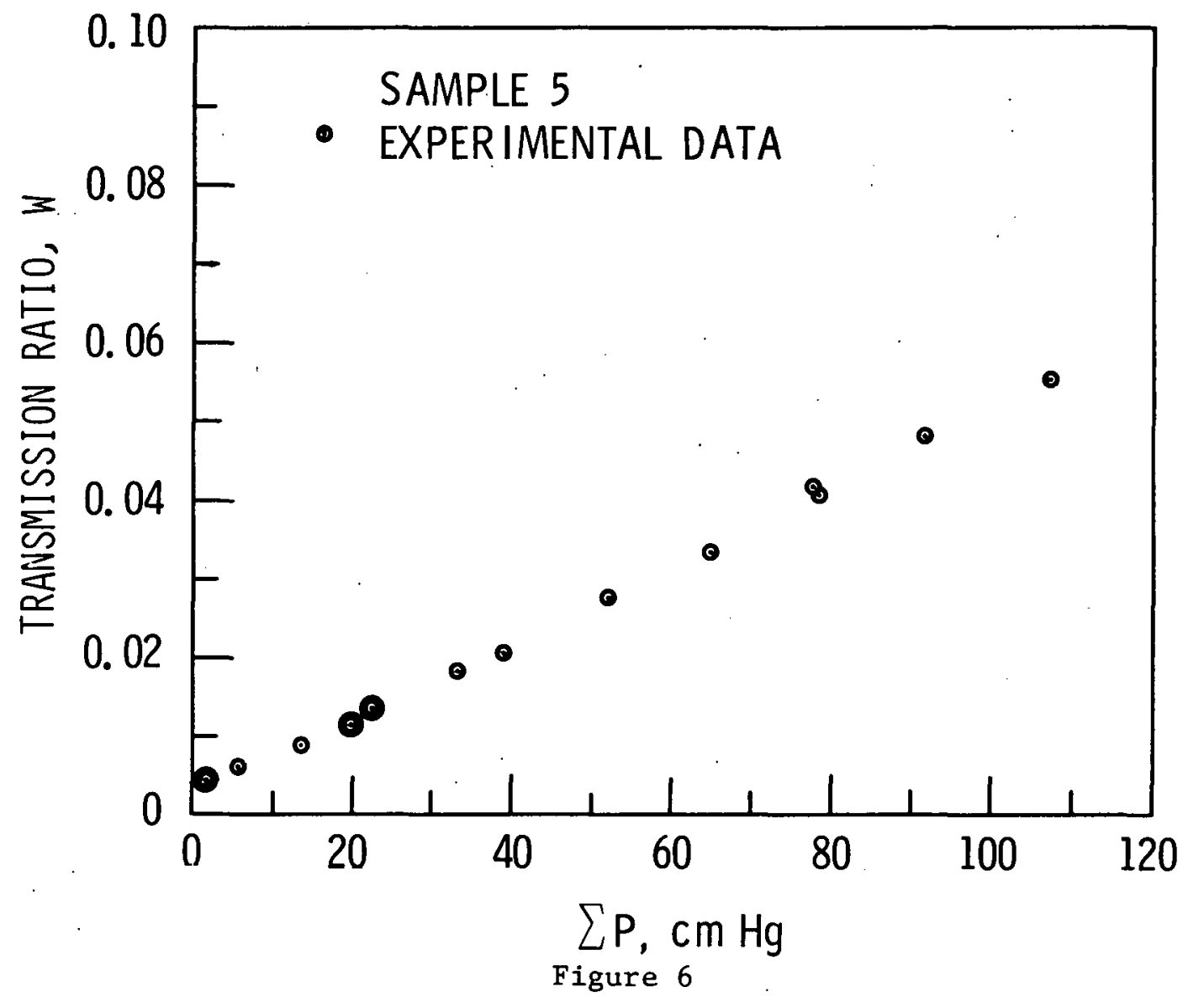

HIGH PRESSURE NITROGEN FLOW DATA FOR

A 10.29-MICRON PARALLEL PLATE SAMPLE 
the transport through capillaries of any length-to-radius ratio. Other notable works include Scott and Dullien in 1962 [17], Fryer in 1966 [18], and Barrer and Nicholson in 1966 [19].

The superposition idea gives a good mechanistic picture of the transport phenomena, but it remains a model since there is no mathematical derivation of the slip term. However, analytical results are presently being obtained with the use of the linearized Boltzmann equations. This was first accomplished in 1963 by Albertoni, Cercignan1, and Gatusso [20] for an infinite parallel plate. A more recent reference is the work of Maegley and Berman [21] with an annulus.

\section{BINARY SEPARATION}

Af ter Aston's work in 1920, Hertz [22] in 1932 and Woolridge and Smythe [23] in 1936 set up cascades using porous tubes to separate neon isotopes. However, no experimental or theoretical work was done on the pressure dependence of the separation of a binary gas mixture. During World War II, when interest in separating uranium isotopes became of military significance, separation by gaseous diffusion was naturally considered. A great deal of both theoretical and experimental work ensued. Present and deBethune [1] and Bosanquet [24], working independently, developed a theory for the separation of gases flowing through uniform capillaries. Bosanquet used an approach based on generalized diffusion coefficients, and Present and deBethune.used an approach based on momentum transfer. Using simple one-dimensional kinetic theory, Present and deBethune calculated the momentum transferred from one gas to the other by intermolecular collisions. These intermolecular collisions decrease the net drift velocity of the lighter gas and increase the net drift velocity of the heavier gas. The separation is therefore less than that which would be observed if the intermolecular collisions had not occurred. This momentum transfer between molecules does not change the total free molecule flow, but simply the ratio of the free molecule components of the two gases. In order to cumplete their theory, they added viscous flow as a nonseparative component. Thus, they assumed that the total flow was the sum of free molecule and viscous flows. This assumption is consistent with experimental data on porous materials where no Knudsen minimum is observed in the specific flow at low pressures. However, with long capillaries, long parallel plates, or any geometry which will result in a Knudsen minimun in the specific flow at low pressures, the total flow is not the sum of the free molecule and viscous flows. Therefore, the assumption of additivity of the two flows is expected to be, at best, only a good approximation for these geometries.

In order to investigate the accuracy of the Present and deBethune theory, separation data with well-defined capillaries are needed. The only data that have been available were obtained by Huggill [25] in 1952. He used capillaries with diameters of about $0.08 \mathrm{~mm}$ and observed changes in concentration of mixtures of nitrogen-carbon dioxide, argon-carbon dioxide, and nitrogen-ethylene. Partial pressures were measured to determine concentrations. Huggill's results indicated that the rate of decrease 
of light gas enrichment with increasing pressure was less than predicted by the theory. However, his separation data also showed an anomaly at the zero pressure limit: the separation was greater than would be predicted for pure free molecule flow. This deviation indicates an anomaly in the free molecule flow of one or both of the two components. Free molecule flow anomalies have been observed and are treated in some detail by Lund and Berman [3]. Because of the lack of purity of his gases, Huggill also had some difficulty with his partial pressure measurements. Thus, Huggill's main conclusion was that there are significant anomalies in the free molecule flow of different gas species, presumably because of differences in the scattering law from the walls of the capillaries for the different species of molecules. Because of these anomalies and the lack of sufficient precision, his separation data could not be used to check the theory of Present and deBethune.

A much more critical analysis of the theory can be made by separating isotopes where there should be no difference in the free molecule flow anomaly for the two isotopic species and where the theory is generally expected to be more nearly correct for other reasons. It is also important to obtain precise data with isotopes in the region where the initial slope of the separation efficiency vs. pressure difference curve can be accurately estimated, because the slope of this curve can be accurately related to the dimensions of the flow channel.

Recently, Malling [2] has used the Lund and Berman flow equations to derive an expression for the separation of a binary isotopic gas mixture. In his derivation, Malling assumed that the diffusional flow is ideally separative, the slip and viscous flow are nonseparative, and there is no coupling between the separative and nonseparative flows. Although the derivation of Malling is different in principle from that of Present and deBethune, the differential equations for separation which are obtained by the two methods are quite similar. The advantage of Malling's formulation over that of Present and deBethune is that there are several parameters which account for the detailed differences in flow behavior data and therefore should produce a better correlation with separation data than the one-parameter equations of Present and deBethune.

\section{Experimental Design}

The primary purpose of the present work is to obtain data accurate enough to be used to test the accuracy of any model for the separation phenomenon. In order to obtain accurate experimental measurements, it is essential to use the least complicated test. There are two good reasons why so little experimental work has been performed on the separation of gases in regular capillaries. First, bundles of capillaries with sufficiently small diameters have not been generally available and are difficult to prepare. In order to measure a reasonable range in separation, the gas mean free path must be of the order of the diameter of the capillary. For large capillaries this means operating at low pressures. For example, measurements with neon at atmospheric pressure would require capillaries $1 \mu$ in diameter or smaller; conversely, a $0.1-\mathrm{mm}$-diameter capillary would require 
operating pressures below 0.01 atmospheres. However, if small capillaries were available, a large number of them would be required to provide the flow rate necessary to characterize the capillaries accurately and to obtain a gas sample large enough to analyze for mole fraction changes. A second reason for the lack of experimental data is the difficulty in accurately measuring the small changes in mole fraction produced by the phenomenon. In addition, the low pressures required make the separation measurements themselves rather difficult to perform.

Neon isotopes were chosen for use as the test gas because neon is a simple low molecular weight noble gas with only two natural isotopes which occur in significant amounts. The use of isotopes should eliminate anomalous separation data that would result from anomalies in the free molecule flow behavior of one of the isotopes relative to the other. The low molecular weight produces a high separation factor which can be accurately measured with a double-collector mass spectrometer. An additional advantage in using neon is that at a given pressure neon has a longer mean free path than that of most gases with an isotope pair. This allows higher separation with neon at a given pressure. For example, the pressure level needed to obtain a given separation efficiency can be twice as large for neon as that for argon. 
MATHEMATICAL MODELS

PRESENT AND deBETHUNE MODEL (PBM)

In the theory developed by Present and deBethune [1] the flow rate is assumed to be the sum of two terms. One term represents the free molecule or Knudsen flow and the other represents the viscous or Poiseuille flow. When a single gas flows through a capillary, it is assumed that the Knudsen component is unaffected by molecular collisions. The molecules have the same mass and same average velocity so that the molecules cannot be distinguished before and after collision, and no net momentum is exchanged in a collision. However, when a binary mixture flows through a capillary, the two components have different average velocities and masses so that there can be a net momentum transfer between the unlike molecules due to collisions. The basis for the theory is the calculation of momentum transfer between the unlike molecules. The velocity of the faster, lighter molecule is reduced and that of the slower, heavier molecule is increased by the average momentum exchanged during collisions between unlike molecules. This decreases the relative amount of separation which occurs. In addition, the Poiseuille flow is the same for both molecules. This also reduces the amount of separation which occurs.

First, Present and deBethune considered the momentum transferred to the wall as a means of calculating the free molecule velocity:

$$
m_{1} u_{1}\left(\frac{n_{1} \bar{v}_{1}}{4}\right) 2 \pi r d x=-\pi r^{2}\left(\frac{d P_{1}}{d x}\right) d x
$$

The left-hand side of the equation is the momentum per second carried to a wall element of area $2 \pi r d x$ by the molecules of component 1 with an average velocity of $u_{1}$ and a collision frequency of $\left(n_{1} \bar{v}_{1}\right) / 4$. The right-hand side is the difference in the pressure at the entrance and exit to the element defined by the differentlal length $\mathrm{dx}$.

$$
\therefore \frac{\mathrm{dP}}{\mathrm{dx}}=\frac{\mathrm{m}_{1} \overline{\mathrm{v}}_{2} \mathrm{n}_{1} \mathrm{u}_{2}}{2 \mathrm{r}}
$$

If Knudsen's expression for free molecule flow is put in this same form, then

$$
\frac{\mathrm{dP}_{1}}{\mathrm{dx}}=\frac{3 \pi \mathrm{m}_{1} \overline{\mathrm{v}}_{1} \mathrm{n}_{1} \mathrm{u}_{1}}{16 \mathrm{r}}
$$

which differs from equation (2) hy a factor $3 \pi / 8$. Since equation (3) is generally considered to be the more accurate result, Present and deBethune used (3) in the further development of their theory. At this point a deviation from the original derivation of the theory will be made. A factor, K, will be introduced which will later be used to account for other geometries or any deviation in the relation between the mean velocity and the momentum transferred to the wall. 


$$
\frac{\mathrm{dP}}{\mathrm{dx}}=\frac{3 \pi \mathrm{m}_{1} \overline{\mathrm{v}}_{1} \mathrm{n}_{1} \mathrm{u}_{2}}{16 \mathrm{Kr}}
$$

That is, $\mathrm{K}$ is the ratio of free molecule flow for any geometry to that for an infinitely long capillary with completely diffuse wall reflection as was calculated by Knudsen. If $\mathrm{u}_{1}>\mathrm{u}_{2}$ and the scattering is isotropic in the center of mass coordinate system, then the average momentum of a molecule of component 1 after collision is

$$
\mathrm{m}_{1} \mathrm{u}_{\mathrm{c}}=\mathrm{m}_{1}\left(\frac{\mathrm{m}_{1} \mathrm{u}_{1}+\mathrm{m}_{2} \mathrm{u}_{2}}{\mathrm{~m}_{1}+\mathrm{m}_{2}}\right) \text {. }
$$

Since the average momentum before collision is $\mathrm{m}_{1} \mathrm{u}_{1}$, the average momentum lost in one collision is

$$
m_{1}\left(u_{1}-u_{c}\right)=m^{+}\left(u_{1}-u_{2}\right)
$$

where $\mathrm{m}^{+}$is the reduced mass

$$
\mathrm{m}^{+}=\frac{\mathrm{m}_{1} \mathrm{~m}_{2}}{\mathrm{~m}_{1}+\mathrm{m}_{2}} \text {. }
$$

Therefore, the average momentum loss per collision is proportional to the difference in the average velocity of the two molecules. This point is an important aspect of the problem and should be kept in mind when considering other geometries and flow anomalies.

The number of collisions per second per unit volume between unlike molecules is

$$
\mathrm{n}_{1} \mathrm{n}_{2} \pi_{12}^{2}\left(\overline{\mathrm{v}}_{1}{ }^{2}+\overline{\mathrm{v}}_{2}{ }^{2}\right)^{1 / 2}
$$

and the momentum transferred per unit time per unit volume from component 1 to component 2 would appear to be

$$
M_{12}=m^{+}\left(u_{1}-u_{2}\right) n_{1} n_{2} \pi d_{12}{ }^{2}\left(\bar{v}_{1}{ }^{2}+\bar{v}_{2}{ }^{2}\right)^{1 / 2}
$$

on the average. This development of the theory is very instructive, but Present and deBethune pointed out that the average momentum transferred is not quite the same as the average momentum loss per collision times the number of collisions. Furthermore, the assumption of "hard elastic sphere" molecules is unnecessarily restrictive. It was then shown that the momentum transferred per unit time per unit volume can be put into the form

$$
M_{12}=\left(u_{1}-u_{2}\right) \frac{n_{1} n_{2} k T}{n_{12}}
$$

In this form the use of the experimental value for the diffusion coefficient, $D_{12}$, avoids the two above objections. 
Now the momentum balance equations are

$$
\begin{aligned}
& -\pi r^{2} \frac{d_{1}}{d x}=\frac{3 \pi}{8 K} m_{1} u_{1}\left(\frac{n_{1} \bar{v}_{1}}{4}\right) 2 \pi r+\left(u_{1}-u_{2}\right) \frac{n_{1} n_{2} k T}{n_{12}} \pi r^{2} \\
& -\pi r^{2} \frac{d P_{2}}{d x}=\frac{3 \pi}{8 K} m_{2} u_{2}\left(\frac{n_{2} \bar{v}_{2}}{4}\right) 2 \pi r-\left(u_{1}-u_{2}\right) \frac{n_{1} n_{2} k T}{n D_{12}} \pi r^{2} .
\end{aligned}
$$

The abbreviation

$$
\mathrm{b}=\frac{8 \mathrm{Kr}}{3 \pi}\left(\frac{\mathrm{kT}}{2 \mathrm{~m}^{+}}\right)^{1 / 2} \frac{\left\langle\mathrm{m}^{1 / 2}\right\rangle_{\mathrm{N}}}{\left(\mathrm{m}_{1}+\mathrm{m}_{2}\right)^{1 / 2}} \frac{1}{\mathrm{pD}_{12}}
$$

is introduced, with

$$
\left\langle\mathrm{m}^{1 / 2}\right\rangle_{\mathrm{N}}=\mathrm{Nm}_{1}^{1 / 2}+(1-\mathrm{N}) \mathrm{m}_{2}^{1 / 2}
$$

$N$ denotes the mole fraction of component 1 .

Poiseuille flow is also introduced as being additive. lhen

$$
\mathrm{G}_{1}=\frac{2}{3} \frac{\overline{\mathrm{v}}_{1}}{\mathrm{kT}} \mathrm{Kr}\left\{\frac{1}{(1+\mathrm{bP})} \frac{\mathrm{d}(\mathrm{NP})}{\mathrm{dx}}+\frac{\mathrm{m}_{1}^{1 / 2}}{\left\langle\mathrm{~m}^{1 / 2}\right\rangle_{\mathrm{N}}} \frac{\mathrm{NbP}}{(1+\mathrm{bP})} \frac{\mathrm{dP}}{\mathrm{dx}}+\mathrm{NaP} \frac{\mathrm{dP}}{\mathrm{dx}}\right\} \text {. }
$$

The first term is inversely proportional to $\mathrm{m}_{1}^{1 / 2}$ and is ideally, separative. The second and third terms are nonseparative. Equation (10) can now be rewritten for both components, and the differential equation for separation efficiency is obtained by setting the ratio of the molecular flows equal to the ratio of the mole fractions of components 1 and 2 in the outlet or product stream:

$$
\frac{G_{1}}{G_{2}}=\frac{N_{1}}{1-N_{1}}
$$

This differential equation can be converted into one for the separation efficiency by defining $Z=\delta / \delta *$ where $\delta=N_{1}-N$ and $\delta *=N_{1}-N^{*}$ : $\mathrm{N}^{*}$ is the feed concentration necessary to give a product concentration of $\mathrm{N}_{1}$ with a perfect Knudsen barrier operating at zero backpressure.

It is shown that for most cases $\left(\mathrm{m}_{2} / \mathrm{m}_{1}\right.$ not too large) the differential equation can be integrated to give

$$
Z=\frac{\int_{b}^{P_{f}} \exp \left[\left(\frac{\bar{f} b+a}{h}\right) P+\frac{a b}{2 h} P^{2}\right] d P}{P_{f} \exp \left[\left(\frac{\bar{f} b+a}{h}\right) P_{f}+\frac{a b}{2 h} P^{2}\right]}
$$


where

$$
\begin{aligned}
& \overline{\mathrm{f}}=\mathrm{m}_{2}{ }^{1 / 2} /\left\langle\mathrm{m}^{1 / 2}\right\rangle_{\mathrm{N}} \\
& \mathrm{h}=1+(\mathrm{f} *-1)\left(1-\mathrm{N}_{1}\right) \\
& \mathrm{a}=\frac{3 \mathrm{~K}^{\prime} \mathrm{r}}{16 n \overline{\mathrm{v}}_{2} \mathrm{~K}}
\end{aligned}
$$

where $K^{\prime}$ is the ratio of Poiseuille flow for any geometry to that for a long capillary. As with the constant $K$, the constant $K^{\prime}$ does not appear in the original Present and deBethune theory. In this work equation (12) is referred to as the Present and deBethune equation.

As can be seen from this derivation, factors that affect the free molecule flow will affect the $a$ and $b$ values through the constant $K$. For example, deviations in the wall scattering law such as specular reflection or backscattering will affect the $a$ and $b$ values through the constant $k$. Changes in geometry will affect $a$ and $b$ through both the constants $K$ and $K^{\prime}$.

There are three approximations which should be considered. The first is a perfect barrier. There are several ways to arrive at the same result. The easiest is to set $a=b=0$. Then $z=(1-w)$ is the separation efficiency of a perfect barrier, and $z /(1-w)$ is the separation efficiency ratio, i.e., the ratio of the separation efficiency of a barrier to that for a perfect barrier operating with the same pressure ratio. The second is the effect of assuming no viscous flow. This can be done easily by setting the constant $a=0$. Then the differential equation for the separation efficiency can be integrated to give

$$
Z=\frac{\Delta P}{P_{0}} \frac{\left(1-e^{-X}\right)}{X}
$$

where

$$
\mathrm{X}=\frac{\overline{\mathrm{f}} \mathrm{b} \Delta \mathrm{P}}{\mathrm{h}}
$$

or

$$
\frac{Z}{1-w}=\frac{1-e^{-X}}{X}
$$

An expansion of this equation gives

$$
\frac{\mathrm{z}}{1-\mathrm{w}}=1-\frac{\overline{\mathrm{f}} \mathrm{b} \Delta \mathrm{P}}{2 \mathrm{~h}}+\frac{1}{3 !}\left(\frac{\overline{\mathrm{f}} \mathrm{b} \Delta \mathrm{P}}{\mathrm{h}}\right)^{2}+\ldots
$$

This shows that when viscous flow is insignificant, i.e., at low average pressures, the separation efficiency ratio is linear with $\Delta \mathrm{P}$, the pressure difference across the separating element. This expression can be used to estimate the capillary radius when the initial slope of the separation efficiency ratio vs. pressure difference curve is known. 
A third approximation can be obtained by expanding equation (12) to obtain

$$
\frac{\mathrm{Z}}{1-\mathrm{w}}=1-\left(\frac{\overline{\mathrm{f}} \mathrm{b}+\mathrm{a}}{\mathrm{h}}\right) \frac{\Delta \mathrm{P}}{2}+\left(\frac{\overline{\mathrm{f}} \mathrm{b}+\mathrm{a}}{\mathrm{h}}\right)^{2} \frac{\Delta \mathrm{P}^{2}}{3 !}+\ldots
$$

This gives the same results as (1.3) except the initial slope is increased by the additive factor a. This expression can also be used to estimate the capillary radius. It is particularly interesting to note that for a nearly perfect separation efficiency ratio the deviations from perfect behavior depend on the pressure difference and not on the average pressure.

MODIFIED PRESENT AND deBETHUNE MODEL (PBFM)

The Present and deBethune theory assumes the strict additivity of free molecule and viscous flows. It has been proven experimentally that this, in general, is not correct. Strict additivity appears to be correct only for porous materials. Therefore, the PBM theory can at best be considered a good approximate theory. An attempt has been made to modify the PBM theory to account for the known difficulties and also to produce better agreement with the experimental data obtained in this work.

In the PBM theory it is seen that the momentum transferred between unlike molecules is directly proportional to the difference in the velocity of the two molecules. Therefore, anything which increases or decreases the two velocities by the same ratio will increase or decrease the amount of momentum transferred between theil. The minimum which is observed in the specific flow curves for long capillaries and parallel plate geometries is evidence of a decrease in the specific velocity of the gases. This minimum is observed for all gases. It therefore corresponds to approximately the same decrease in the specific flow velocity for both species of mole-. cules in a binary mixture, and therefore the decrease in specific flow evidenced by a Knudsen minimum should correspond to a decrease in the momentum transferred between unlike molecules.

The $\mathrm{b}$ constant in the Present and deBethune equations can be affected by changec in the sperific flow velocity through the constant $K$. Therefore, one way to reflect these changes in specific flow into the separalluii theory is to pressure-weight the $b$ constant so that it varies from the free molecule value at zero pressure to the slip flow value at high pressure. It can be shown that for parallel plate geometry the contribution to the wall collision frequency from molecules leaving another wall is

$$
\nu_{w}=\frac{n \bar{v}}{4}\left[\exp \left(-\frac{h}{\lambda}\right)-\frac{h}{\lambda} \exp \left(-\frac{h}{\lambda}\right)+\frac{h^{2}}{\lambda^{2}} E_{1}\left(\frac{h}{\lambda}\right)\right]
$$

where $E_{1}$ is the exponential integral, $h$ is the plate separation, and $\lambda$ is the mean free path. The contribution from molecules which had their last collision in the gas phase is

$$
\nu_{g}=\frac{n \bar{v}}{4}\left[1-\exp \left(-\frac{h}{\lambda}\right)+\frac{h}{\lambda} \exp \left(-\frac{h}{\lambda}\right)-\frac{h^{2}}{\lambda^{2}} E_{1}\left(\frac{h}{\lambda}\right)\right] \text {. }
$$


It may be assumed that a molecule striking a wall has a velocity equivalent to the free molecule value if it had its last collision with another wall and a velocity equivalent to the slip velocity if it had its last collision in the gas phase. Then a pressure-weighting function of this type should be appropriate to make the $b$ constant in the Present and deBethune equation vary from the free molecule value at zero pressure to the slip flow value at high pressures. The third term in equation (15) is a small contribution, and so it was dropped for calculation convenience. The changes in the $b$ constant caused by changes in the relation between the average velocity and the momentum transferred to the wall were introduced through the constant $\mathrm{K}$.

Therefore the constant $\mathrm{K}$ is pressure-weighted according to

$\mathrm{K}_{\mathrm{P}}=\mathrm{K}\left\{\left[\exp \left(-\frac{\mathrm{Br}}{\lambda}\right)-\frac{\mathrm{Br}}{\lambda} \exp \left(-\frac{\mathrm{Br}}{\lambda}\right)\right]+\frac{\mathrm{W}_{\mathrm{m}}}{\mathrm{W}_{\mathrm{K}}}\left[1-\exp \left(-\frac{\mathrm{Br}}{\lambda}\right)+\frac{\mathrm{Br}}{\lambda} \exp \left(-\frac{\mathrm{Br}}{\lambda}\right)\right]\right\}$,

where

$$
\begin{aligned}
& \mathrm{B}=\text { a constant depending on geometry } \\
& \mathbf{r}=\text { capillary radius or plate spacing } \\
& \lambda=\text { mean free path } \\
& \mathrm{W}_{\mathrm{m}}=\text { Maxwell transmission ratio (transmission ratio from a linear } \\
& \mathrm{W}_{\mathrm{K}}=\text { free molecule transmission ratio. }
\end{aligned}
$$

The modification is accomplished by using $\mathrm{K}_{\mathrm{P}}$ instead of $\mathrm{K}$ as given in the previous section. This change should roughly account for changes in.both the $a$ and $b$ values due to variations in the velocity at the wall because of geometry, wall scattering law, or pressure dependence.

This type of approximation insures that it will also represent the flow data fairly well since it must agree at the high and low pressure limits and produce a pressure-weighted variation in between. A detailed inspection of this type of approximation to the flow equations has not yet been made. It should be obvious from this study that a much better approximation is needed to represent flow data than that required to represent the separation data.

\section{GENERAL CAPILLARY MODEL (GCM)}

G. F. Malling has used the Lund and Berman flow equation to form a general capillary model, GCM, for separation. Malling has used extensive arguments to justify the results and certain significant further variations can be introduced, but in its present simplest form the Lund and Berman flow equations were used for the component equations instead of equations (10) as used by Present and deBethune. The partial pressure gradient was used with the diffusion term, and the total pressure gradient was used with the slip and viscous terms. 
The general equations are rather complex and, of course, machine calculations are required, but for comparison with the Present and deBethune equation they reduce to the following for long capillaries.

Lund and Berman's equation is

$$
G=\frac{\bar{v} \Delta P}{4 k T}\left\{\frac{(8 / 3) F}{L\left[c+\left(20 / 9 \pi A^{*}\right) X\right]}+\frac{X}{4 L}\left[1+\frac{2.368 \sigma A^{*}}{A^{*}+0.592 X}\right]\right\}
$$

where $\mathrm{X}=\left(\mathrm{r} \sum \mathrm{P} / \mathrm{n} \overline{\mathrm{v}}\right)$, also $\mathrm{X} \propto(\mathrm{r} / \lambda), \mathrm{c}$ represents deviations from ideal free molecule flow, and $\sigma$ represents the slip flow constant which is also affected by deviation in the wall scattering law. $A^{*}$ represents variations in the collision integrals for different molecules. F is a function which differs no more than $5 \%$ from unity and is equal to the ratio of the Pollard and Present to Bosanquet diffusion coefficients. It can easily be shown that

$$
\mathrm{X}=1.414 \mathrm{~A} * \mathrm{bP}
$$

where $b$ is the same as in the Present and deBethune equations.

The above equation (18), in the same form as equation (10), is

$$
\mathrm{G}=\frac{2 \overrightarrow{\mathrm{v}}_{1} \mathrm{r}}{3 \mathrm{kT}}\left\{\frac{\mathrm{F}}{(\mathrm{c}+\mathrm{bP})} \frac{\Delta \mathrm{P}_{1}}{\mathrm{~L}}+\frac{0.6915\left(\sigma / \sigma_{\mathrm{O}}\right) \mathrm{bP}}{(1.094+0.9158 \mathrm{bP})} \mathrm{N} \frac{\Delta \mathrm{P}}{\mathrm{L}}+\mathrm{NaP} \frac{\Delta \mathrm{P}}{\mathrm{L}}\right\} .
$$

If the Lund and Berman equations are considered as differential equations and $\left(\Delta \mathrm{P}_{1} / \mathrm{L}\right) \rightarrow\left(\mathrm{dP}_{1} / \mathrm{dx}\right)$ and $(\Delta \mathrm{P} / \mathrm{L}) \rightarrow(\mathrm{dP} / \mathrm{dx})$, then there are only two significant differences between equations (10) and (19). The coefficient of the second term is smaller for the GCM than for PBM and is the primary source of the differences in the calculated separation efficiencies for the same long capillary. Nominal values of $c$ and $\sigma$ from flow data are $c=1$ and $\sigma=\sigma_{0}=1.84$. But, for example, if $c=1$ and $\sigma=1.446 \sigma_{0}$, then nearly identical results will be obtained with either model. The other significant difference is in the manner in which deviations in the free moleculc and clip flows due to wall scattering law deviations enter into the models. In the GCM, these deviations affect the equations through $c$ and $\sigma$. In the PBM the effect is to change the $a$ and $b$ constants. This causes the PBM and therefore also the PBFM to have a stronger dependence on the deviations from ideal free molecule and slip flow than does the GCM. These will be emphasized further in the discussion of results.

The close correspondence between the forms of the GCM and PBM is probably sufficient to justify the assumption that the Lund and Berman equations shuuld be differential equations instead of integrated equations as they were originally presented. Malling has made the calculations shown in figure 31 where $b P$ in equation (19) was replaced by $b \bar{P}$. While this is not the same as using the differentiated Lund and Berman equations, it does show significantly. different results and further indicates that the Lund and Berman equations should be differential equations. 
EXPERIMENTAL TEST SAMPLES

\section{SAMPLE SELECTION}

In order to obtain data that can be used in evaluating a mathematical model, it is essential that the samples have very well-defined geometries. It would also be desirable to obtain data on samples that have different geometries. The geometries should exhibit the largest possible differences in their flow characteristics. The three geometries that have the greatest difference in their flow behavior in the transition region between free molecule flow and Poiseuille flow are the orifice, the long capillary, and the parallel plate channel. The orifice is a circular capillary with a length-to-radius ratio approaching zero, and a long capillary is a circular capillary with its length large compared to its radius.

If a curve is plotted of specific flow vs. average pressure, in the transition region between free molecule and Poiseuille flow the following will be noted:

1. For a short copizlary, where the length of the capillary is approximately 2 to 5 times its radius, the specific flow curve is essentially linear over the entire pressure range.

2. For a long capizlary, where the capillary length is greater than approximately 12 times its radius, the specific flow curve will show a shallow minimum of as much as $10 \%$.

3. A parallel plate channel will show a very deep minimum of $50 \%$ or greater in the specific flow curve.

Because of these significant differenres in the flow charactoriotico and the differences predicted by the theories, a short capillary, a long capillary, and a parallel plate were chosen as the samples to be used for separation measurements. Examples of the flow curves obtained on representative test samples are shown in figures 1 through 6 . Where possible, similar samples were prepared with different materials so that the surface finish would be different. By choosing different materials, the effect of gas phase flow anomalies such as specular reflection and backscattering on the flow and diffusion phenomena can be investigated. For example, one set of glass capillaries was fire polished to smooth the surfaces. Table 1 shows a description of the samples which were prepared for separation measurements.

\section{SAMPLE PREPARATION}

Test sample preparation was a particularly important part of this work. Capillary test samples with the smallest possible diameters were desired to allow the highest operating pressures. However, small diameters made it necessary to have a large number of capillaries mounted in parallel in order to have large enough flow rates to characterize the sample and to collect sufficient gas for analysis by the mass spectrometer. 
Table 1

TEST SAMPLE CHARACTERISTICS

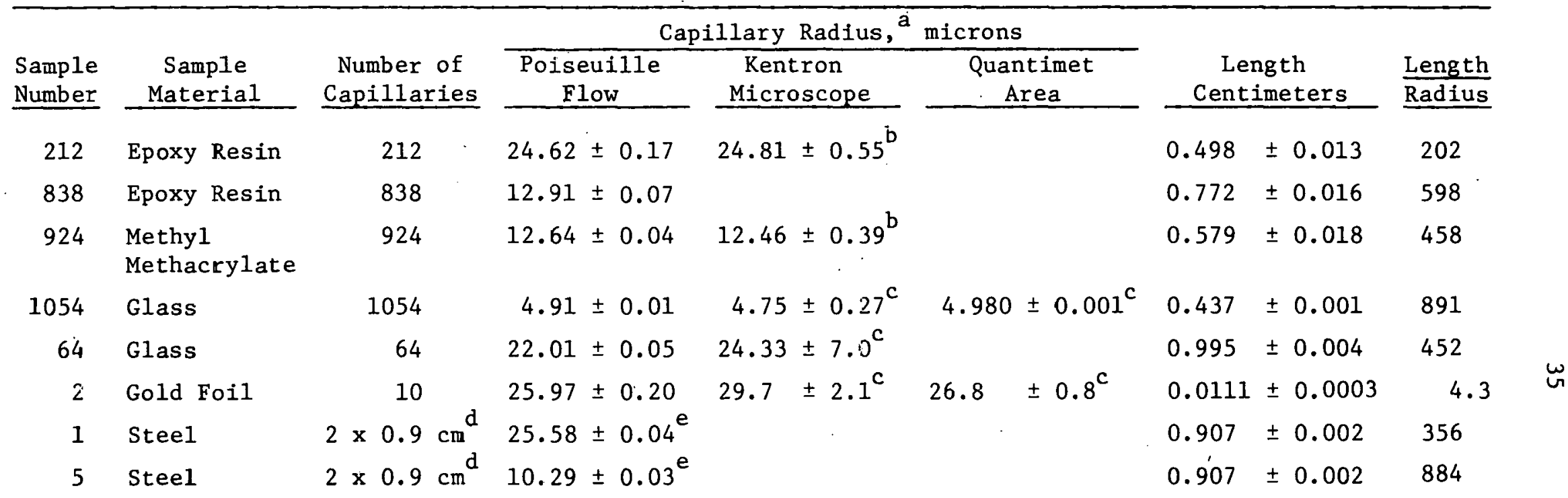

${ }^{a}$ Comparison of capillary radius measured by three techniques.

${ }^{b}$ Samples prepared in the same manner, but polished by metallographic techniques before measuring.

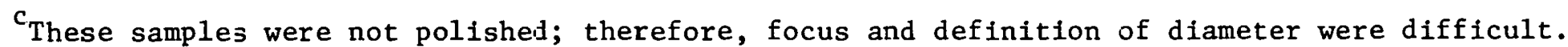

¿ Width and length of plates.

$\mathrm{e}_{\text {Height }}$ or spacing between plates. 


\section{Capillary Samples}

The first test samples were made from two different sizes of glass capillaries. Each required a somewhat different fabrication method. The largest size capillary tubing which was used to prepare test samples had a nominal inside diameter of $2 \mathrm{mils}$ or $50 \mu$ and an outside diameter of 0.25 in. The first step in the preparation was to score and break the tubing into $1-\mathrm{cm}$ lengths. The tubing was broken rather than cut to avoid getting dust into the capillaries. Because of the large outside diameter, some of the excess glass was removed by grinding the diameter so that more capillaries could be placed in a given sample area. Wet grinding was used and care was taken to avoid getting dust into the capillaries. After the grinding operation, the glass tubing had a triangular-shaped outside cross section. To be certain the capillaries were still open, a 1-mil wire was passed through each capillary. They were then cleaned with hot chromic acid and washed in distilled water. The capillaries were next heated to $550^{\circ} \mathrm{C}$ to clean them further and to give the wall a smooth', fire-polished surface finish. Small pieces of tape (Scotch transparent tape) were placed over each end of the capillary to avoid contamination during handling. The outside of the glass was coated with an epoxy resin wetting agent, and 64 capillaries were arranged on end on a piece of tape in order to hold them in position. This assembly was then placed in a silastic mold and the capillaries were cast in a block of epoxy resin. Care was taken not to cover the top of the capillaries with the epoxy resin. After the resin had hardened, the tape was removed and the sample was examined microscopically to assure that there was no adhesive obstructing the opening. The test sample was stored in a desiccator to avoid dust and possible moisture etching of the fire-polished surfaces. This sample was designated as sample 64. A photograph of the sample and one of the capillaries is shown in figures 7 and 8 .

While test sample 64 provided an excellent sample, a test sample with a smaller radius was needed to provide separation data at higher separation efficiencies. Therefore, a search was made for smaller capillary tubing. A special order of capillary tubing with a tube diameter of 20 mils and a capillary diameter of approximately $10 \mu$ was obtained from the Fredrich and Dimmock Glass Co. in Milleville, New Jersey.

Because of the small capillary diameter, a very large number of capillaries were required. The capillary tubing was first coated with a silane wetting agent; then the capillaries were scored and broken into approximately 3/16-in. lengths. In order to assemble this sample, a jig was made with two pieces of wire screen. The screens were separated by a spacer and positioned so that their grid structures were coincident. They were then fastened in position. The area available for the capillaries was confined to a rectangle $0.75 \mathrm{in}$. by $1.5 \mathrm{in.}$ The 3/16-in.-1ong capillaries were placed in the first row of the wire screen grid structure. A silicafilled epoxy resin was carefully placed on the outside of each capillary and the top screen wire with a hypodermic needle. Enough epoxy resin was placed on each capillary to fill the void between them and the void in the screen. It was very important not to allow the epoxy resin to get into the next row of the grid. More capillaries had to be placed into 


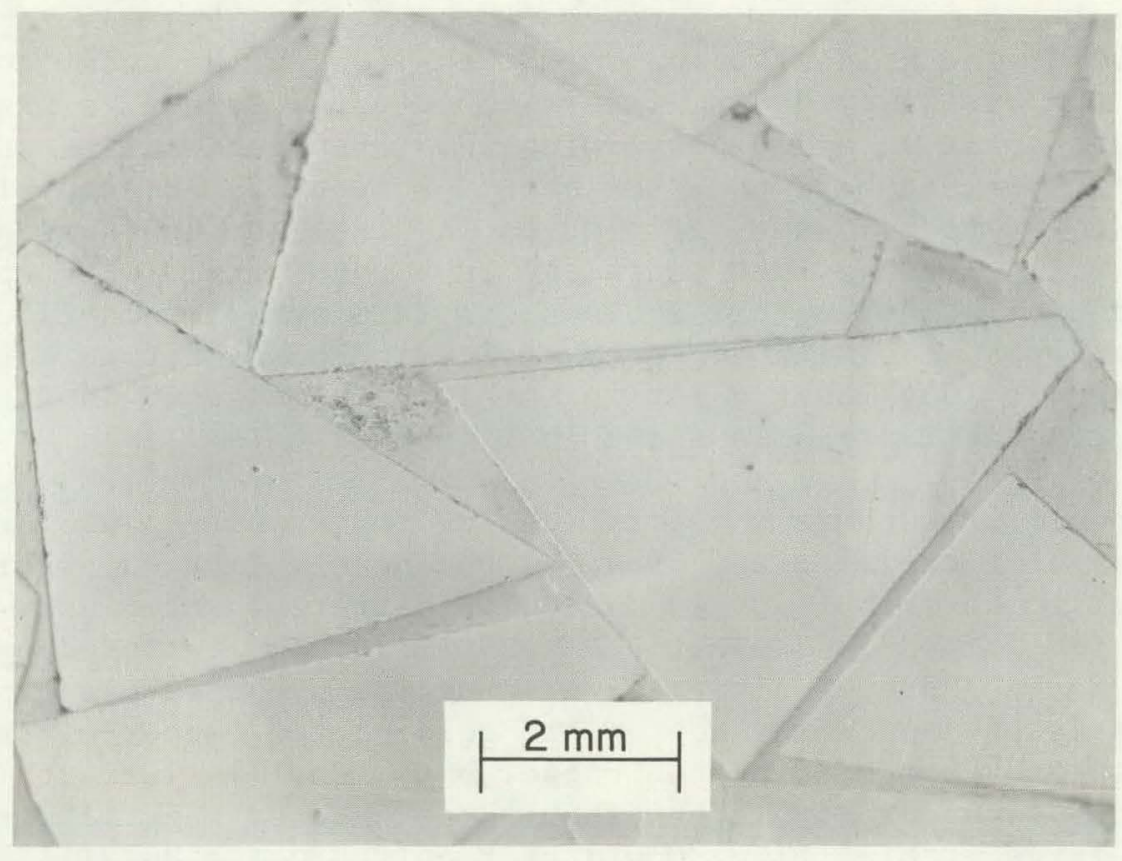

Figure 7

A SECTION OF SAMPLE 64

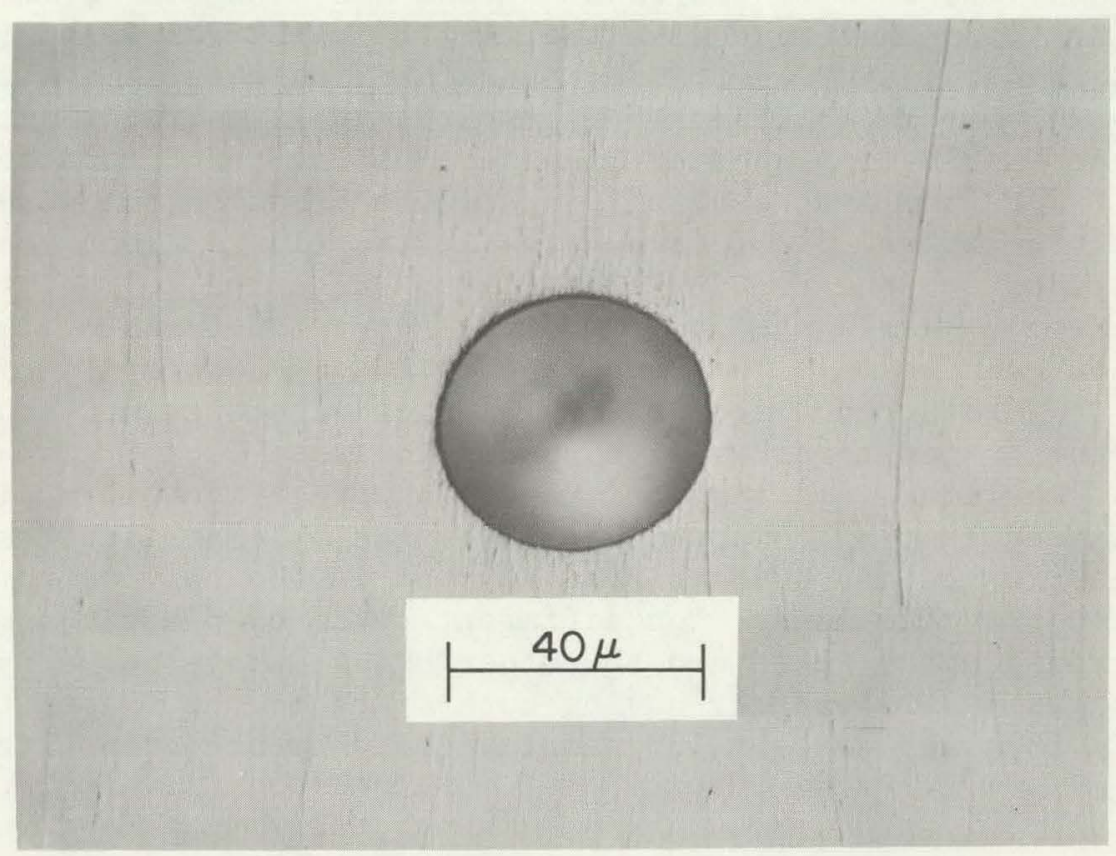

Figure 8

GLASS CAPILLARY FROM SAMPLE 64 
the next row of the grid structure without allowing the epoxy to contact the end of the capillary during insertion into the screen. This process was continued until an array containing 1054 open capillaries was completed. After the epoxy resin hardened, the bottom screen was removed since its only purpose was to hold the capillaries in place during fabrication. The array of capillaries was then contained in a metal frame with epoxy resin. A prototype of the sample that shows a complete array of capillaries and wire screen grids, but with no epoxy resin, is shown in figure 9. The completed sample 1054 mounted in its metal frame is shown in figure 10, and one of its capillaries is shown in figure 11.

The glass capillaries were the first choice for preparing uniform, welldefined arrays of capillaries. But, as has been indicated previously, it is important to have capillaries made with different materials. An array of capillaries formed in a plastic block similar to that used by Huggill [22] seems to be the best alternative. Huggill prepared his arrays of capillaries by encapsulating copper and gold-plated copper wires in methyl methacrylate and then etching the copper out. Capillaries with length-toradius ratios considerably larger than those used by Huggill were desired. Since very large etching times would be required using Huggill's method, other means of forming them were investigated. The following technique was developed.

First, stainless steel wire was wound around a rectangular frame as shown in figure 12. Then the frame with the wire in place was washed with trichloroethylene, sodium hydroxide, and distilled water. Next, it was dipped into an acetone solution of an experimental fluorocarbon surfactant, called FX-161, furnished by Minnesota Mining and Manufacturing Co. This deposited a monolayer coating of a fluorocarbon on the wires. Since hydrocarbons do not wet fluorocarbons well, the fluorocarbon coating would subsequently prevent the molding plastic from adhering to the wires. In order to make the sample the desired size, about 100 turns of the wire were wound on each frame. This gave approximately 200 capillaries from each frame. The desired number of capillaries were obtained by fastening several of the frames together with spacers between each frame. The frames with the wires in a vertical position were placed in a silastic mold. A plastic casting compound was deaerated by centrifuge and care was taken to see that no air bubbles were trapped in the casting compound as it was poured into the mold. Two different types of plastic samples were made: one using epoxy resin and the other using methyl methacrylate. Figure 13 shows a sample after having both sides of the frames cast in plastic. In this way two similar samples could be prepared with each set of frames.

After hardening, the sample was removed from the mold and the ends and bottom of the sample were ground off to remove the frame. The bottom was then metallurgically polished. At this point the wires were removed by pulling them out of the plastic one at a time using a microscope and a pair of tweezers. This was possible because the fluorocarbon prevented the plastic from adhering to the wires. Some of the wires did break when attempting to remove them; therefore all of the wires were not removed. Those that did remain in the sample were held very tightly and did not 
PHOTO NO. PH-70-2302

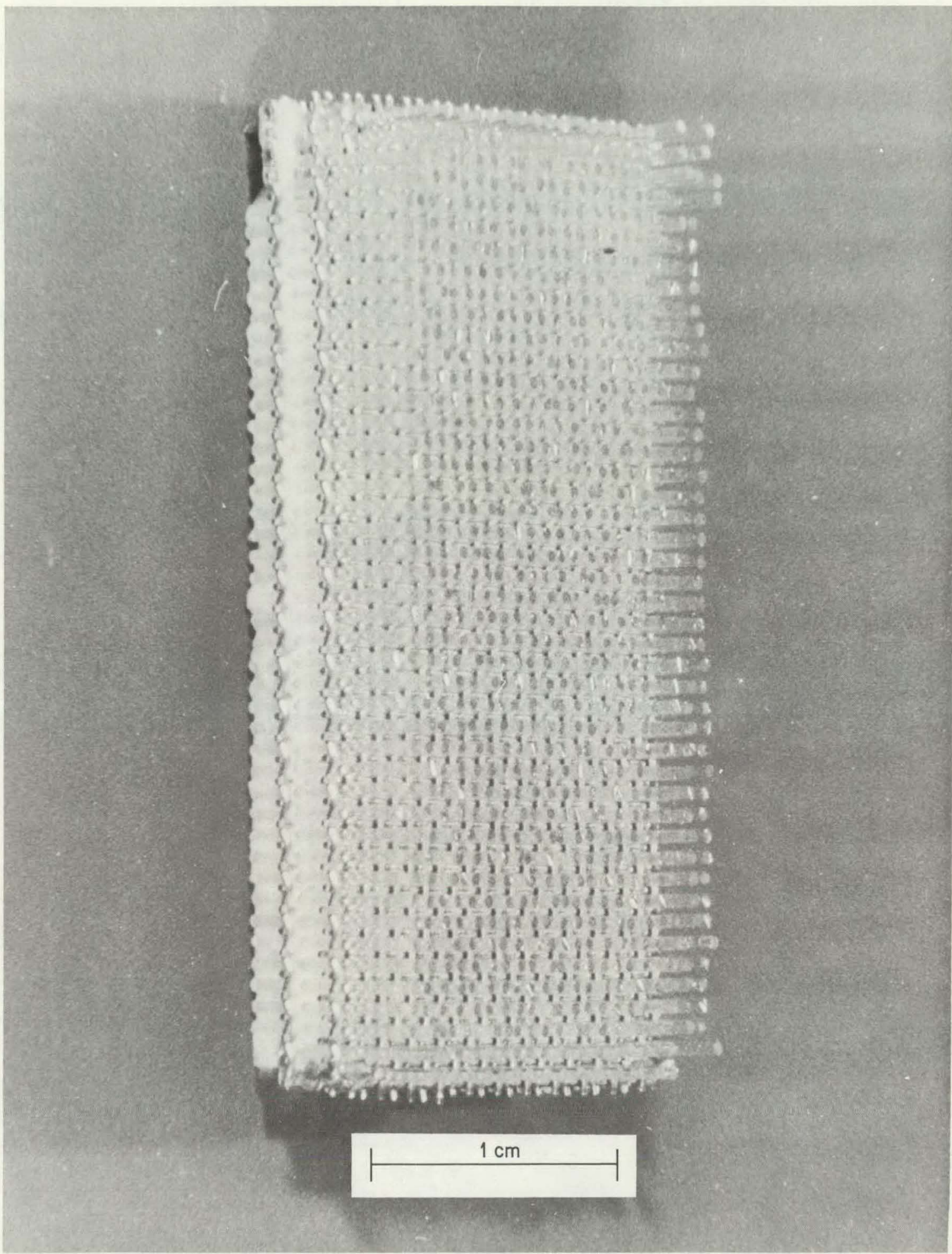

Figure 9

PROTOTYPE OF SAMPLE 1054 


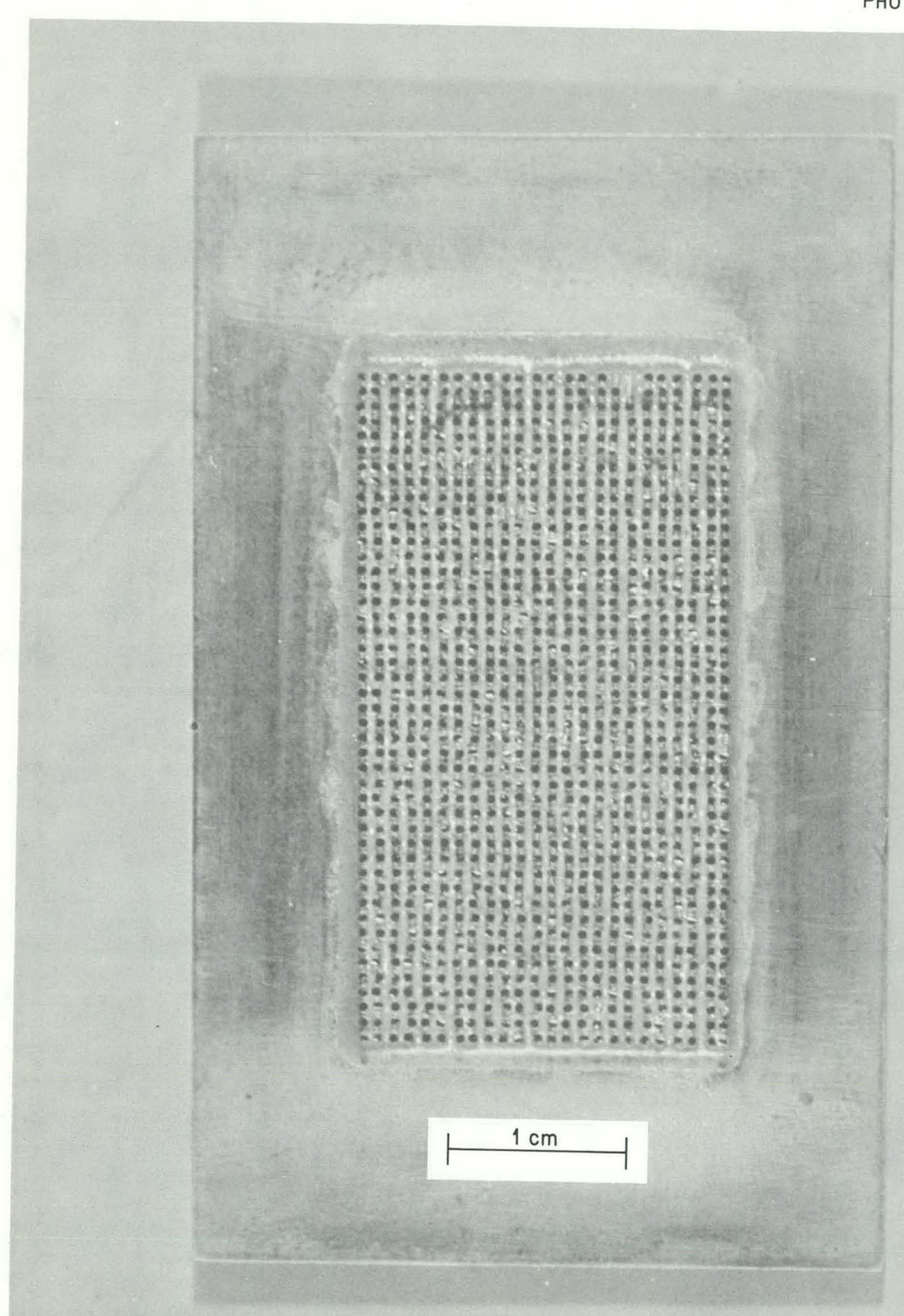

Figure 10

SAMPLE 1054 


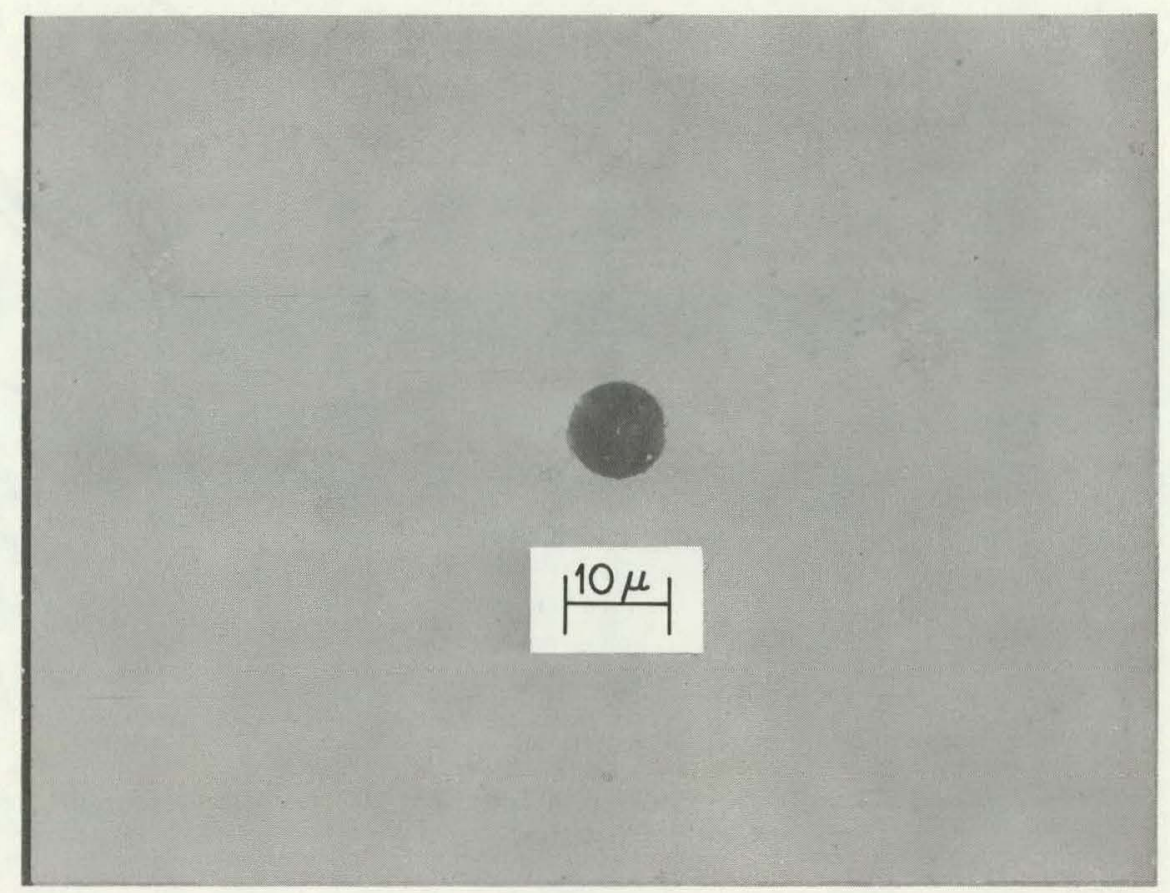

Figure 11

GLASS CAPILLARY USED IN SAMPLE 1054

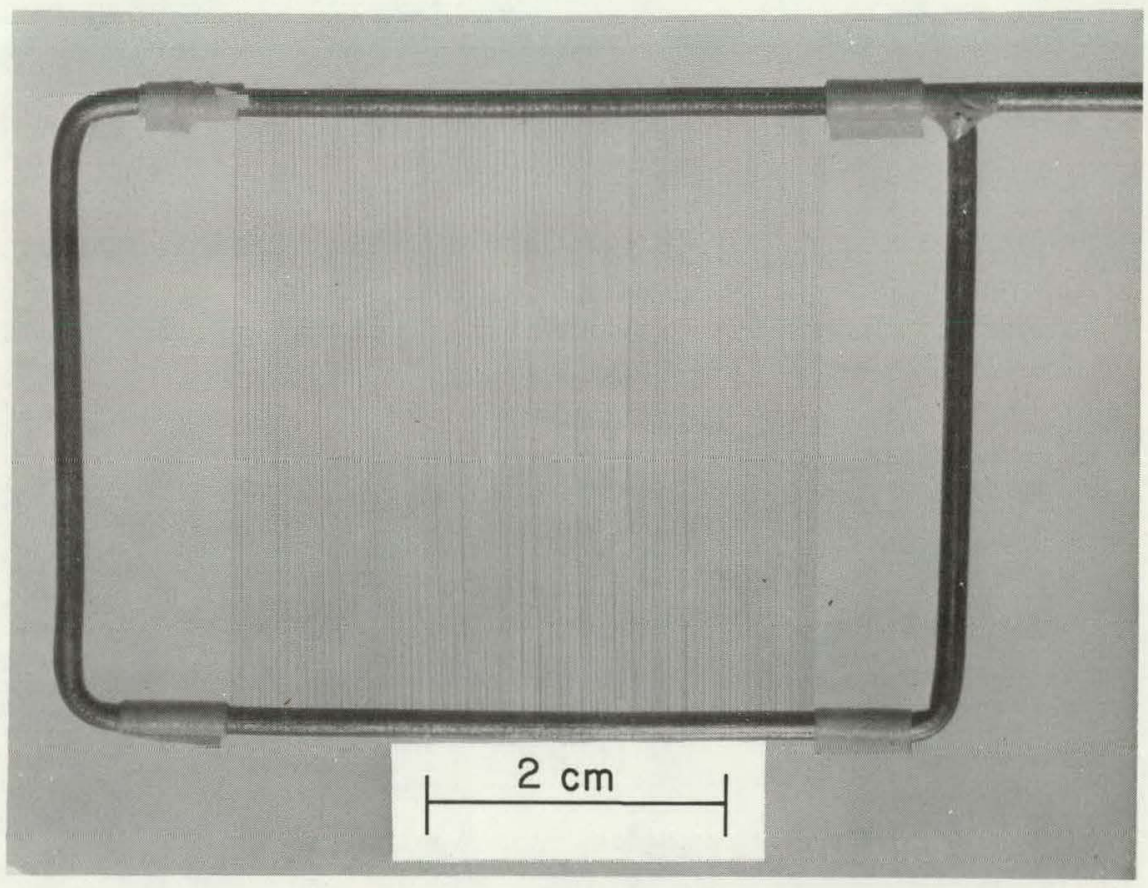

Figure 12

STAINLESS STEEL WIRE ON METAL FRAME 


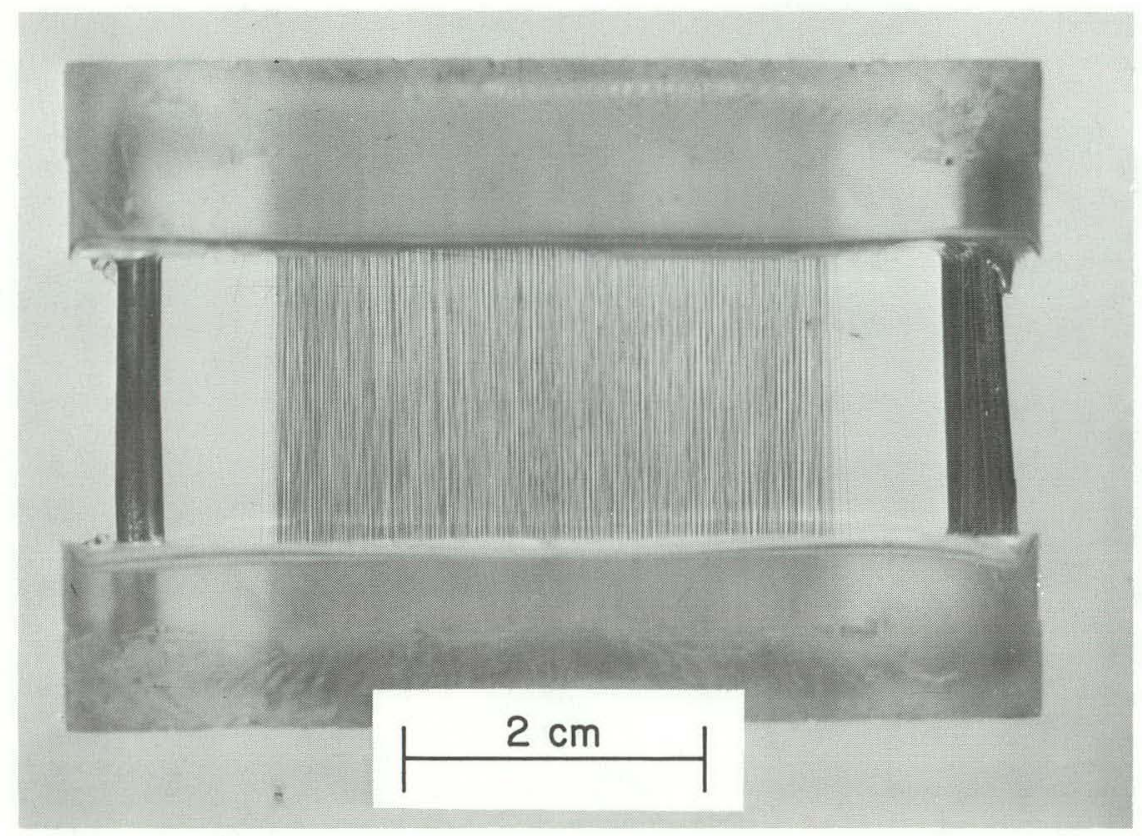

Figure 13

METAL FRAMES WITH STAINLESS STEEL WIRE CAST IN PLASTIC

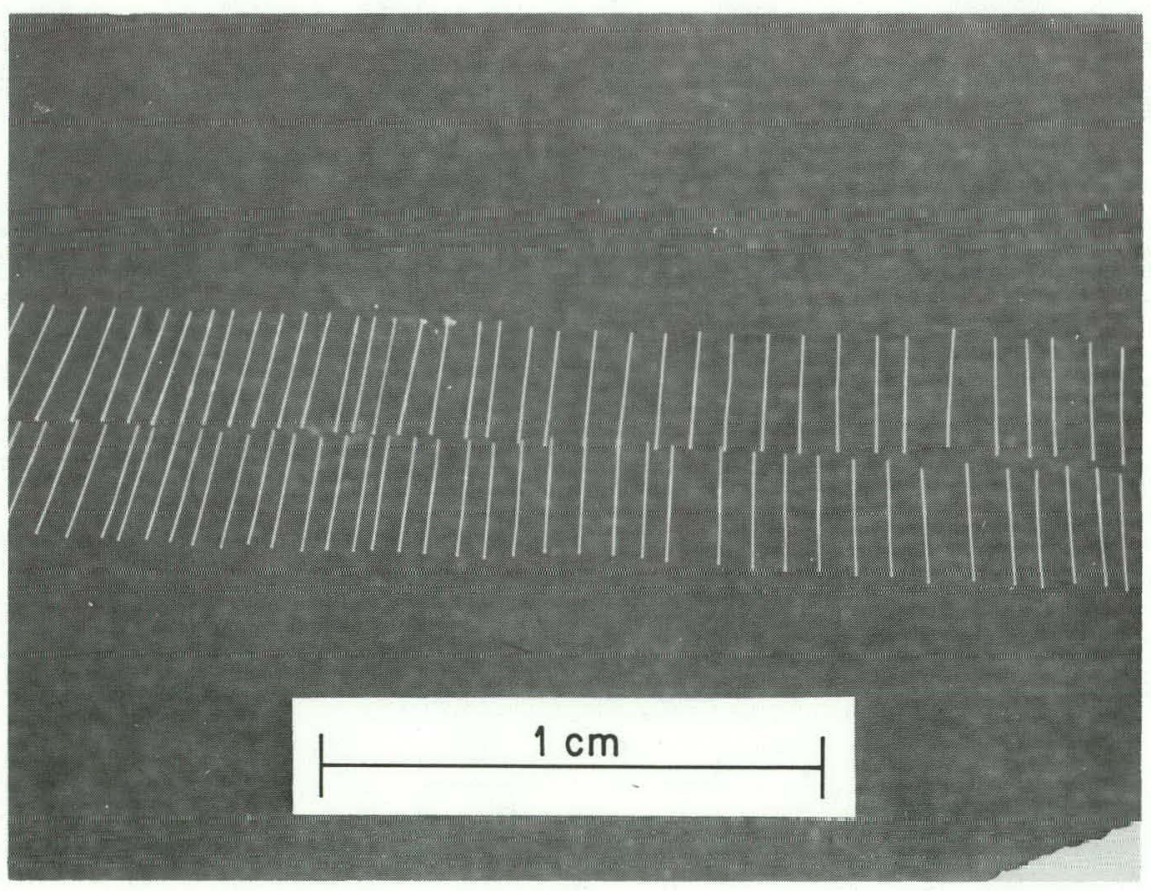

Figure 14

CAPILLARIES IN PLASTIC SAMPLE 
represent a problem or adversely affect the sample. Again, because of the size of the sample holder, the area available for the capillaries was confined to a rectangle 0.75 in. by $1.5 \mathrm{in.}$

Samples were made with 1- and 2-mil-diameter stainless steel wire. The samples made with 1 -mil wire contained approximately 1000 capillaries, and those with the 2-mil wire contained approximately 250 capillaries. Several samples of each size were made for flow measurements, and generally good reproducibility of $1 \%$ or better in the capillary radius inferred from the flow measurements was obtained. Figure 14 shows one of the preliminary samples made with methyl methacrylate and only two rows of capillaries.

\section{Short Capillary Sample}

Several methods were considered for preparing an orifice or short capillary sample. However, because of the many difficulties involved, a drilled metal foil was chosen. A 1-in. square of 5-mil-thick gold foil was rolled to a thickness of about $3 \mathrm{mils}$. Then ten 2-mil-diameter holes were drilled into the gold foil with a precision drilling instrument. The holes which were made were very slightly elliptical, but the biggest difficulty was in defining the length. The drilling process tended to push the soft gold through toward the back side, causing a mound which made the length of the capillaries larger than the foil thickness. However, the length was fairly well defined by optical measurements. Unfortunately, the capillaries were not perfectly clean. Several of the capillaries had significant burrs resulting from the drilling. These burrs were the primary source of the difference in capillary radius as observed by the area measured by an Imanco Quantimet Image Analyzer and the radius measured with a Kentron microscope. The length-to-radius ratio using the radius determined by the Quantimet was 4.3. Figure 15 shows one of the capillaries. This sample was designated sample 2 .

\section{Parallel Plate Samples}

One of the requirements for the parallel plate samples was that the faces of the channel be very smooth, flat, and parallel. This was accomplished by using hardened steel grade At gage blocks, which have a flatness of 4 microinches and an RMS surface finish of 0.09 microinches. The gage blocks were thoroughly cleaned and degreased. The blocks were positioned with a metal foil spacer between them on each end to determine the approximate channel height. They were placed in a press and approximately 1000 psi. pressure was applied while epoxy resin was applied to the ends of the blocks to fasten them together. After the epoxy resin hardened, they were removed from the press and mounted in a plastic block. Figure 16 shows test sample 1 .

\section{FLOW MEASUREMENTS}

While microscopic measurements were made to estimate the dimensions of the samples, the most accurate means of characterizing these small dimensions is with flow measurements. The Hagen-Poiseuille law for laminar flow of fluids is so well established that this law can be used to calculate the 


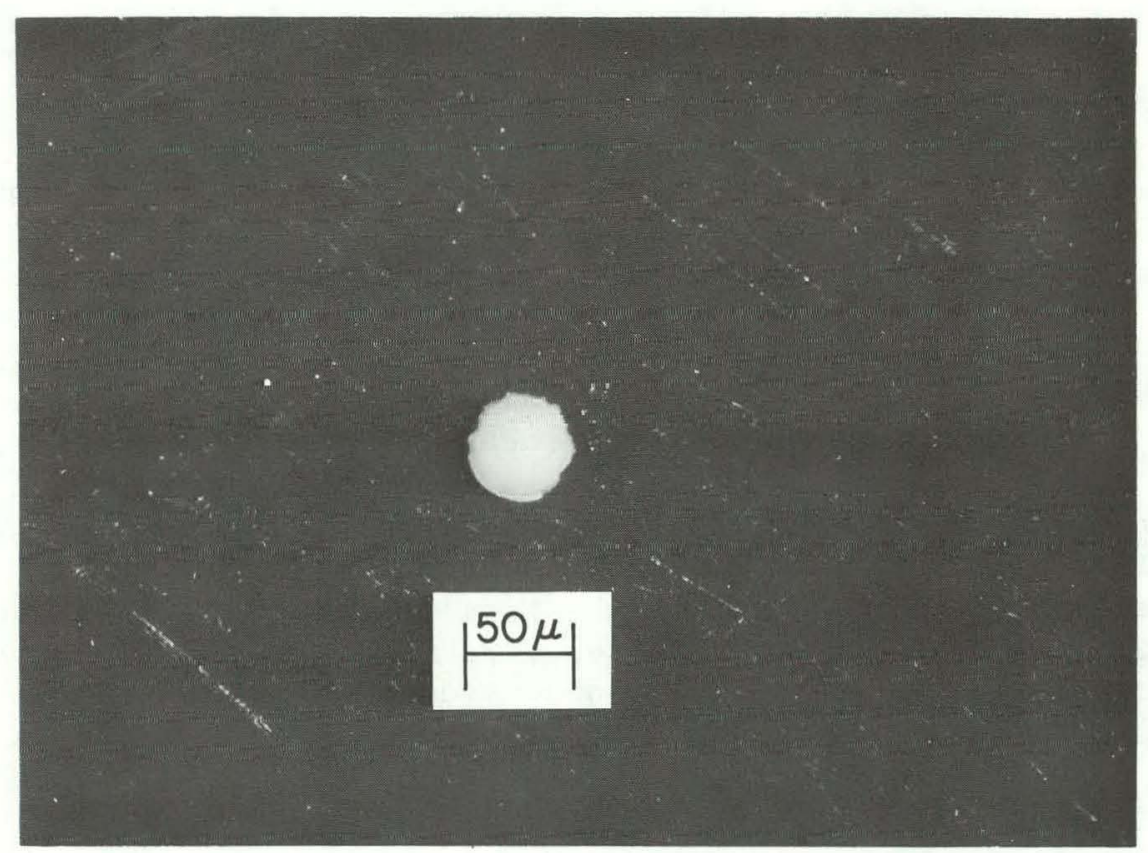

Figure 15

CAPILLARY IN GOLD FOIL 
PHOTO NO. PH-72-2126

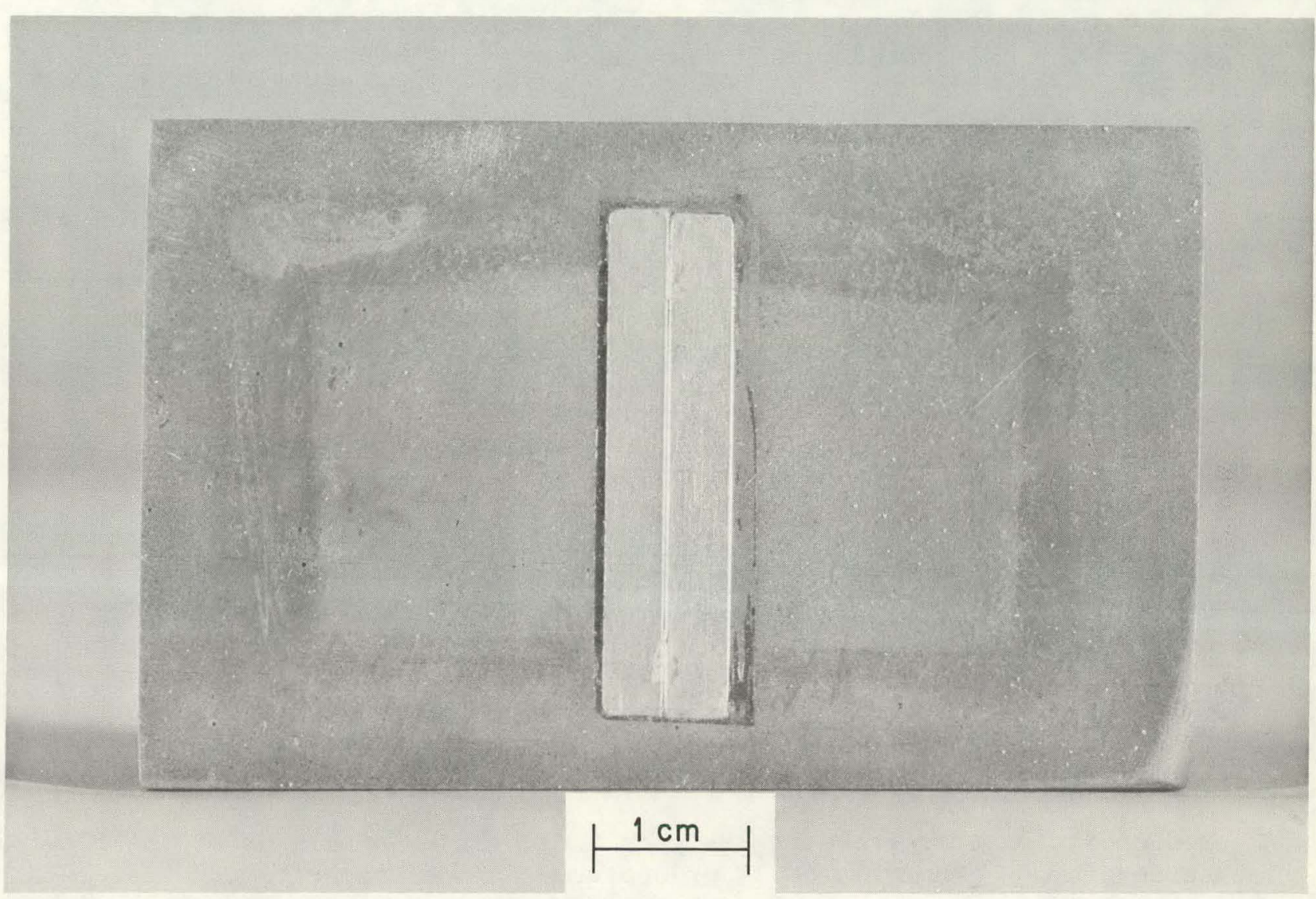

Figure 16

PARALLEL PLATE SAMPLE 1 
appropriate characterizing dimension of a test sample. Very precise flow measurements were made on all of the test samples as part of a flow study which will be discussed in a later report. The measurements were made with a specially designed flow system which can be used to make either steady state flow measurements or pressure decay measurements at constant average pressure.

The steady state measurements were made by a volumetric technique in which the time required for a given pressure change in a calibrated volume was measured. The calibrated volume was evacuated at the beginning of a measurement so that the change in pressure was large compared to the starting pressure. This method reduces errors associated with temperature changes in the volume during the measurement time. However, the temperature of the volume was monitored and no significant changes were observed. The test sample was isolated from the calibrated volume with a needle valve which was operated with a critical pressure drop across it so that the pressure on the downstream side of the test sample was not affected by the pressure change in the calibrated volume. The pressure on the upstream side of the test sample was kept constant with a pressure regulator.

The pressure decay measurements were made with a specially designed test sample holder which made use of a small high vacuum butterfly valve. The sample was located on a flange very close to the butterfly. The holder was arranged so that when the butterfly was open, there was a volume of $100 \mathrm{cc}$ on each side of the test sample. When the butterfly valve was closed, the volume on the valve side of the sample was divided into two segments. The segment between the sample and the valve was about $15 \mathrm{cc}$ with the other segment about $85 \mathrm{cc}$. With the butterfly open, the holder was filled to some measured pressure. Then the butterfly was closed and the $85-c c$ volume was filled to a somewhat higher pressure. The butterfly was then opened and the time interval for a specifir differential pressure decay was medsured.

Reproducibility and regression analyses indicate the precision of the flow measurements was generally $\pm 0.1 \%$ or better. Barocel capacitance manometers and the timing device which was triggered by the output from the Barocel were the principal reasons for the high degree of precision.

The pressure decay technique was used principally for the low pressure measurements where the specific flow deviates from linearity with pressure. The steady state measurements were made in the high pressure region where the specific flow was linear with pressure. The continuum expression for viscous flow through a capillary with slip at the wall as developed by Maxwell is given in Kennard [26]. Written in terms of the transport ratio, defined as the flow rate divided by the free molecule flow through an ideal orifice with the same cross-sectional area, this expression is

$$
W A=S \Sigma P+W_{m} A
$$

where

$$
\mathrm{S}=\frac{\pi r^{4}}{2 n \bar{v} \ell}
$$


The capillary radius can then be calculated from the slope, $S$, of the curve obtained by plotting the transport ratio times the area vs. the sum of the upstream and downstream pressures. The intercept at zero average pressure, $W_{m} A$, is also related to the capillary radius. Maxwell's slip theory given by Kennard shows that

$$
W_{m} A=\frac{(2-f)}{f} \frac{\pi^{2}}{2} \frac{r^{3}}{l}
$$

where the gas interaction with the wall is divided simply into diffuse or random and specular or mirror reflections from the wall. The quantity $f$ is the fraction of diffuse reflections. Hanks and Weissberg [27] calculate a value of the slip coefficient which gives

$$
W_{m} A=\frac{(2-f)}{f} \frac{2 \pi^{2}}{3} \frac{r^{3}}{\ell}
$$

An exact solution using the modeled linearized Boltzmann equation gives $W_{\mathrm{m}} \mathrm{A}$ equal to 1.1466 times Maxwell's value.

The corresponding expressions for the slope and intercept for a semi-infinite parallel plate channel are

$$
S=\frac{w h^{3}}{6 \eta^{\bar{v}} \ell}
$$

and

$$
W_{m} A=\frac{(2-f)}{f} \frac{\pi}{2} \frac{w h^{2}}{l}
$$

Berman [28] has shown that when backscattering is present instead of specular reflection, the term $(2-f) / f$ is replaced by

$$
\frac{2}{\pi}+\frac{\alpha}{2(2-\alpha)}
$$

where $\alpha$ is the fraction of diffusion reflections, and $1-\alpha$ is the fraction of backscattered reflections.

The low pressure transmission ratios measured with the pressure decay method were also plotted against average pressure and extrapolated to zero pressure. According to Knudsen, the free molecule transport ratio for an infinitely long capillary should be

$$
\mathrm{W}_{\mathrm{K}}=\frac{8}{3} \frac{\mathrm{r}}{\ell} \text {. }
$$

Smoluchowski [29] showed that specular reflections produce the same effect on free molecule flow as they do on slip flow:

$$
W_{K}=\frac{(2-f)}{f} \frac{8}{3} \frac{r}{l} .
$$


For finite capillaries, Clausing [30] showed that an end correction was necessary, giving

$$
W_{K}=\frac{(8 / 3) r}{\ell+\Delta \cdot r}
$$

The Clausing end correction, $\Delta$, for capillaries is given by Lund and Berman [3]. DeMarcus [31] has made a more rigorous calculation confirming this result and also showed that the Maxwell correction for specular reflections apply but only for the infinite capillary. Similarily, for a semi-infinite parallel plate channel,

$$
\mathrm{W}_{\mathrm{K}}=\frac{(2-\mathrm{f})}{\mathrm{f}} \frac{\mathrm{h}}{\ell} \ln \frac{\ell}{\mathrm{h}} .
$$

An appropriate end correction for the finite parallel plate slit has also been calculated by Clausing and is given by Berman [32]. Berman [28] has also shown that for free molecule flow when backscattering is present, the term $(2-f) / f$ should be replaced with $\alpha /(2-\alpha)$.

A listing of the flow parameters measured on all of the test samples is given in table 2 .

\section{SEPARATION MEASUREMENTS}

Figure 17 shows a schematic diagram of the neon separation system. The system provides a means of flowing neon gas past the test sample at a gas velocity of 100 to 1000 times higher than the gas velocity through the test sample. In one mode of operation the gas was recirculated in a closed loop with sealed piston-type pumps. This mode of operation was used at the higher flow rates to conoorve gas. At the lower pressures and \pm low rates, operating conditions could be obtained better when the neon was simply exhausted to atmosphere through vacuum pumps. The feed throttle valve was interchangeable. The valve used was dependent upon the forepressure and the sample being tested. At the higher pressures and flow rates a hand-controlled needle valve or ball valve was adequate. At low flow rates a Granville-Phillips Automatic. Pressure Controller was used to control a servo-driven variable leak valve. The reject throttle valve was a needle valve. A Meriam Laminar flowmeter was used to measure the feed flow. The pressure drop across the flowmeter was measured with a 0- to 1-in. water pressure Pace transducer. This permitted measurement of feed flow rates of less than one standard $c c$ of gas per minute.

The pressures were measured with a Datametric Electronic manometer using a Barocel pressure sensor type 511,0 to $10 \mathrm{~cm} \mathrm{Hg}$, for the forepressure and a type 538, 0 to 1 psi., for the backpressure. This provided a very accurate means of measuring the pressures. When the forepressure exceeded the limits of the Barocel, a mercury manometer referenced to vacuum was used to measure the forepressure. 
Table 2

FLOW MEASUREMENT PARAMETERS

\begin{tabular}{|c|c|c|c|c|c|c|c|c|c|c|c|c|}
\hline \multirow[b]{2}{*}{$\begin{array}{l}\text { Sample } \\
\text { Number } \\
\end{array}$} & \multicolumn{3}{|c|}{ Nitrogen } & \multicolumn{3}{|c|}{ Helium } & \multicolumn{3}{|c|}{ Argon } & \multicolumn{3}{|c|}{ Neon } \\
\hline & $\begin{array}{l}5 \times 10^{-4} \\
\left(\mathrm{~cm}^{-1} \mathrm{Eg}:\right.\end{array}$ & $w_{0} \times 10^{-4}$ & $w_{m} \times 10^{-4}$ & $\begin{array}{l}\mathrm{S} \times 10^{-4} \\
\left(\mathrm{~cm}^{-1} \mathrm{Hg}\right) \\
\end{array}$ & $w_{0} \times 10^{-4}$ & $w_{m} \times 10^{-L}$ & $\begin{array}{l}\mathrm{S} \times \div 0^{-4} \\
\left(\mathrm{~cm}^{-\frac{1}{+}} \mathrm{Hg}\right) \\
\end{array}$ & $w_{0} \times 10^{-4}$ & $\underline{w_{m} \times 10^{-4}}$ & $\begin{array}{l}\mathrm{S} \times 10^{-4} \\
\left(\mathrm{~cm}^{-1} \mathrm{Hg}\right)\end{array}$ & $w_{0} \times 10^{-4}$ & $w_{\mathrm{m}} \times 10^{-4}$ \\
\hline 212 & 47.23 & - & 97.3 & 16.0 & 107 & 80.3 & . & & & & & \\
\hline 838 & 8.55 & - & 33.4 & - & - & - & & & & & & \\
\hline 924 & 10.71 & 53.5 & 44.1 & - & - & - & & & & & & \\
\hline 1054 & 1.91 & 28.0 & 21.9 & 0.632 & 26.0 & 21.0 & 1.81 & 28.0 & 21.4 & 0.904 & 29.6 & 21.7 \\
\hline 64 & 19.2 & 60.8 & 44.2 & 6.60 & 60.5 & 44.0 & 17.7 & - & 46.7 & 9.12 & - & 44.4 \\
\hline 2 & 1949 & 3500 & 3400 & 666 & - & 3600 & & & & & & \\
\hline 1 & 20.02 & - & 54.1 & - & - & - & & & & & & \\
\hline 5 & 4.95 & 66.0 & 17.3 & 1.59 & 75 & 36 & & & & . & & \\
\hline
\end{tabular}

aeasured several months later after separation measurements. 


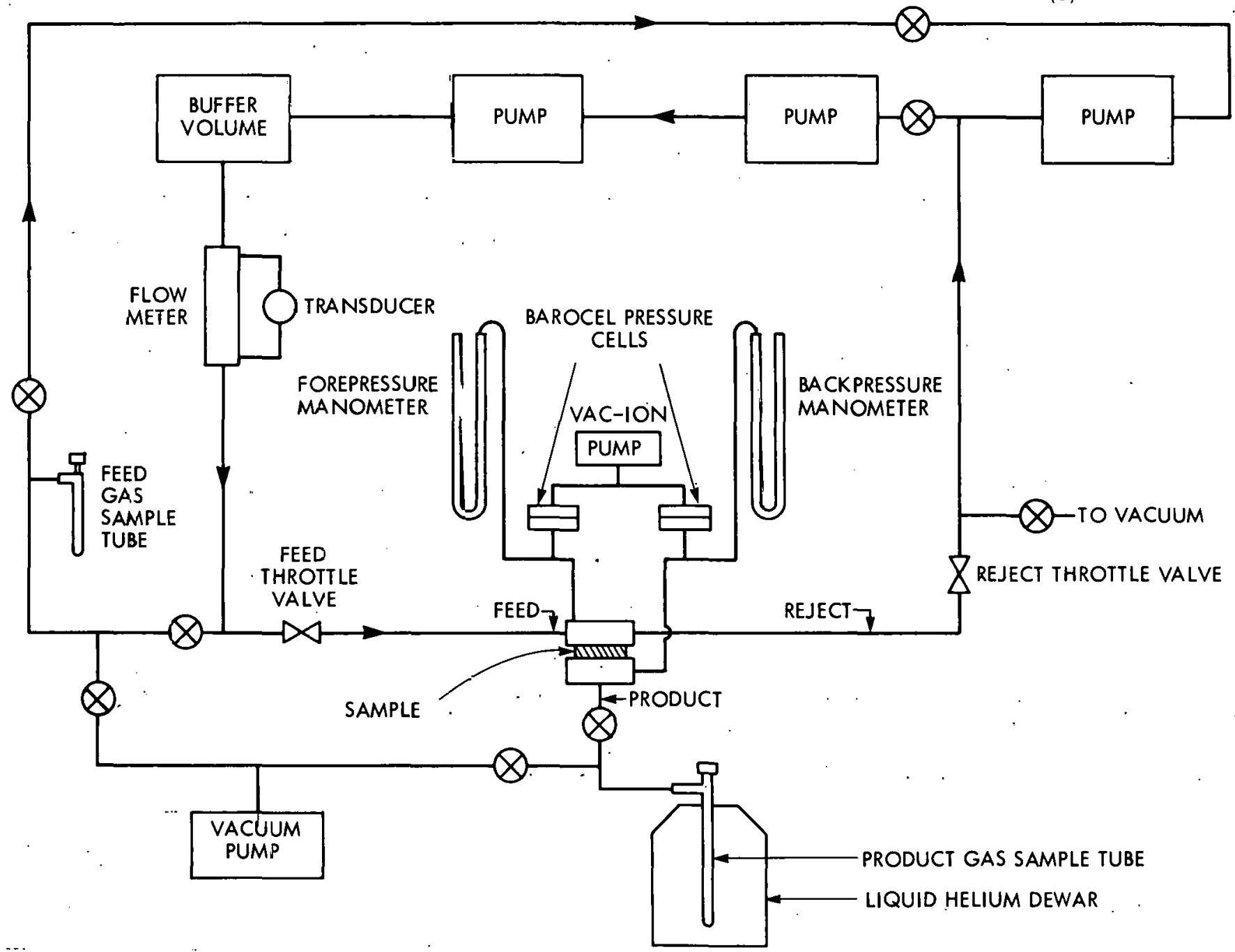

Figure 17

INER: GAS SEPARATION SYSTEM 
The samples were mounted in a holder in which the feed gas flows horizontally across the face of the sample. Figure 18 shows the high pressure side of the holder. Three pressure taps are located in the holder to permit measurement of the forepressure, $P_{f}$, and the pressure drop across the face of the holder. The flow channel across the holder is $20 \mathrm{mils}$ deep, 7/8 in. wide, and $1 \frac{5}{8}$ in. long. The gas enters the holder perpendicular to the channel. Figure 19 shows the low pressure side of the holder. A pressure tap for measuring the backpressure, $\mathrm{P}_{\mathrm{b}}$, is located at point $A$. The product flow line is $0.5 \mathrm{in}$. in diameter to help reduce the pressure drop between the test sample and the sampling tube. Figure 20 shows the complete holder assembly bolted together, without a sample.

A very important and necessary part of the system was a 25-1iter dewar of liquid helium which was used to freeze out the neon product sample. It proved to be a very efficient and inexpensive method of collecting the product gas. The product sample tubes were made of Inconel with a 6-mil wall thickness in order to reduce the amount of liquid helium boiled off each time a sample was taken.

The apparatus and sample holder were constructed with concern that no significant concentration gradients ever develop on the high pressure side of the sample. This is necessary in order that any observed isotopic concentration changes will accurately reflect only those changes which occur as a result of flow through the sample. Because of the wide variety of conditions under which measurements were to be made and since a large number of the small capillaries were required for the flow measurements, it was felt that more accurate and reproducible results could be obtained by analyzing collected gas samples of the feed and diffused or product streams under similar conditions in the mass spectrometer laboratory rather than having a mass spectrometer physically attached to the separation system.

The mass spectrometer laboratory prepared a special spectrometer with a double-collector system for use in analyzing the neon samples. The ion current produced by the neon-20 isotope and the small amount of neon-21 present is measured by the first collector. The first collector has an appropriately located slit to allow the neon-22 ions to pass through to the second collector. The ion current produced by the neun-22 isotope is measured by the second collector. The ratio of the ion currents gives the ratio of mole fractions in a given sample. The neon-21 isotope collected with the neon-20 isotope is such a small fraction of the neon-20 isotope that analytically it produces a negligible error and can be ignored. The ratio of mole fractions of neon-20 and neon-22 is measured for both the feed and product streams. The ratio of these ratios then gives the separation factor for a given measurement.

Separation measurements by the laboratory revealed that best results could be obtained with a gas sample at about $10 \mathrm{~cm} \mathrm{Hg}$ absolute pressure. This requirement made sampling of the product stream difficult and could have greatly restricted the conditions under which separation measurements would be made. Initial attempts at collecting a product gas sample in an evacuated sample tube under varying backpressure conditions were totally 
PHOTO NO. PH-69-895

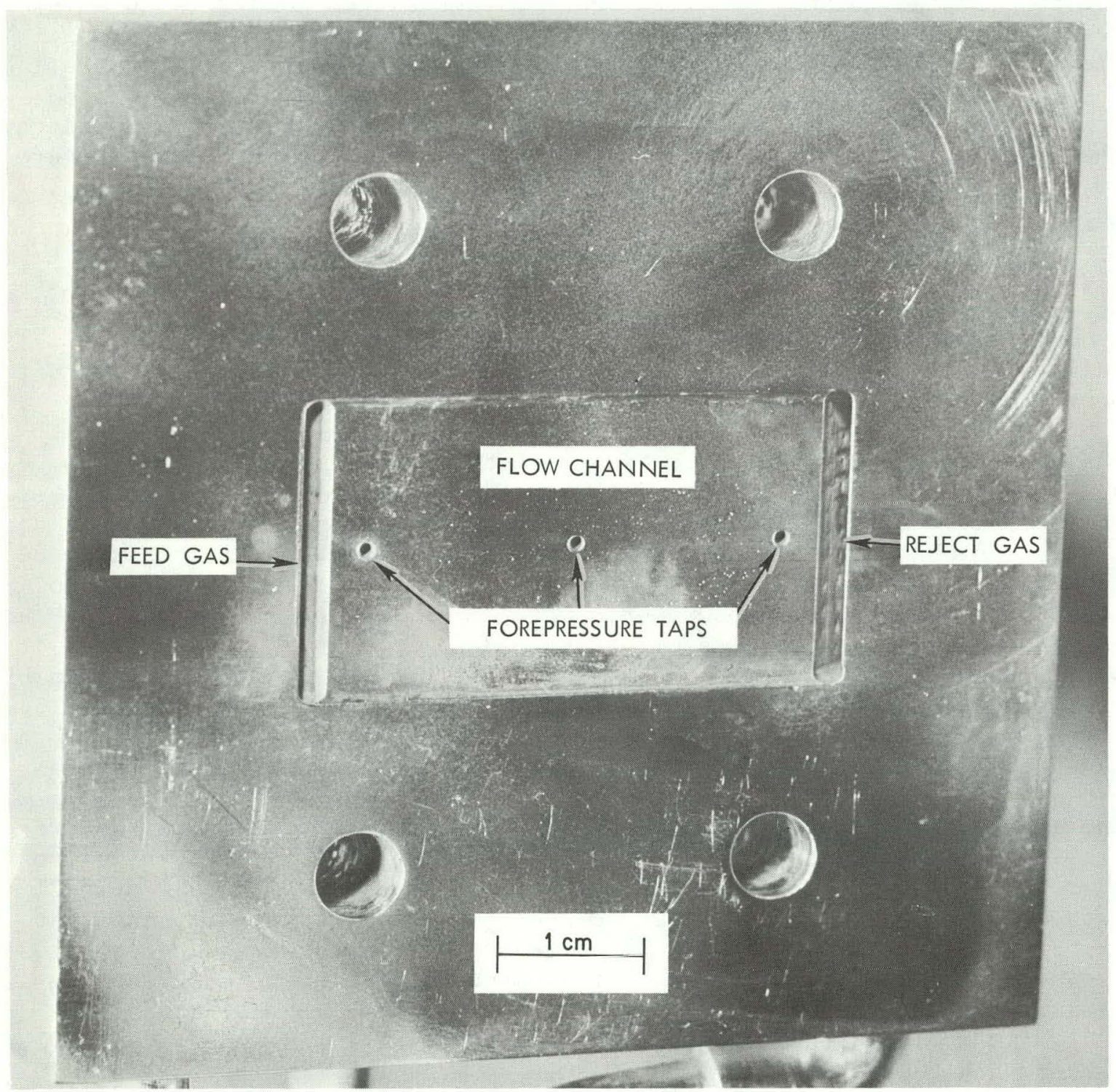

Figure 18

HIGH PRESSURE SIDE OF SAMPLE HOLDER 


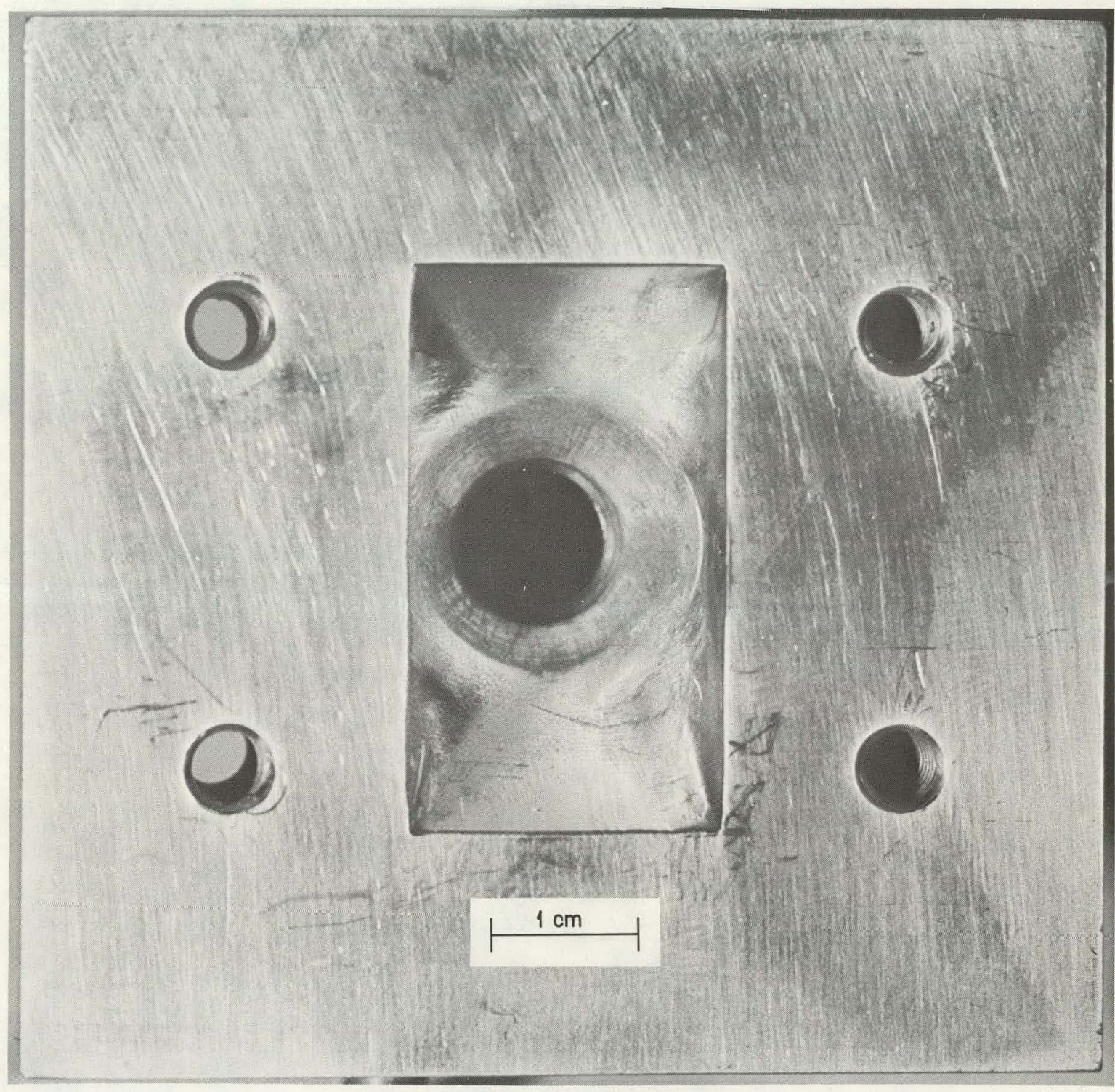

Figure 19

LOW PRESSURE SIDE OF SAMPLE HOLDER 
PHOTO NO. PH-69-896

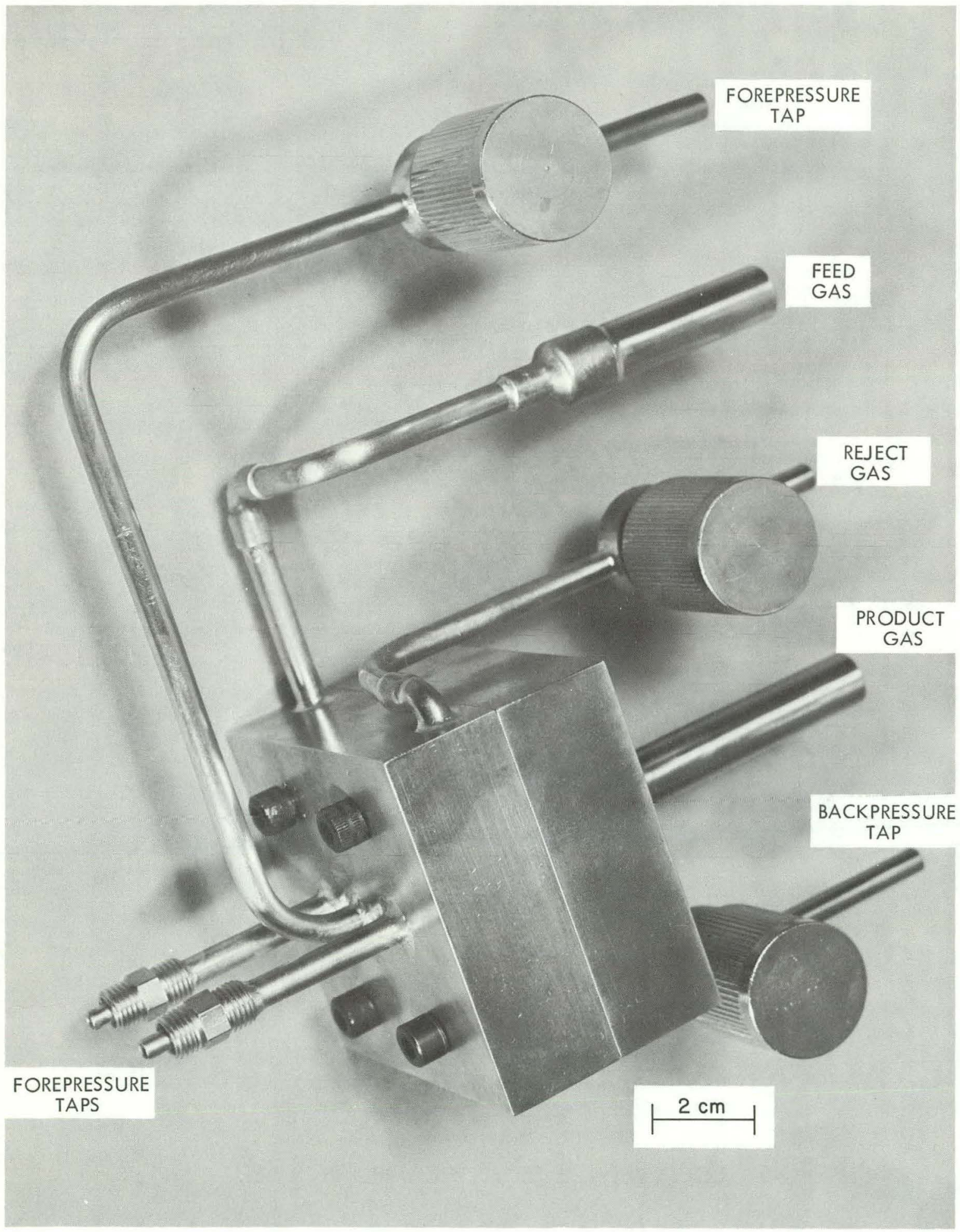

Figure 20

COMPLETE HOLDER ASSEMBLY 
unsuccessful. As a last resort, the neon product sample was collected in a liquid helium dewar. This proved to be so satisfactory that all measurements were made in this manner. The product samples were collected with relatively low helium loss, and the cost of liquid helium to freeze out the neon samples was a small part of the overall effort. From the known flow rates through the test sample, the run times could be adjusted so that when the sample tubes were removed from the helium dewar, the sample pressures would be about $10 \mathrm{~cm} \mathrm{Hg}$. This technique provided a means of maintaining a very low pressure on the downstream side of the sample during the entire time required for the test. Most of the separation measurements were made with a high side-to-low side pressure ratio of between 100 and 1000. Since the test samples had different flow rates and a wide range of pressures was used in the measurements, several different sizes of product gas sampling tubes were used to avoid excessively short or long run times. Test sample forepressure varied from one atmosphere down to as low as about $0.5 \mathrm{~mm} \mathrm{Hg}$. Feed samples were always easily collected at the required $10-\mathrm{cm} \mathrm{Hg}$ pressure.

The sample to be tested was mounted in the separation sample holder using 0.05-in.-thick rubber gaskets on each side, and the two pieces of the holder were bolted together to compress the gasket and seal the sample. After the holder was mounted on the system, the system was evacuated and leak checked. The system was then filled with neon to an absolute pressure corresponding to the pressure necessary to permit a test to be made at a given pressure. Usually the high pressure measurements were made first to conserve neon.

There were two methods of operation: one in which the system operated as a closed loop where the gas was recirculated, and the other where the reject gas was exhausted to atmosphere. In the first method the first step was to circulate the gas. Next, the feed and product sample tubes were evacuated to a pressure of $10 \mu \mathrm{Hg}$ or less. A feed sample was taken by adjusting the feed line pressure to $10 \mathrm{~cm} \mathrm{Hg}$ absolute and circulating the gas past the feed sample tube with the sample tube open for approximately 30 seconds. The valves on the line to the feed gas sample tube were then closed to return the feed gas to the test sample holder.

In the second method of operation the circulating pumps were not used. The feed gas sample was taken in the same manner but at a higher pressure. After sampling, the pressure was adjusted to the required $10 \mathrm{~cm} \mathrm{Hg}$. Since the depleted gas was not being recirculated, feed samples were not taken each time. In this method of operation the feed gas came directly from the supply cylinder to the system and the reject gas was exhausted through a pump to atmosphere; therefore, the feed gas always had the same concentration. This second method was used only at the lower pressures where the flow rales were very small and recirculation was difficult with the dry head piston pumps used for recirculation. A 20-1iter buffer volume in the feed line was used as a reservoir so that pressures would not change rapidly. A Granville-Phillips automatic pressure controller which uses a servo-driven variable leak valve was used in the feed line to maintain a constant pressure on the high pressure side of the test sample. 
In both methods of operation, after the product sample tube was evacuated, the valve was closed and the sample tube was immersed in a dewar of liquid helium. The pressure conditions for the test were set by regulating the feed throttle valve and the reject throttle valve. The product line was opened to the vacuum pump to start the flow through the test sample and reduce the backpressure as much as possible. After the pressure was reduced and sufficient time was given for reaching an equilibrium flow condition, the product sample tube valve was opened and the valve to the vacuum pump was closed. The length of time for the test was determined by the flow rate at the particular test conditions and the size of the sample tube being used. Enough neon was collected in the sample tube to give a pressure of at least $10 \mathrm{~cm} \mathrm{Hg}$ absolute when the tube was at ambient temperature conditions. Exception was made when the run times required to collect neon at a pressure of $10 \mathrm{~cm} \mathrm{Hg}$ exceeded six hours. In these cases only enough neon to give $5 \mathrm{~cm} \mathrm{Hg}$ was collected. In these latter cases the separation results are somewhat less reliable, since pressures lower than $5 \mathrm{~cm} \mathrm{Hg}$ absolute in the smallest sample tubes did not provide enough neon to obtain very reliable measurements from the spectrometer. During the test the forepressure, backpressure, and feed flow rate readings were recorded. After the test was complete, the product sample tube valve was closed and the sample tube removed from the liquid helium. It was allowed to warm to ambient conditions, and then the degree of separation achieved was measured with the double-collector mass spectrometer.

Figure 21 shows the separation apparatus and associated instruments.

\section{SEPARATION EFFICIENCY CALCULATION METHOD}

When a binary isotopic gas mixture is diffused through an appropriate test sample, the light component diffuses more rapidly than the heavy component so that the diffused mixture is enriched in the 1ight component. When the diffusion occurs through an ideal Knudsen barrier with zero backpressure, the ratio of the flow of the light component to the heavy component is given by

$$
\frac{F_{1}}{F_{2}}=\frac{k \bar{v}_{1} N P_{f}}{k \bar{v}_{2}(1-N) P_{f}}=\frac{f * N}{(1-N)}
$$

where

$$
\mathrm{f} *=\frac{\overline{\mathrm{v}}_{1}}{\overline{\mathrm{v}}_{2}}=\sqrt{\frac{\mathrm{m}_{2}}{\mathrm{~m}_{1}}} .
$$

A1so,

$$
\frac{F_{1}}{F_{2}}=\frac{N_{1} F}{\left(1-N_{1}\right) F}=\frac{N_{1}}{1-N_{1}} ;
$$

therefore,

$$
\frac{\mathrm{f} * \mathrm{~N}}{1-\mathrm{N}}=\frac{\mathrm{N}_{1}}{1-\mathrm{N}_{1}} \text {. }
$$


PHOTO NO. PH-71-665

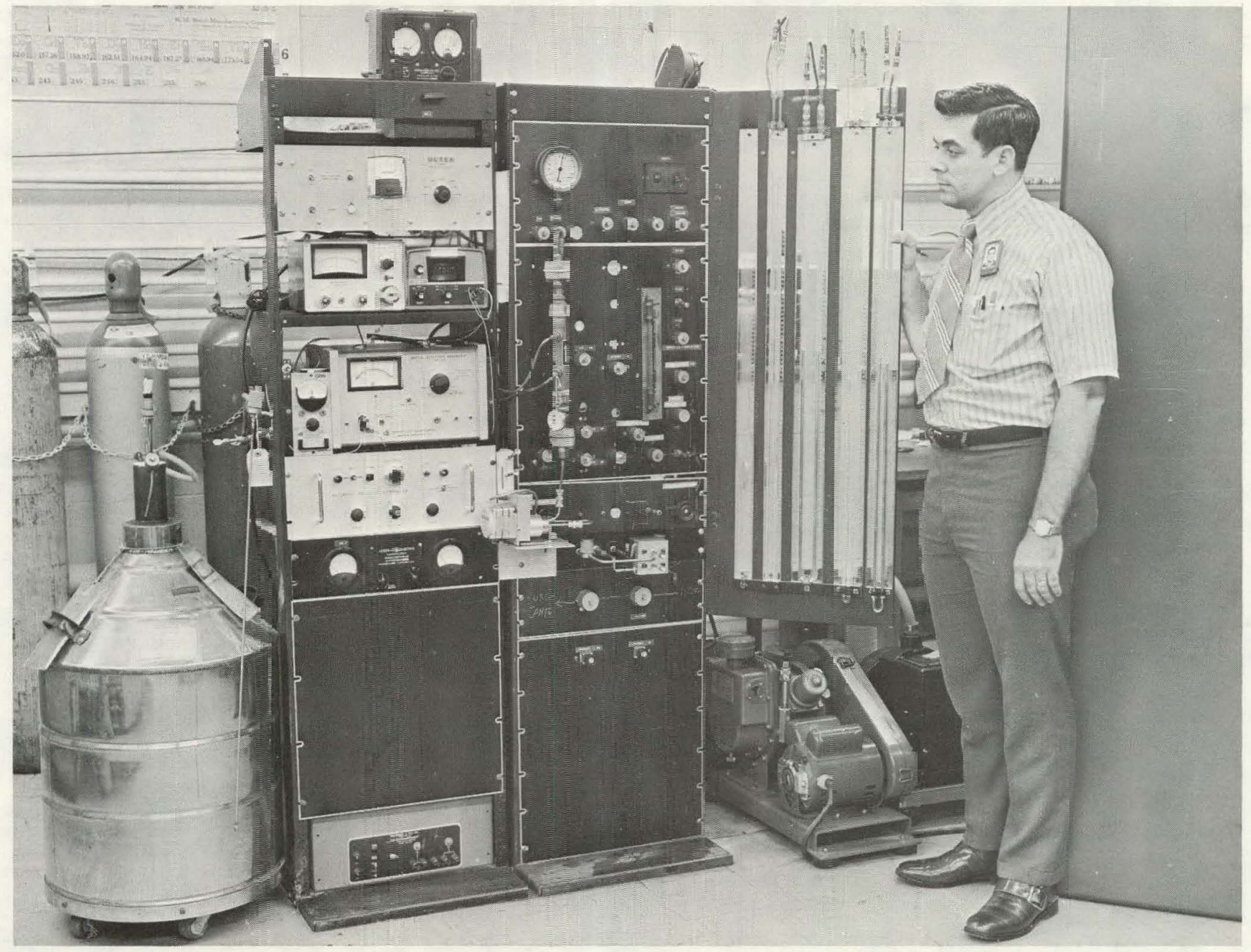

Figure 21

INERT GAS ¿EPARATION SYSTEM 
Then for a given product mole fraction $N_{1}$ the ideal feed mole fraction would be

$$
N *=\frac{N_{1}}{N_{1}+f *\left(1-N_{1}\right)} \text {. }
$$

Then the ideal enrichment produced by an ideal barrier is

$$
\delta *=N^{*}-N_{1} \cdot
$$

For a non-ideal barrier where the enrichment is

$$
\delta=\mathrm{N}-\mathrm{N}_{1},
$$

the separation efficiency is defined as

$$
Z=\frac{\delta}{\delta *}
$$

For an ideal barrier operating at finite backpressures the flow ratio is

$$
\frac{F_{1}}{F_{2}}=\frac{k \bar{v}_{1}}{k \bar{v}_{2}} \frac{\left(N P_{f}-N_{1} P_{b}\right)}{(1-N) P_{f}-\left(1-N_{1}\right) P_{b}} .
$$

From this it can be shown that the ideal enrichment is

$$
\delta^{O}=\delta *(1-w)
$$

where $w=P_{b} / P_{f}$. Then the separation efficiency for an ideal barrier operating at any pressure ratio is

$$
Z=\frac{\delta^{O}}{\delta *}=1-w \text {. }
$$

The separation efficiency ratio, $\mathrm{Z} /(1-\mathrm{w})$, is then the ratio of the separation efficiency of a diffusion barrier to that of an ideal diffusion barrier. Deviation of the separation efficiency ratio from unity represents deviations from ideal behavior.

A mass spectrometer can be used to measure the ratio of mole fractions of a binary mixture. The separation factor, $f$, measured with a mass spectrometer, is defined as

$$
f=\frac{N^{\prime} /\left(1-N^{\prime}\right)}{N /(1-N)} \text {. }
$$

It can be shown that equation (35) can also be written as

$$
Z=\left[N+(1-N) \frac{f *}{f}\right] \frac{f-1}{f *-1} .
$$


In the case of neon isotopes, $\mathrm{Z}$ can be approximated by neglecting the term in brackets in equation (40). The value of this term varies from unity for high separation factors to 1.004 for the lowest separation factors. Thus, the problem of not knowing the exact value of the feed mole fraction introduces a negligible error. Then, since $f^{*}=1.04881$ for neon isotopes,

$$
Z=\frac{f-1}{f *-1}=\frac{f-1}{0.04881}
$$

where $f$ is the value for the separation factor or ratio of mole fraction ratios as measured with a double-collector mass spectrometer.

In order to obtain an accurate separation efficiency, consideration needs to be given to the effect of the gas depletion or cut (ratio of product flow to feed flow) and to the effect of concentration gradients in front of the sample. The separation tests were made with a turbulent holder and at very low cuts to avoid a concentration gradient. However, this point was investigated on several occasions by varying the cut with all other conditions held constant. This was never a problem except at the lowest operating pressures. A correction was calculated for each test to account for the finite amount of gas removed from the stream by using the Rayleigh distillation correction:

$$
\frac{\theta}{(1-\theta) \ln [1 /(1-\theta)]}
$$

where $\theta$ is the cut or ratio of the product flow to the feed flow. Generally, this value deviated from unity by less than $1 \%$. The separation efficiency is given by

$$
z=\left(\frac{f-1}{f^{*}-1}\right) \frac{\theta}{(1-\theta) \ln [1 /(1-\theta)]} .
$$

Other factors which affect the separation efficiency are the forepressure, $P_{f}$, and the backpressure, $P_{b}$. All of the measurements were made at a room temperature of about $25^{\circ} \mathrm{C}$; the omall variations in room temperature have a negligible effect on the results. 


\section{DISCUSSION OF RESULTS}

All of the separation data that were taken on all of the samples which were tested are shown in Appendix B. Graphs of separation efficiency ratio, $\mathrm{Z} /(1-\mathrm{w})$, vs. pressure difference across the sample, $\Delta \mathrm{P}$, are shown for each of the samples investigated in figures 22 to 29 . For some of the data a larger variance in the low pressure region is due to an early problem of measuring the backpressure accurately. During the study, improvements were made in measuring the backpressure that eliminated this source of error. It is also believed that the lower pressure data tend to be biased low and have a larger variance because of the accumulation of larger amounts of air in the sampling tube with the longer times required to collect a gas sample. The presence of air in the mass spectrometer causes errors due to varying amounts of beam dispersion. There was also another problem at the lowest pressure relative to the fraction of the feed gas withdrawn as product which will be discussed later. The problem of long sampling times could be reduced if the test samples contained more capillaries. Sample 212 was the first sample tested. Since the sample had the highest flow rate of any of the samples tested, significantly better data might have been obtained with this sample if the separation measurements had been repeated later after all the improvements were made.

The data for sample number 838 shown in figures 23 and the data for sample number 924 shown in figure 24 appear to have somewhat more scatter in the higher pressure region than for other samples. It is believed that this increased variance was related to system problems and temporary problems with the mass spectrometer. The mass spectrometer analysis was the main source of test variance. The standard deviation per measurement should have been about \pm 0.009 . A discussion of the mass spectrometer variance is given in Appendix $C$.

The primary purpose of this study was to obtain experimental data of a quality that could be used to evaluate any theory for the separation of a binary gas mixture of isotopes. No attempt has been made to obtain a least squares fit of the experimental data with an analytic expression to obtain an interpolation formula. Instead, an empirical modification of the Present and deBethune equations has been made which appears to represent the data quite well and may be used as an interpolation formula for the data. Table 3 gives some combinations of constants used in the modified Present and deBethune equation to show the sensitivity of the fits to variations in the constants as indicated by a calculated standard deviation. The best trial and error fit of the data is indicated by the lowest standard deviation.

It is easily recognized from the PBM theory that the primary variable is the product of the characteristic dimension of the geometry being tested, which from these data appears to be the hydraulic radius as suggested by Present and deBethune, and the pressure difference across the test sample. If that product is also divided by the product of the gas viscosity and the mean molecular velocity, a unique parameter is obtained which will allow all separation data to be plotted on the same scale. 
SAMPLE NO. 212

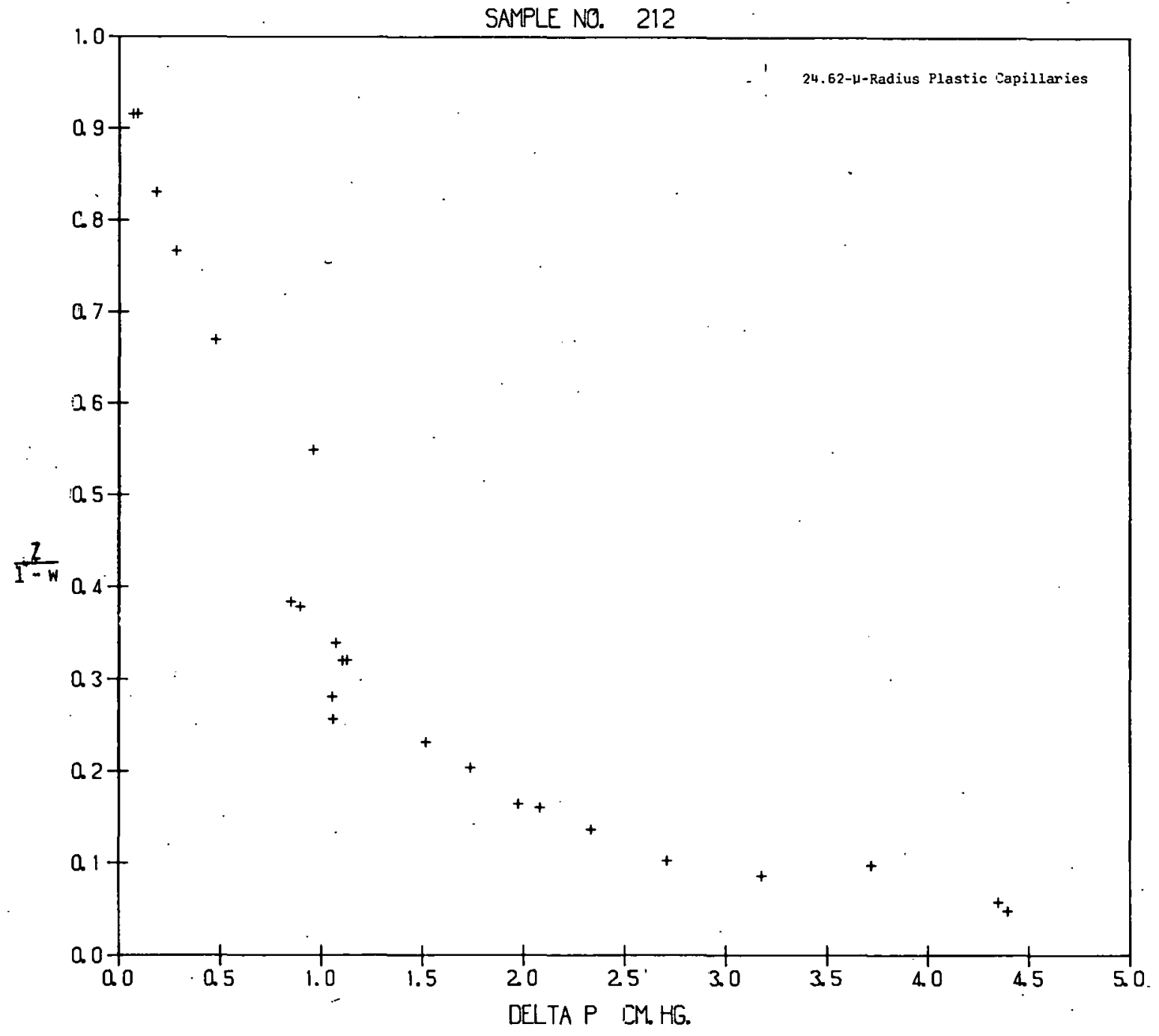

Figure 22

EXPERIMENTAL SEPARATION DATA FOR SAMPLE 212 


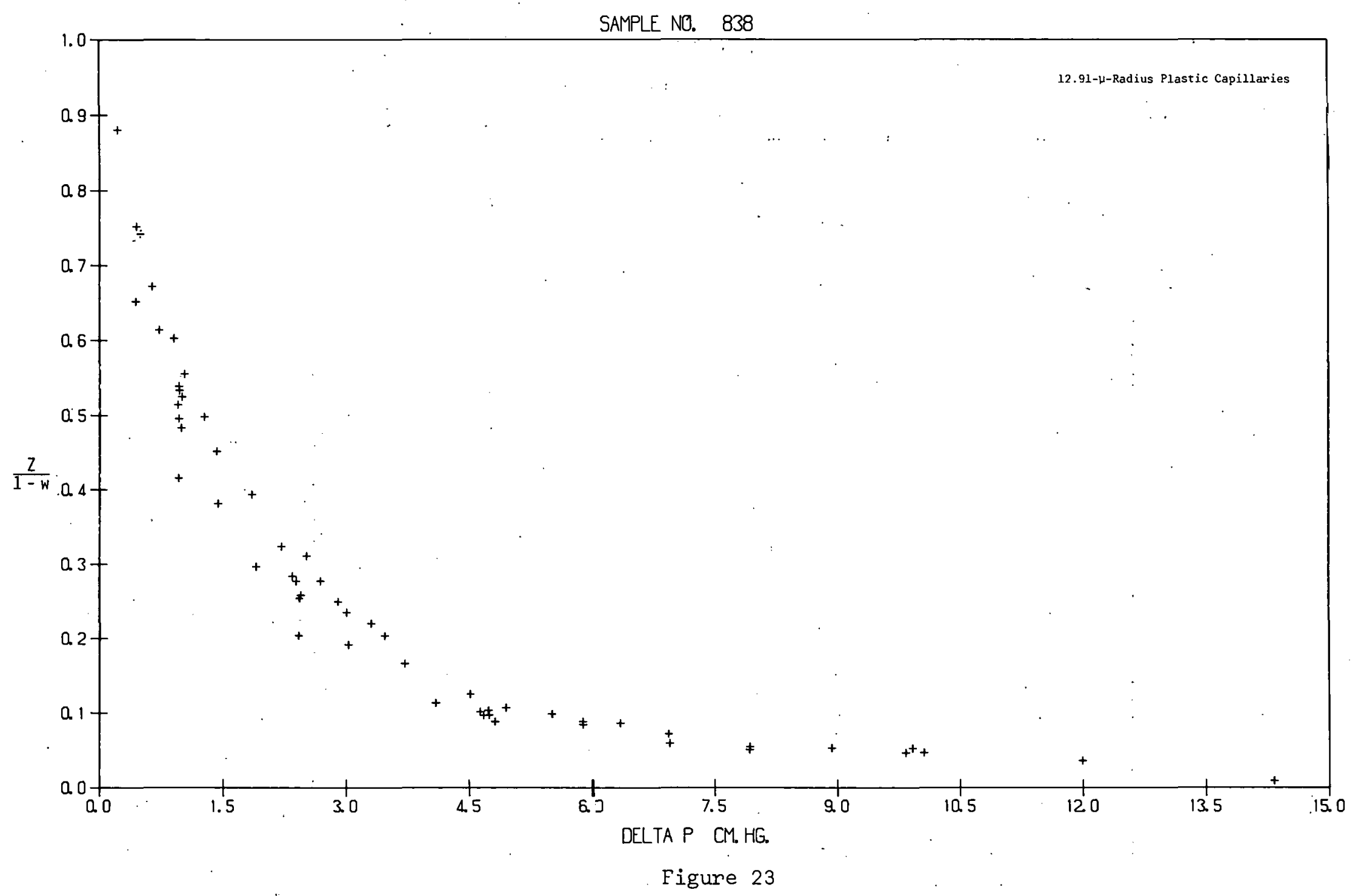

EXPERIMENTAL SEPARATION DATA FOR SAMPLE 838 
SAMPLE NO. 924

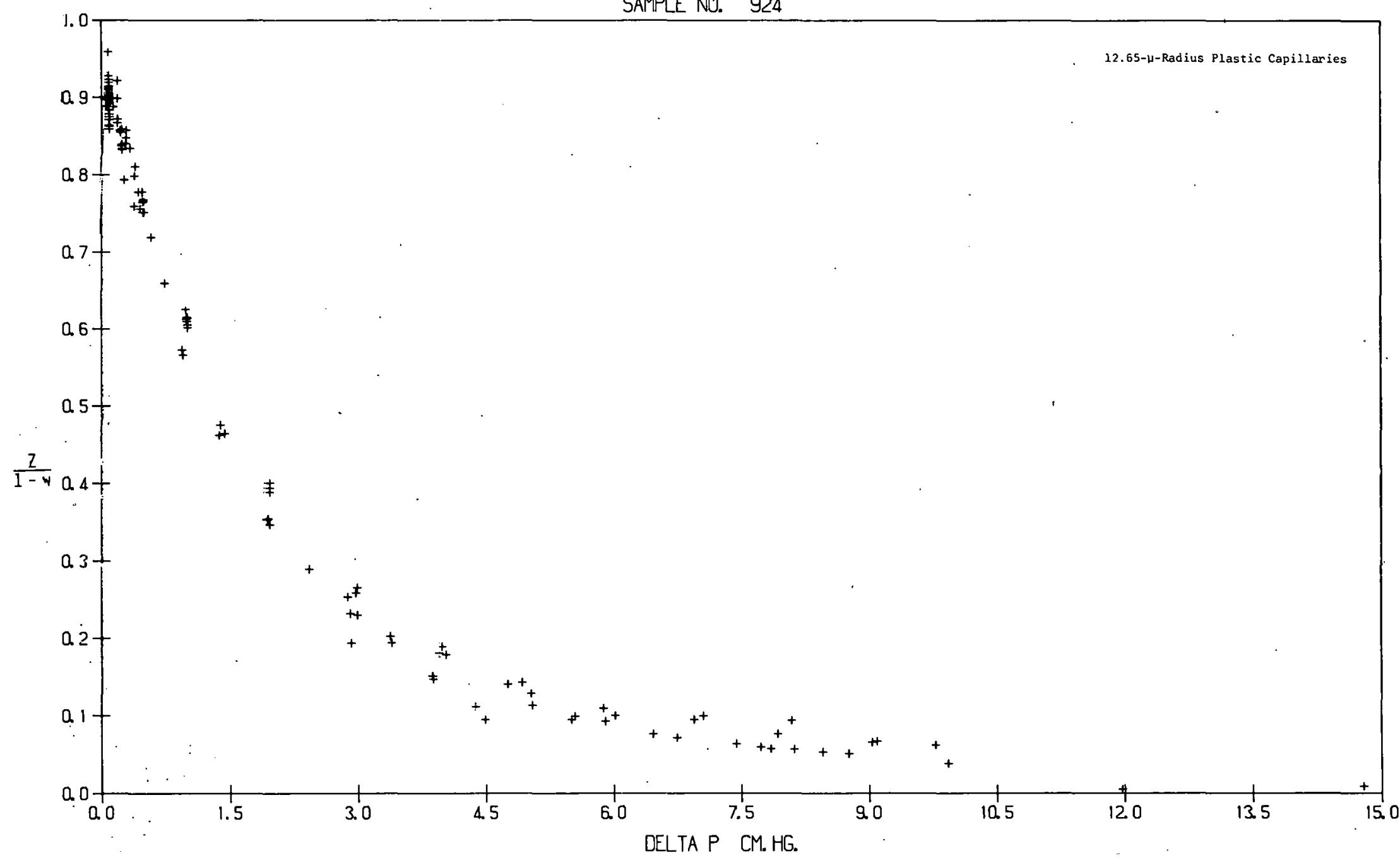

Figure 24

EXPERIMENTAL SEPARATION DATA FOR SAMPLE 924 
SAMPLE NO. 1054

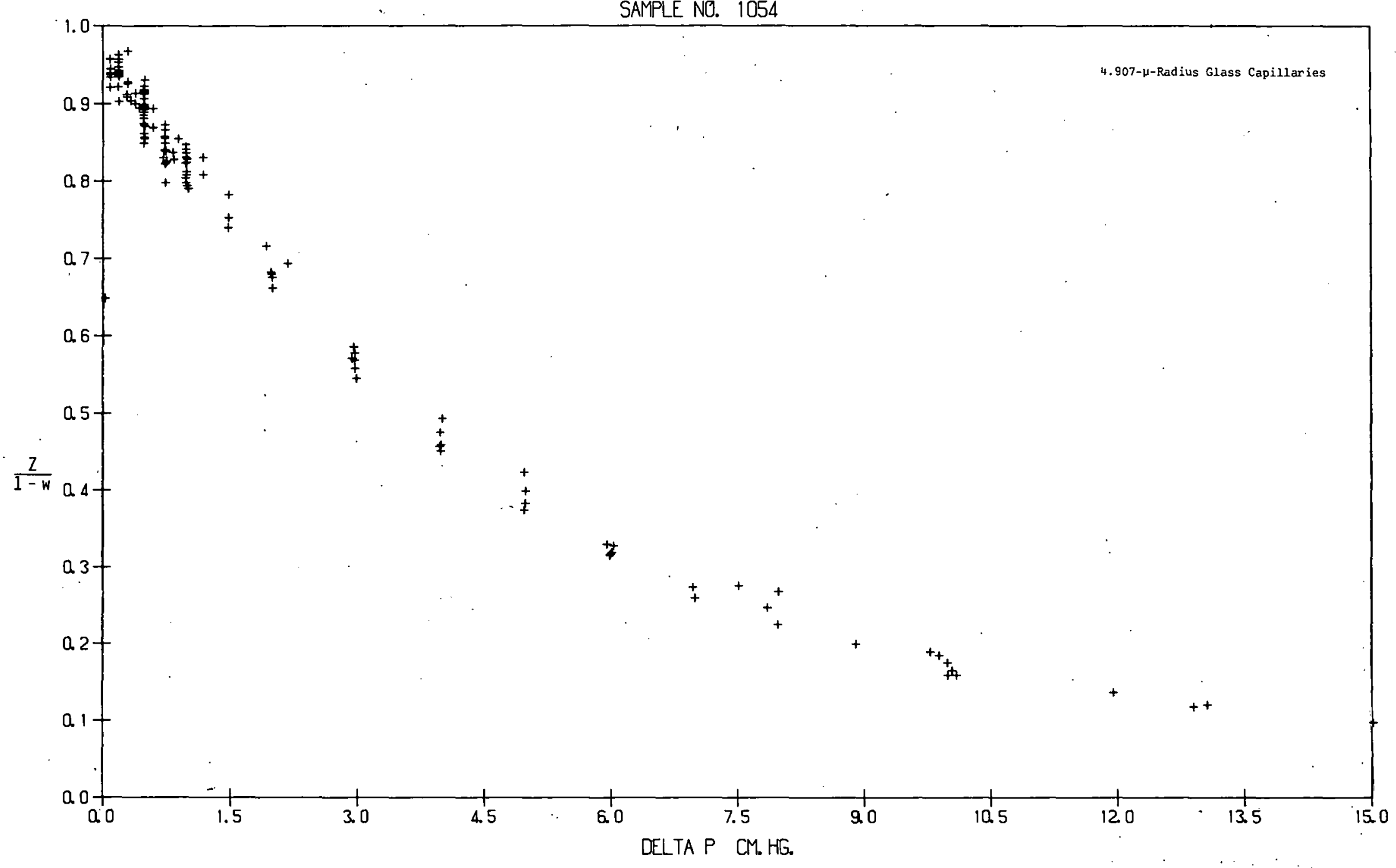

Figure 25

EXPERIMENTAL SEPARATION DATA FOR SAMPLE 1054 


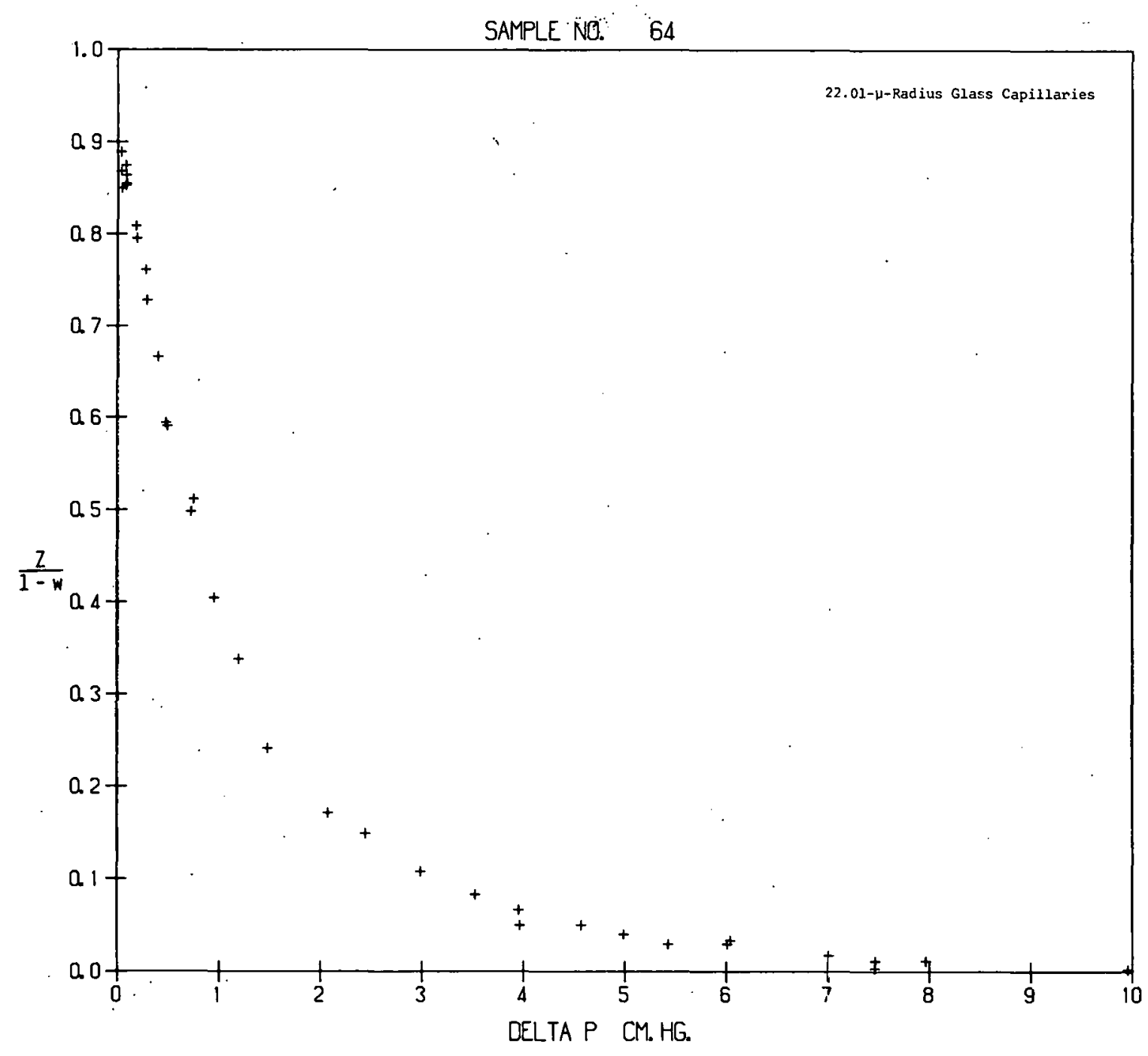

Figure 26

EXPERIMENTAL SEPARATION DATA FOR SAMPLE 64 


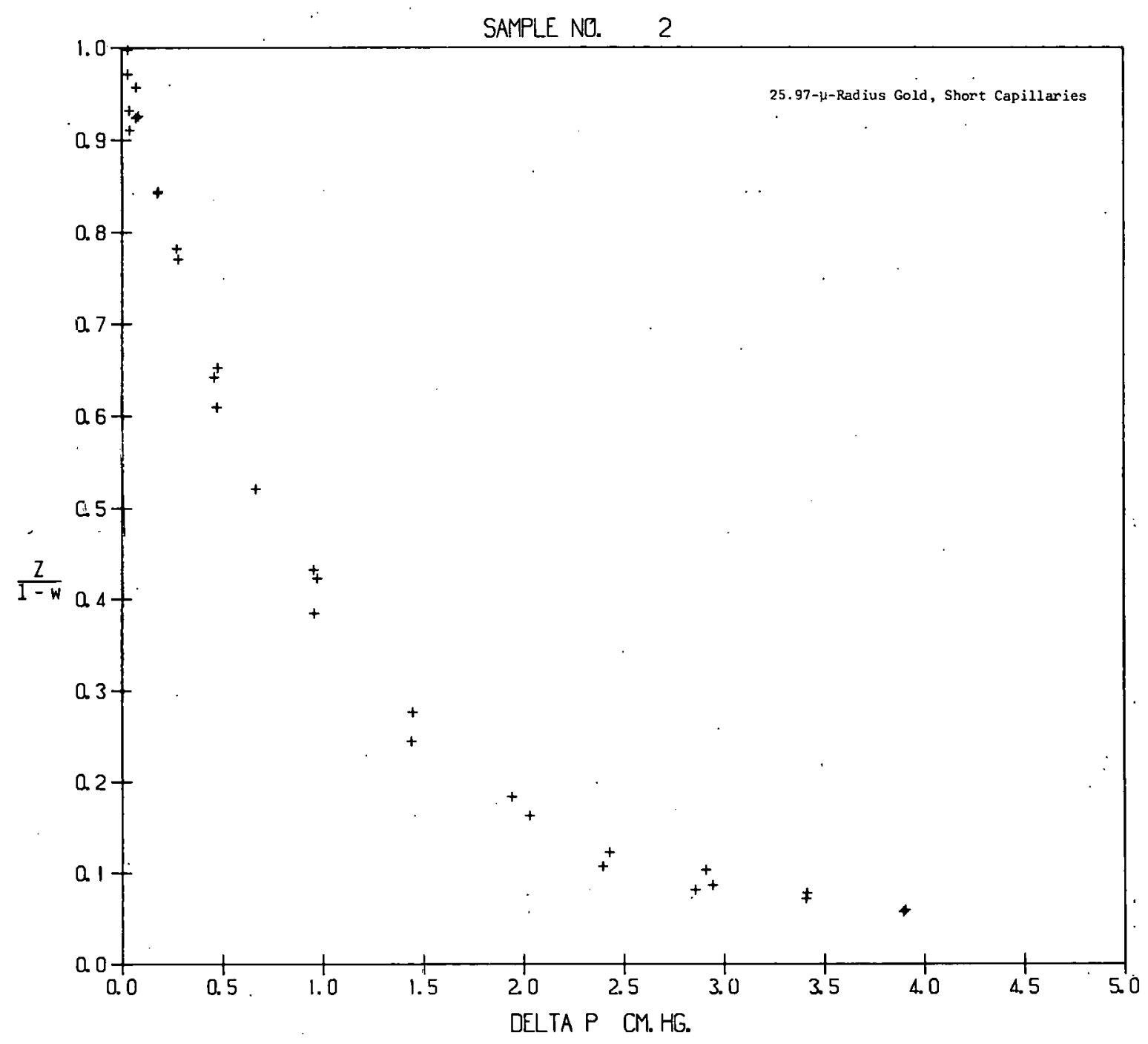

EXPERIMENTAL SEPARATION DATA FOR. SAMPLE 2 
SAMPLE NO.

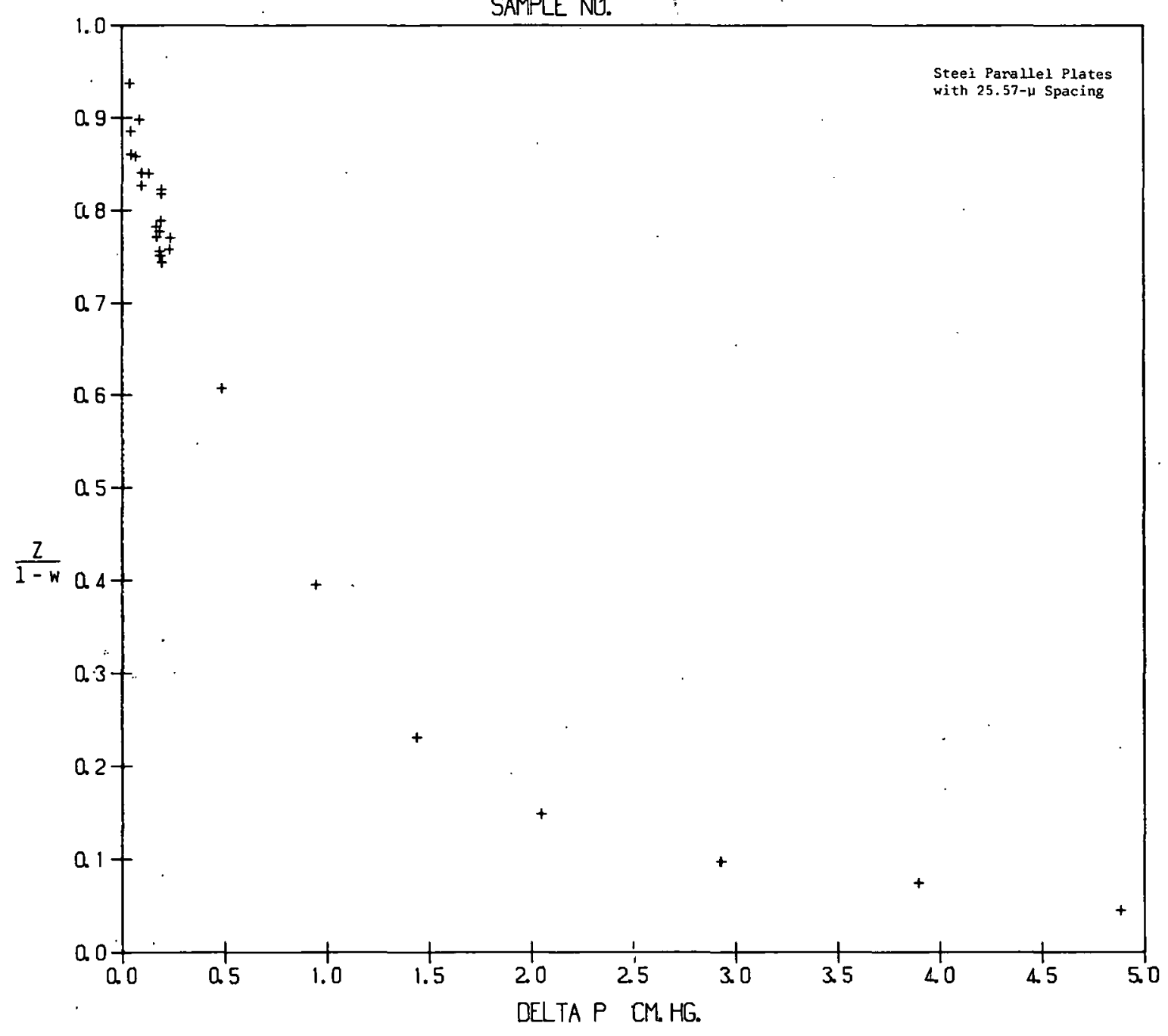

Figure 28

EXPERIMENTAL SEPARATION DAIA FOR SAMPLE I 


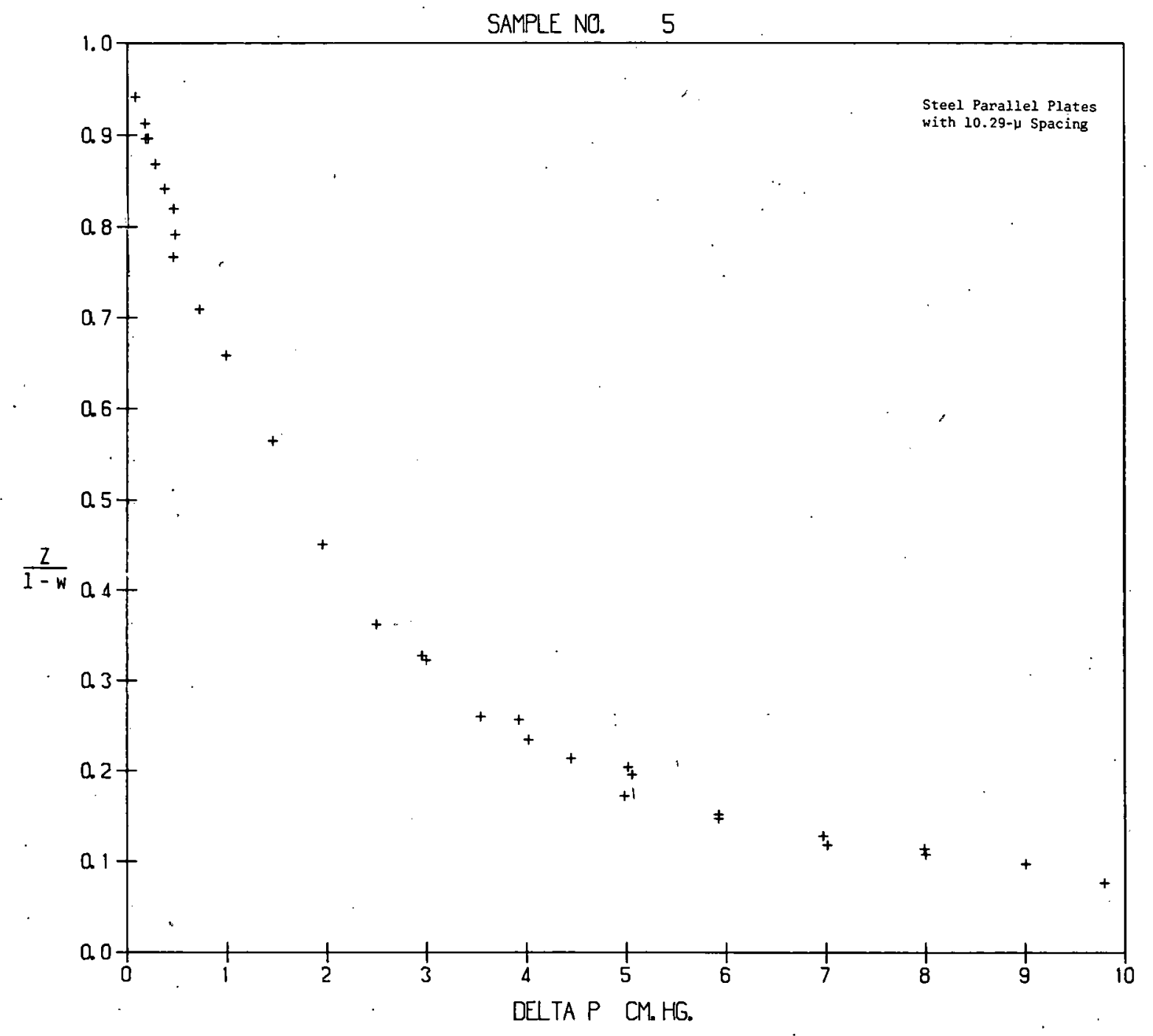

EXPERIMENTAL SEPARATION DATA FOR SAMPLE 5 
Table 3

CONSTANT FOR THE MODIFIED PRESENT AND deBETHUNE MODEL

\begin{tabular}{|c|c|c|c|c|c|}
\hline Sample & $\mathrm{K}$ & $w_{\mathrm{m}} / w_{\mathrm{K}}$ & B & $\mathrm{K}^{\prime}$ & $s^{*}$ \\
\hline 212 & $\begin{array}{l}1.05 \\
0.85 \\
0.85 \\
0.85 \\
0.75 \\
0.75\end{array}$ & $\begin{array}{l}1.00 \\
1.00 \\
0.75 \\
0.70 \\
0.75 \\
0.70\end{array}$ & $\begin{array}{l}3 \\
3 \\
3 \\
3 \\
3 \\
3\end{array}$ & $\begin{array}{l}1 \\
1 \\
1 \\
1 \\
1 \\
1\end{array}$ & $\begin{array}{l}0.0695 \\
0.0492 \\
0.0335 \\
0.0319 \\
0.0306 \\
0.0301\end{array}$ \\
\hline 838 & $\begin{array}{l}0.75 \\
0.75 \\
0.75 \\
0.70\end{array}$ & $\begin{array}{l}0.85 \\
0.75 \\
0.85 \\
0.85\end{array}$ & $\begin{array}{l}3 \\
1 \\
1 \\
1\end{array}$ & $\begin{array}{l}1 \\
1 \\
1 \\
1\end{array}$ & $\begin{array}{l}0.0315 \\
0.0309 \\
0.0292 \\
0.0291\end{array}$ \\
\hline 924. & $\begin{array}{l}0.75 \\
0.75 \\
0.70 \\
0.70 \\
0.70\end{array}$ & $\begin{array}{l}0.85 \\
0.75 \\
0.75 \\
0.85 \\
0.85\end{array}$ & $\begin{array}{l}3 \\
1 \\
1 \\
1 \\
3\end{array}$ & $\begin{array}{l}1 \\
1 \\
1 \\
1 \\
1\end{array}$ & $\begin{array}{l}0.0367 \\
0.0366 \\
0.0360 \\
0.0362 \\
0.0358\end{array}$ \\
\hline 1054 & $\begin{array}{l}0.85 \\
0.85 \\
0.75 \\
0.75\end{array}$ & $\begin{array}{l}0.75 \\
0.70 \\
0.75 \\
0.70\end{array}$ & $\begin{array}{l}3 \\
3 \\
3 \\
3\end{array}$ & $\begin{array}{l}1 \\
1 \\
1 \\
1\end{array}$ & $\begin{array}{l}0.0306 \\
0.0280 \\
0.0268 \\
0.0256\end{array}$ \\
\hline 64 & $\begin{array}{l}0.75 \\
0.85 \\
0.85 \\
0.85 \\
1.05\end{array}$ & $\begin{array}{l}0.70 \\
0.70 \\
0.70 \\
0.75 \\
0.70\end{array}$ & $\begin{array}{l}1 \\
3 \\
1 \\
1 \\
3\end{array}$ & $\begin{array}{l}1 \\
1 \\
1 \\
1 \\
1\end{array}$ & $\begin{array}{l}0.0235 \\
0.0228 \\
0.0213 \\
0.0221 \\
0.0225\end{array}$ \\
\hline 2 & $\begin{array}{l}0.67 \\
0.50 \\
0.40 \\
0.40 \\
0.50\end{array}$ & $\begin{array}{l}1.00 \\
1.00 \\
1.00 \\
0.70 \\
0.70\end{array}$ & $\begin{array}{l}1 \\
1 \\
1 \\
1 \\
1\end{array}$ & $\begin{array}{l}0.78 \\
0.78 \\
0.78 \\
0.78 \\
0.78\end{array}$ & $\begin{array}{l}0.0335 \\
0.0182 \\
0.0158 \\
0.0161 \\
0.0156\end{array}$ \\
\hline 1 & $\begin{array}{l}1.178 \\
1.178 \\
1.178 \\
1.178\end{array}$ & $\begin{array}{l}0.50 \\
0.60 \\
0.70 \\
0.70\end{array}$ & $\begin{array}{l}1.5 \\
1.5 \\
1.5 \\
2.0\end{array}$ & $\begin{array}{l}0.67 \\
0.67 \\
0.67 \\
0.67\end{array}$ & $\begin{array}{l}0.0377 \\
0.0344 \\
0.0328 \\
0.0338\end{array}$ \\
\hline 5 & $\begin{array}{l}0.88 \\
0.88 \\
1.178 \\
1.178 \\
1.178 \\
1.178\end{array}$ & $\begin{array}{l}0.50 \\
0.70 \\
0.70 \\
0.60 \\
0.50 \\
0.50\end{array}$ & $\begin{array}{l}1.5 \\
1.5 \\
1.5 \\
1.5 \\
1.5 \\
2.0\end{array}$ & $\begin{array}{l}0.67 \\
0.67 \\
0.67 \\
0.67 \\
0.67 \\
0.67\end{array}$ & $\begin{array}{l}0.0284 \\
0.0215 \\
0.0249 \\
0.0180 \\
0.0176 \\
0.0192\end{array}$ \\
\hline
\end{tabular}




$$
\mathrm{Y}=\frac{\mathrm{r} \Delta \mathrm{P}}{\mathrm{\eta} \overline{\mathrm{v}}}
$$

Most of the data were obtained with very low backpressure; for cases when $\mathrm{P}_{\mathrm{b}} \rightarrow 0$,

$$
Y=\frac{r P_{f}}{\eta \bar{v}}=\frac{\pi r}{2 \bar{\lambda}}
$$

where $\eta=\frac{1}{2} \bar{\rho} \bar{v} \lambda$ defines the mean free path $\lambda$ at the average pressure. This parameter $Y$ emphasizes the relationship between the gas mean free path and the dimensions of the flow channel and provides a good scale to indicate the separation efficiency in relation to the ratio of the radius to mean free path. However, it must be emphasized that the important parameter is pressure difference and not pressure level. This correspondence follows only when the backpressure is small compared to the forepressure.

Figure 30 shows the data obtained with five different samples plotted as a function of $Y$. An initial examination of these data appears to indicate that there is no fundamental difference in the pressure dependence of the separation efficiency in these different geometries in contrast to the large differences in the pressure dependence of the transmission ratio in these same geometries. However, on closer examination it can be noted that the data band is relatively wider at the left- and right-hand sides of figure 30 than it is in the midrange. The parallel plate data are at the lower side of the data band on the left-hand side and at the higher side of the data band on the right-hand side of the figure. There are also pattern deviations in the data for the other samples which reveal significant information about the individual test samples. These pattern deviations are most easily obsorvod in terms of the parameters required to fit the separation data with the PBFM as shown in table 3 . The implications of the parameters will be discussed later.

Sample number 1054 is the sample with the smallest capillary radius, and for that reason more data were obtained with this sample than with any of the others. Figure 31 is a plot of these experimental data compared with four mathematical model calculations. These calculated curves were obtained using the measured values of the parameters required in the models and the parameters which gave the best fit for those which were not measured. It is quite clear that GCM using the average pressure weighting does not fit the data well. The GCM using local pressure weighting fits the data significantly better but still does not fit the data over the entire curve. The PBM calculations are too low over the entire range of the data, but the PBFM calculations fit the data well over the entire range of the measured separation efficiençies.

As is shown by equations (13) and (14), analytical expressions in terms of the capillary radius can be obtained for the initial slope of the separation efficiency vs. the pressure difference curve from the PBM. Because of the poorer reliability of the lower pressure data, the initial 
DWG. NO. G-72-1162

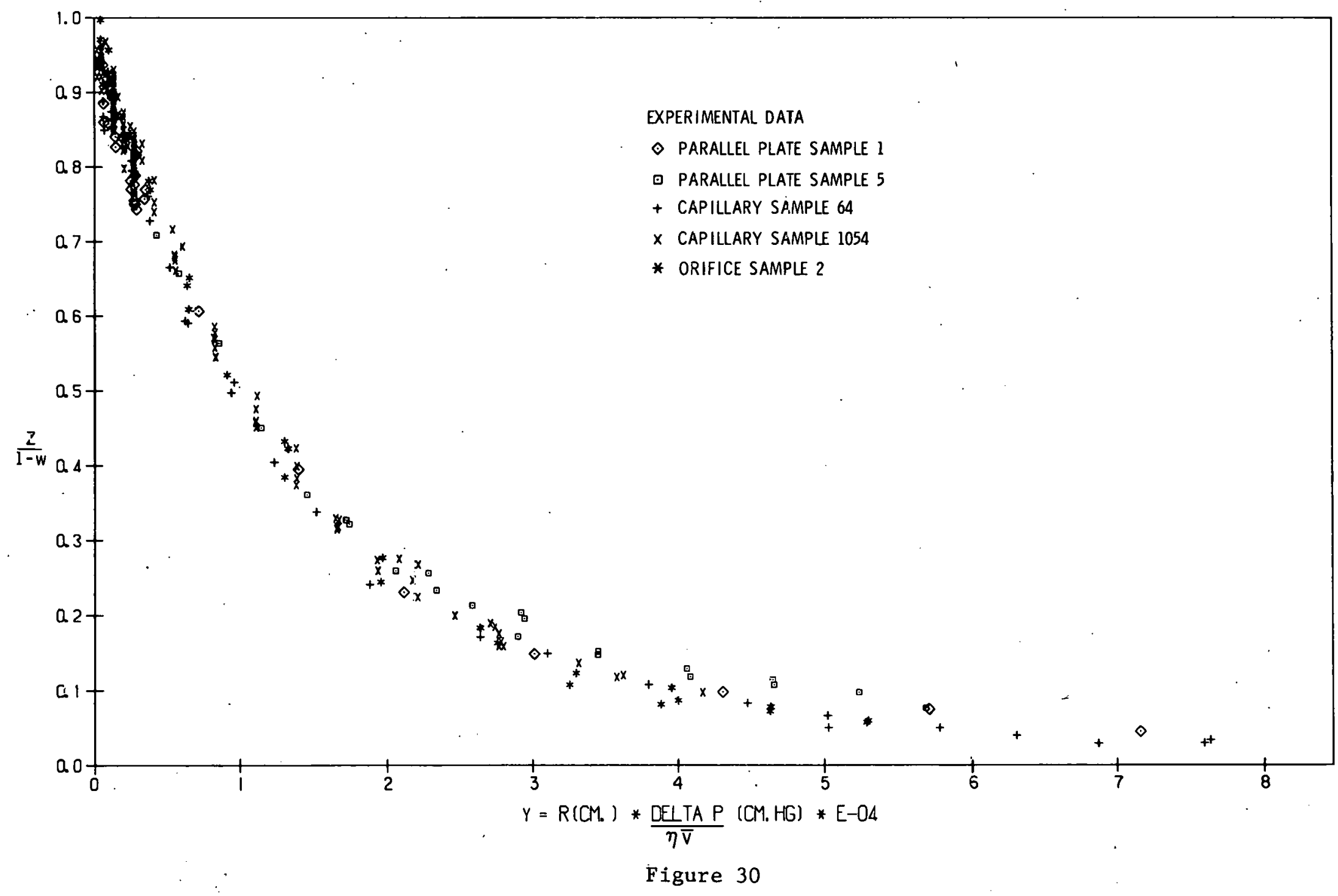

EFFECTIVE PRESSURE PARAMETER. FOR SEPARATION 


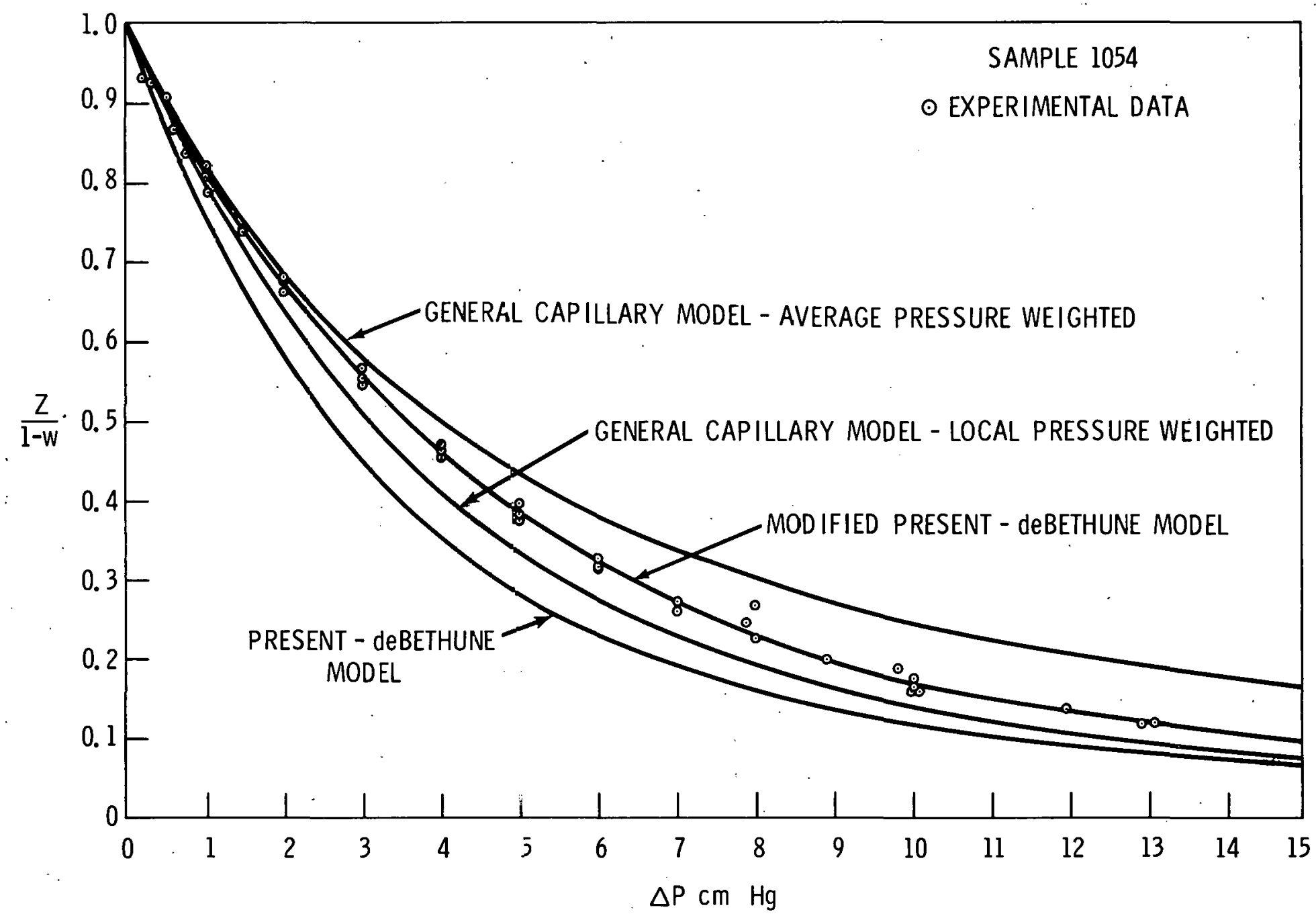

SEPARATION EFFICIENCY OF 4. 907-MICRONRADIIS GLASS CAPILLARY SAMPLE 
slope for sample 1054, as well as that for all the other samples, was estimated by calculating the slope required to give the average experimental point at a separation efficiency of 0.85 . This calculation was made by using the first three terms in the expansion of the analytical expressions (13) or (14). This approximation is in good agreement with the values obtained from the full calculation either with or without viscous flow. The capillary radii determined in this way for all of the samples are shown in table 4 compared with the radii determined from the measurement of Poiseuille flow through the samples. The ratios of these radii are used to estimate the deviations in the wall scattering law required by each of the models to produce the measured initial slope. These are shown in table 5, which also shows the scattering law deviations inferred from the flow measurements.

Table 4

MEASURES OF CAPILLARY RADIUS

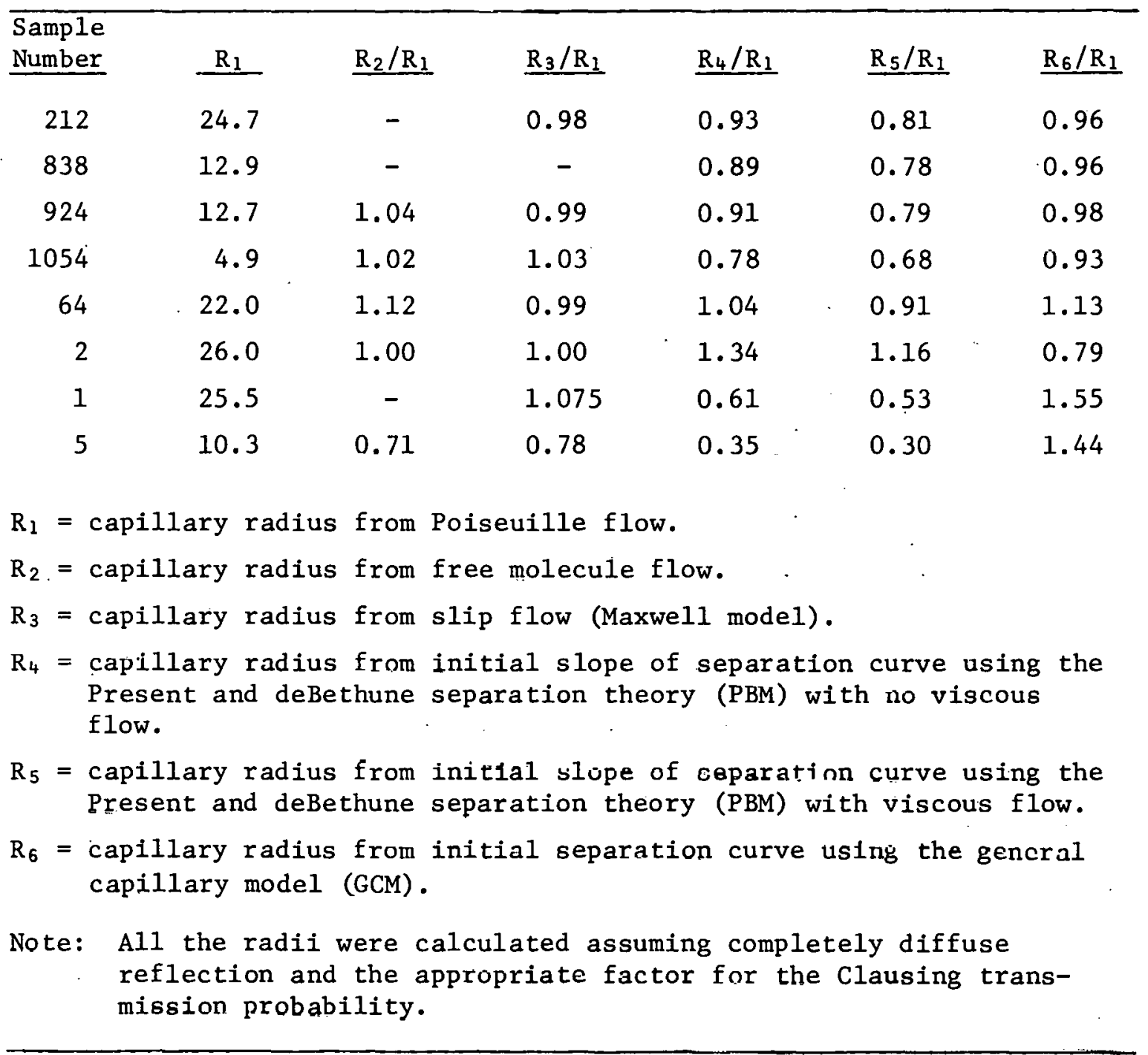


Table 5

DEVIATIONS FROM DIFFUSE WALL SCATTERING

IMPLIED BY MEASUREMENTS

\begin{tabular}{|c|c|c|c|c|c|c|c|c|c|c|}
\hline \multirow{3}{*}{$\begin{array}{l}\text { Sample } \\
\text { Number }\end{array}$} & & & \multicolumn{4}{|c|}{$\begin{array}{l}\text { Present and deBethune } \\
\text { Model }\end{array}$} & \multirow{2}{*}{\multicolumn{2}{|c|}{$\begin{array}{c}\text { General } \\
\text { Capillary } \\
\text { Model } \\
\end{array}$}} & \multirow{2}{*}{\multicolumn{2}{|c|}{$\begin{array}{c}\text { Modified } \\
\text { Present and } \\
\text { deBethune }\end{array}$}} \\
\hline & \multicolumn{2}{|c|}{ Measurements } & \multicolumn{2}{|c|}{$\begin{array}{l}\text { No Viscous } \\
\text { Flow }\end{array}$} & \multicolumn{2}{|c|}{$\begin{array}{l}\text { Viscous } \\
\text { Flow }\end{array}$} & & & & \\
\hline & $\alpha$ & $\underline{f}$ & $\alpha$ & $\mathrm{f}$ & $\alpha$ & $\underline{f}$ & $\alpha$ & $\mathrm{f}$ & $\alpha$ & $\mathrm{f}$ \\
\hline 212 & - & - & 0.962 & - & 0.895 & - & 0.89 & - & 0.86 & - \\
\hline 838 & - & - & 0.942 & - & 0.873 & - & 0.67 & - & 0.82 & - \\
\hline 924 & - & 0.94 & 0.951 & - & 0.881 & - & 0.63 & - & 0.82 & - \\
\hline 1054 & - & 0.97 & 0.876 & - & 0.809 & - & 0.80 & - & 0.86 & - \\
\hline 64 & - & 0.83 & - & 0.980 & 0.952 & - & 0.50 & - & 0.92 & - \\
\hline 2 & - & 1.00 & - & 0.854 & - & 0.936 & 1 & - & 0.91 & - \\
\hline 1 & - & - & 0.759 & - & - & 0.695 & - & - & - & 0.86 \\
\hline 5 & 0.83 & - & 0.519 & - & - & 0.467 & - & - & - & 1 \\
\hline
\end{tabular}

$\alpha=$ fraction of diffuse reflection when backscattering is present.

$f=$ fraction of diffuse reflection when specular reflection is present.

Sample 1054 is also of partirular intcrcst lecuuse there were some changes in the physical characteristics of the sample during the period when it was being tested. Flow measurements were made on the sample (1) before the initial separation measurements, (2) after the first set of separation measurements, and (3) after the second set of separation measurements. The flow measurements indicated that between the first and second set of measurements there was a change in either the number of capillaries, the capillary radius, the surface scattering law, or some combination of these. After the second set of separation measurements, the sample was cleaned with a solution of a commercial cleaning agent called Decontam. Flow measurements after the cleaning indicated flow character essentially the same as that of the original flow measurements. Although it is less certain, there also could have been a decrease of as much as $20 \%$ in the initial slope between the first and second sets of separation measurements. This is less certain because the sample characteristics were probably changing during the separation tests which occurred over a period of over six months. The measured parameters at the different times are shown in table 6 .

Analysis of all the parameters involved indicates that the most probable explanation is that an oil film with a thickness of between 1000 and $2000 \mathrm{~A}$ was adsorbed on the walls of the capillaries, which in turn affected the surface scattering law. A silane wetting agent was used on the outside of 
Table 6

VARIATION IN FLOW PARAMETERS

FOR SMALLEST GLASS CAPILLARIES

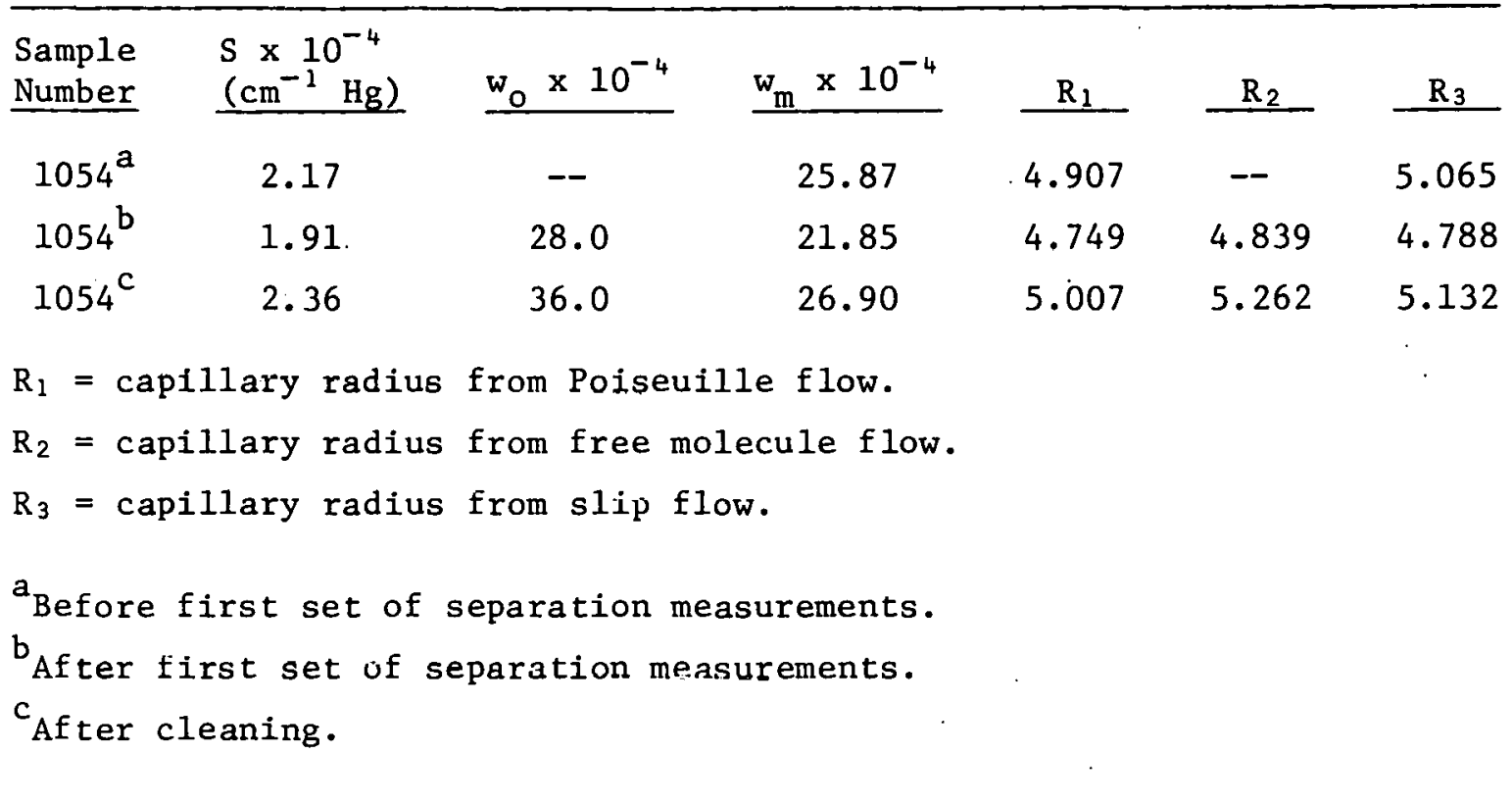

the capillaries to assure good adhesion between the glass and the epoxy bonding agent. This silane could have migrated to the inside of the capillaries. Because of the small change in the capillary radius as indicated by Poiseuille flow in comparison with the larger changes in the slip and free molecule transport ratios, the data are more consistent with a decrease in specular reflection due to the oil adsorption rather than the alternative explanation which would require that the adsorbed oil film produce an increase in backscattering. The data appear to indicate no change in the number of caplllaries which would have required that the capillary radius calculated from the free molecule and slip transport ratios increase more than that calculated from Poiseuille flow. It would also require no change in the initial slope of the separation curve. This conclusion is also supported by the fact that the sample was easily cleaned. It is doubtful that such small capillaries could be cleaned if they were completely plugged.

Figure 32 shows a comparison of the data obtained on sample 1054 with a curve calculated from PBM with the capillary radius arbitrarily adjusted to give the best fit of the data. The best fit of adjusted parameters for the GCM is also shown. With arbitrarily adjusted parameters the data are fairly well represented over the full range of the data. This shows that the PBM and the GCM can be made to be virtually identical with appropriate selection of parameters. 


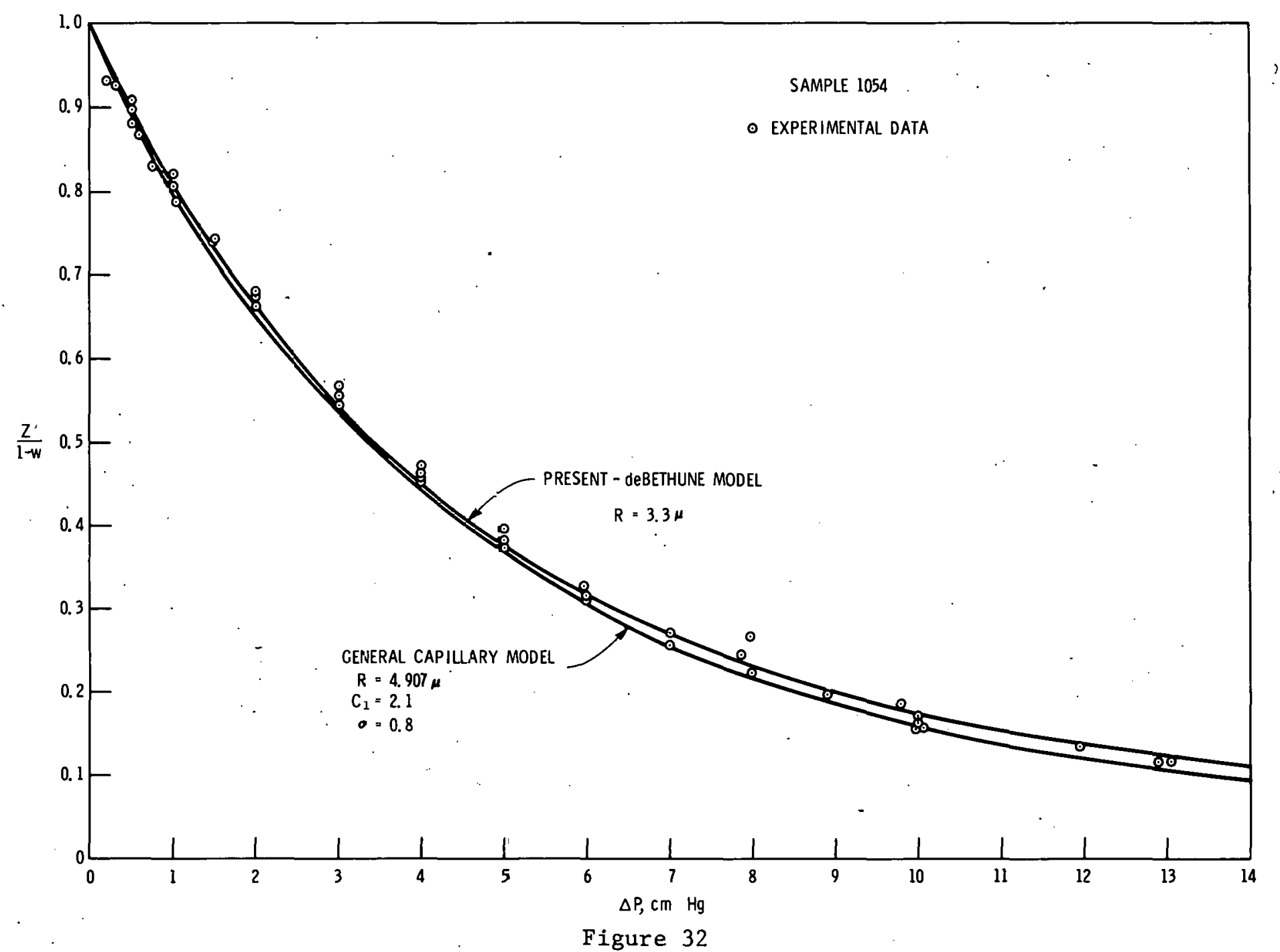

BEST AGREEMENT BETWEEN EXPERIMENTAL DATA AND THEORETICAL CURVES USING ADJUSTED PARAMETERS 
As shown in table 5, the capillary radius from $P B M$ and the $C$ value from GCM both indicate backscattering. However, both the $C$ and $\sigma$ required to $f i t$ the separation data are quite different from the range of values measured by Lund and Berman and, in fact, are quite different from the approximated $\mathrm{C}$ and $\sigma$ obtained from flow measurements on these samples. The values from the flow and separation measurements are approximate because least squares curves have not been obtained. Table 7 compares the $C$ and $\sigma$ values obtained from flow measurements with several combinations of $C$ and $\sigma$ used to fit the separation data for all the test samples. This shows the sensitivity of the fits of the data to variations in the constants $C$ and $\sigma$ by the variation in the calculated standard deviations.

Variations in the surface scattering law should have different effects in the two separation theories. If the appropriate correction is made in the PBM to account for the effect of scattering law deviations on free molecule flow, then this theory predicts that the effect will be to change the slope of the separation curve by the same fraction as the change in the free molecule transport ratio. However, in the GCM the effect is different from that obtained in the PBM. If the Maxwell calculation of the variation of $C$ and $\sigma$ with specular reflection or backscattering as given on pages 34 and 35 is assumed, then very little effect on the initlal slope of the separation curve is produced by scattering law deviations. If the relation between $C$ and $\sigma$ observed by Lund and Berman, which is different from the variation predicted by Maxwell, is assumed, then the effect is to make a fractional change in the initial slope of the separation curve by about one-third of the fractional change in the free molecule transport ratio. All of the theories indicate that the initial slope of the separation curve should be proportional to the hydraulic radius. Therefore, the ratio of the initial slopes of the separation curves to the hydraulic radius for similar geometry test samples should have the same value. Experimentally, variations of the initial slopes of the separation curves due to variations in the wall scattering law can be observed by variations in the slope-to-radius ratio. Table 8 shows at least $20 \%$ variation in the measured ratios of slope-to-radius ratios. This is about the variation observed in the flow data, which is also presumably due to scattering law variations. This slope variation appears to be larger than can be accounted for by the measured range of $C$ and $\sigma$ variations using the GCM, but is within the range of accountability for the modified PBM.

Qualitatively, this difficulty can be seen in the following way. In the PBM form, the effect of specular reflection or backscattering is in direct proportion to the increase or decrease in gas velocity. The momentum exchange between unlike molecules is proportional to the difference in average velocity. An increase in average velocity increases the momentum exchange between unlike molecules and therefore increases the slope of the separation curve. In the GCM, an increase in the free molecule diffusion rate caused by specular reflection tends to decrease the initial slope of the separation curve since this increases the amount of separative flow. An increase in the slip transport ratio from the same cause will tend to increase the initial slope of the separation curve since this increases 
Table 7

COMPARISON OF GCM PARAMETERS OBTAINED FROM FLOW MEASUREMENTS WITH THOSE NEEDED TO FIT THE SEPARATION DATA

\begin{tabular}{|c|c|c|c|c|c|}
\hline \multirow{2}{*}{$\begin{array}{l}\text { Sample } \\
\text { Number }\end{array}$} & \multicolumn{2}{|c|}{ Flow Measurements } & \multicolumn{3}{|c|}{ Separation Measurements } \\
\hline & c & $\sigma$ & c & $\boldsymbol{\sigma}$ & s. \\
\hline 212 & - & 1.77 & $\begin{array}{l}1.00 \\
1.50 \\
1.25^{\mathrm{a}}\end{array}$ & $\begin{array}{l}1.85 \\
1.00 \\
1.25\end{array}$ & $\begin{array}{l}0.0353 \\
0.0342 \\
0.0314\end{array}$ \\
\hline 838 & - & - & $\begin{array}{l}1.00 \\
1.50 \\
1.25 \\
2.00^{a} \\
2.00 \\
2.20\end{array}$ & $\begin{array}{l}1.85 \\
1.00 \\
1.25 \\
1.00 \\
0.75 \\
0.80\end{array}$ & $\begin{array}{l}0.0353 \\
0.0438 \\
0.0406 \\
0.0275 \\
0.0397 \\
0.0295\end{array}$ \\
\hline 924 & 0.878 & 1.80 & $\begin{array}{l}1.00 \\
1.50 \\
2.00 \\
1.75 \\
2.20^{a}\end{array}$ & $\begin{array}{l}1.85 \\
1.00 \\
1.00 \\
1.00 \\
0.80\end{array}$ & $\begin{array}{l}0.0404 \\
0.0390 \\
0.0356 \\
0.0345 \\
0.0336\end{array}$ \\
\hline 1054 & 0.945 & 1.90 & $\begin{array}{l}1.00 \\
1.50^{a} \\
1.33 \\
1.25\end{array}$ & $\begin{array}{l}1.85 \\
1.00 \\
0.925 \\
1.25\end{array}$ & $\begin{array}{l}0.0333 \\
0.0231 \\
0.0325 \\
0.0275\end{array}$ \\
\hline 64 & 0.712 & 2.03 & $\begin{array}{l}1.0 n \\
1.50 \\
2.00 \\
2.00 \\
3.00 \\
3.00^{a}\end{array}$ & $\begin{array}{l}1.85 \\
1.00 \\
1.00 \\
1.25 \\
0.75 \\
0.50\end{array}$ & $\begin{array}{l}0.0238 \\
0.0331 \\
0.0203 \\
0.0328 \\
0.0341 \\
0.0194\end{array}$ \\
\hline 2 & 1.00 & 1.84 & $\begin{array}{l}1.00 \\
1.00^{a} \\
1.00 \\
0.75 \\
1.33\end{array}$ & $\begin{array}{l}1.84 \\
1.00 \\
0.75 \\
1.00 \\
1.00\end{array}$ & $\begin{array}{l}0.0567 \\
0.0215 \\
0.0226 \\
0.0260 \\
0.0367\end{array}$ \\
\hline 1 & - & 2.28 & - & - & - \\
\hline 5 & - & 0.86 & - & - & - \\
\hline
\end{tabular}

${ }^{a}$ Smallest Standard Deviation. 
Table 8

SEPARATION EFFICIENCY INITIAL SLOPE RATIOS COMPARED WITH RADIUS RATIOS

\begin{tabular}{|c|c|c|c|c|}
\hline \multirow{2}{*}{$\begin{array}{l}\text { Sample } \\
\text { Numbers }\end{array}$} & \multirow{2}{*}{$\begin{array}{c}\text { Initial } \\
\text { Slope } \\
\text { Ratio } \\
\end{array}$} & \multirow{2}{*}{$\begin{array}{c}\text { Hydraulic } \\
\text { Radius } \\
\text { Ratio } \\
\end{array}$} & \multicolumn{2}{|c|}{$\frac{\text { Slope Ratio }}{\text { Radius Ratio }}$} \\
\hline & & & Measured & Clausing \\
\hline $212 / 1054$ & 5.22 & 5.039 & 1.036 & 0.982 \\
\hline $838 / 1054$ & 2.75 & 2.633 & 1.033 & 0.997 \\
\hline $924 / 1054$ & 2.72 & 2.580 & 1.054 & 0.994 \\
\hline $64 / 1054$ & 5.43 & 4.488 & 1.210 & 0.994 \\
\hline $2 / 1054$ & 4.65 & 5.506 & 0.844 & 0.550 \\
\hline $1 / 1054$ & 6.52 & 5.200 & 1.254 & 2.202 \\
\hline $5 / 1054$ & 2.45 & 2.092 & 1.171 & 2.544 \\
\hline $1 / 5$ & 2.66 & 2.485 & 1.070 & 0.866 \\
\hline
\end{tabular}

the nonseparative flow. If the $C$ and $\sigma$ are both affected by the same fractional change, as is expected from the Maxwell theory, then the two effects almost cancel each other and result in no change in the initial slope. There will be a decrease in separation efficiency at the higher pressures, however, because of the increase in $\sigma$. Since Lund and Berman have observed that the magnitude of $\sigma$ changes more rapidly than $C$, this type of change because of specular reflection causes a net increase in the initial slope, but by a smaller magnitude than that predicted by the modified Present and deBethune theory.

Becallse of this effect, the PBFM and the GCM should more closely correspond to each other when pure diffuse reflection is observed. Qualitatively, the two theories appear to fit the data better for sample 1034 than for any of the other samples, even though the $\mathrm{C}$ value required by the GCM indicates relatively less backscattering than for the other samples, and the capillary radius required by $P B M$ indicates relatively more backscattering than for the other samples. In contrast, the C's and $\sigma^{\prime} s$ inferred from the flow data imply the least deviation from diffuse reflection for sample 1054, with increasing amounts of specular reflection for the other samples. Although there are some serious questions concerning the level of the flow data, they do indicate the relative value and relative ordering of all the test samples.

Figures 33 through 35 show the experimental data obtained on samples 838 , 924, and 64, compared with three of the mathematical models. In each case the calculations using the PBM are lower than the experimental data over the entire range of pressures when the measured capillary radius with the 
DWG. NO. G-72-1262

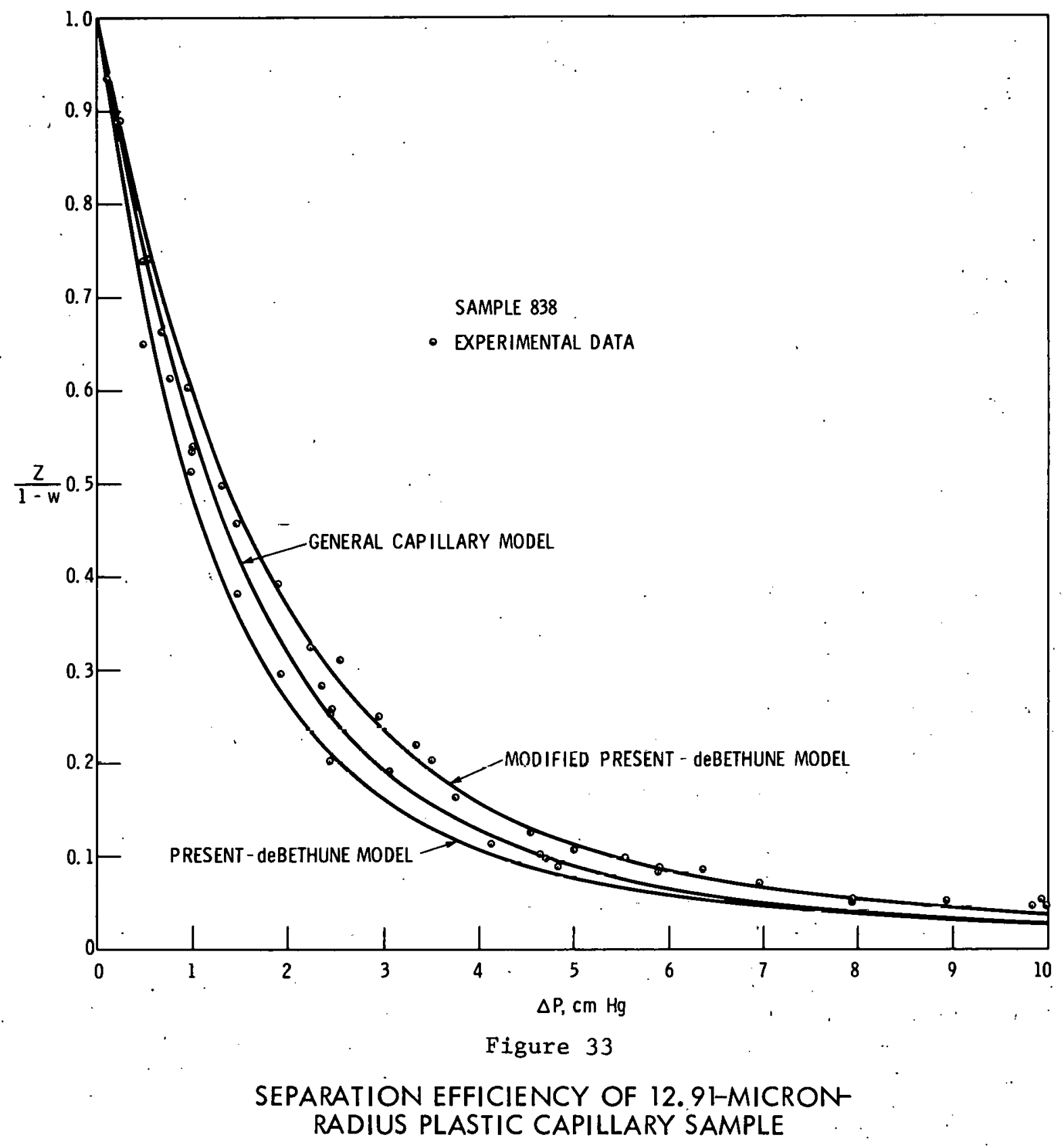


DWG. NO. G72-1265

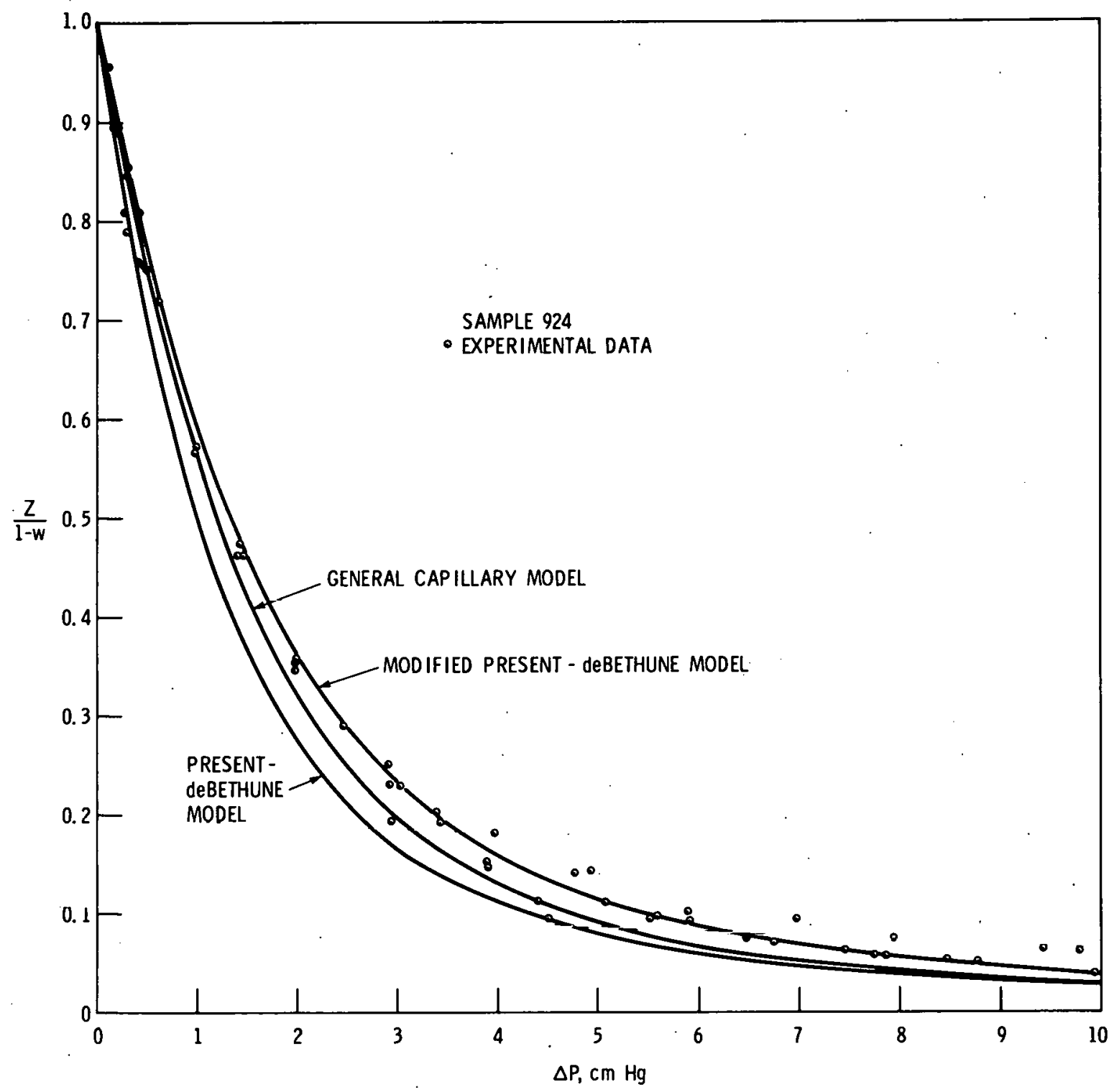

Figure 34

SEPARATION EFFICIENCY OF A 12.65-MICRONRADIUS PLASTIC CAPILLARY SAMPLE 
82

DUG. NO. G-72-1263

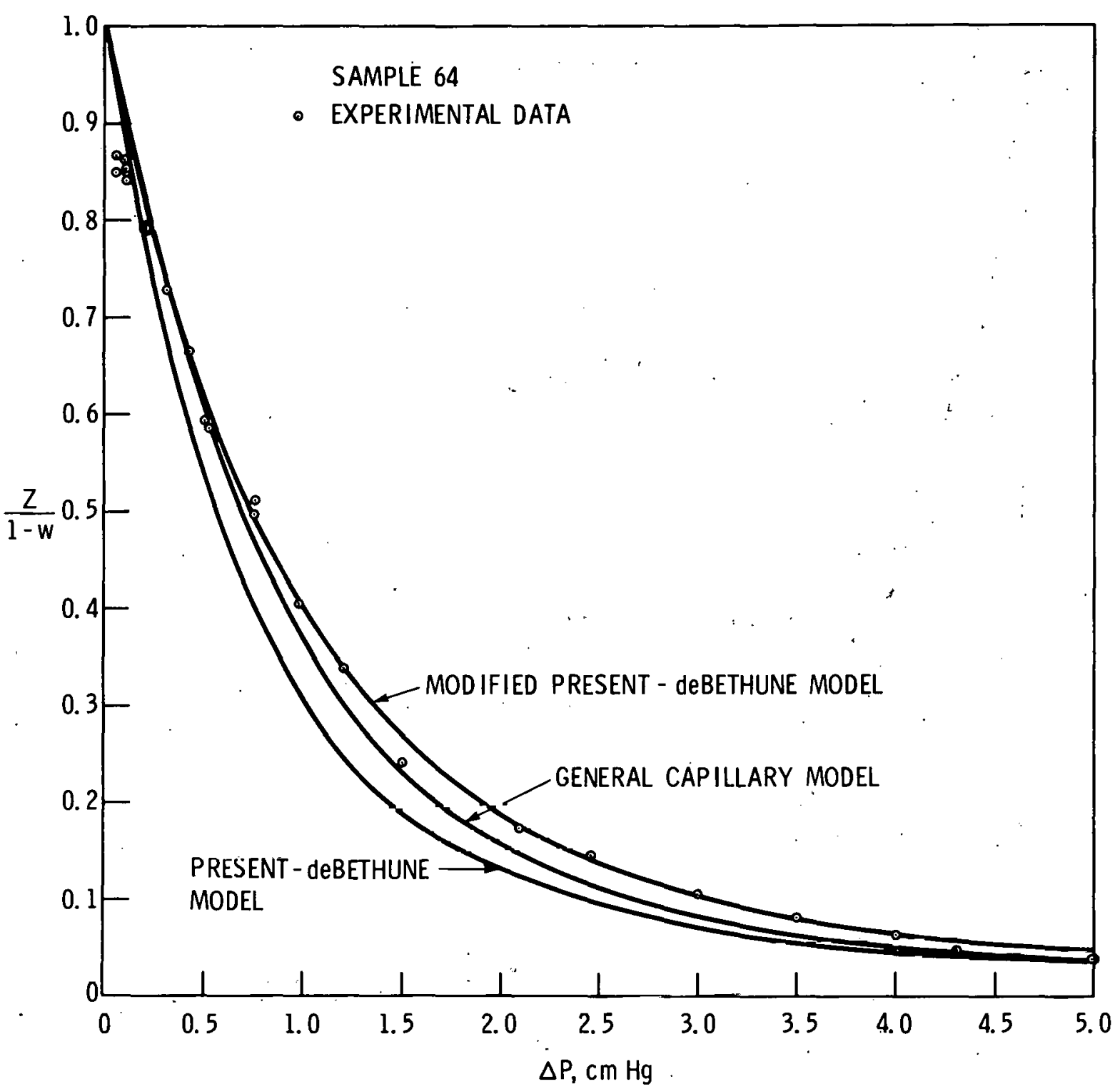

Figure 35

SEPARATION EFFICIENCY OF 22.01-MICRONRADIUS GLASS CAPILLARY SAMPLE 
appropriate Clausing factor is used. The GCM calculations are also lower than the experimental data in every case when the measured capillary radius is used with nominal values of $\mathrm{C}$ and $\sigma$. Again, the arbitrary modifications in the PBFM calculations produce a good fit of the experimental data in each case. Table 9 gives a comparison of the standard deviations on the fits for all the samples with the different calculations.

\section{Table 9}

COMPARISON OF THE STANDARD DEVIATION OF THE EXPERIMENTAL DATA OBTAINED WITH THE DIFFERENT MODELS

\begin{tabular}{|c|c|c|c|c|}
\hline $\begin{array}{l}\text { Sample } \\
\text { Number } \\
\end{array}$ & PBM & $\mathrm{GCM}^{\mathrm{a}}$ & $\mathrm{GCM}^{\mathrm{b}}$ & PBFM \\
\hline 212 & 0.0647 & 0.0353 & 0.0314 & 0.0301 \\
\hline 838 & 0.0500 & 0.0316 & 0.0275 & 0.0291 \\
\hline 924 & 0.0557 & 0.0404 & 0.0336 & 0.0358 \\
\hline 1054 & 0.0617 & 0.0333 & 0.0231 & 0.0256 \\
\hline 64 & 0.0421 & 0.0258 & 0.0203 & 0.0213 \\
\hline 2 & 0.0855 & 0.0567 & 0.0226 & 0.0158 \\
\hline 1 & 0.0486 & 0.0670 & -- & 0.0328 \\
\hline 5 & 0.0722 & 0.0355 & -- & 0.0176 \\
\hline \multicolumn{5}{|c|}{$\begin{array}{l}\text { a Standard values of the constants } c \text { and } \sigma \text {. } \\
\text { b The constants } c \text { and } \sigma \text { were varied to give approximately minimum } \\
\text { variance. }\end{array}$} \\
\hline
\end{tabular}

The deviations in scattering law inferred from each of the assumed models are given in table 5. The PBM implies that backscattering is present, but that the pattern of changes is consistent with the pattern of changes inferred from the flow measurements. The GCM using only the initial slope is also consistent with this ordering as indicated by $R_{6} / R_{1}$. However, the full GCM fits show a pattern of changc opposite to that inferred from the flow measurements. The best agreement is obtained with sample 1054 which shows the smallest deviations in the scattering law, and the poorest agreement is with sample 64 which shows the largest deviation in the scattering law. The pattern of change in the $C$ constant opposite to that indicated by the flow data implies that the GCM is not capable of accounting for deviations caused by specular reflections or backscattering. In addition, the values of the constant $\sigma$ required to fit the separation data are consistently lower than those required to fit the flow data. The PBFM fits. all of the data equally well and, therefore, apparently more accurately accounts for these anomalies. 
The best experimental indication of the scattering law deviations is given by the ratios of the measured initial slopes of the separation curves to the capillary radius as shown in table 8 . The deviations of the initial slope ratios from the capillary radius ratio could be simply due to inaccuracies in estimating the initial slopes, but these deviations are most likely due to the variations in the scattering law for molecules on the different surfaces, since they are consistent with the variations inferred from the flow measurements. It was shown that a fraction of molecules specularly reflected from a surface increases the effective radius of the capillary for free molecule flow and increases the initial slopes of the separation curve through the $K$ constant in the PBM and the PBFM. According to the data of Lund and Berman [3], free molecule flows are usually less than those predicted by the Clausing theory and must be explained by a mechanism similar to the backscattering suggested by Berman. Backscattering will decrease the initial slope of the separation curve since it corresponds to an effective decrease in the capillary radius. The ratios of slope ratios to radius ratios given in table 8 imply either more specular reflection for sample 64 or more backscattering for sample 1054. Since sample 64 was fire polished, the former is more likely. If specular reflection is present, then this implies that a scaling factor to reduce the capillary radius is needed in both theories. This could mean that the Clausing factor as used by Present and deBethune does not give the correct relative momentum transfer to the walls, and therefore the proportionality constant for momentum exchange between molecules is incorrect. Of course, it could also mean that the calculation of momentum exchange between molecules is incorrect. But if the latter is the correct interpretation, the same error in the proportionality constant should be in effect for all geometries. Table 8 shows the calculated ratio of the slope ratio to the radius ratio for the indicated test samples assuming that the initial slope is proportional to the clausing factor for each sample. There does not appear to be a consistent proportionality constant between the measured ratio of slnpe ratio to radius racio and that calculated from the clausing factors for the different geometries. This tends to imply that the problem is associated with the use of the clausing factor rather than an error in the calculation of momentum exchange between molecules.

The experimental separation data generally became rather unrellable for forepressure of $2 \mathrm{~mm}$ or lower. It is believed that this effect and the scatter in the data are a result of a cut effect problem and air contamination because of the required long sampling times. Detailed cut curves were obtained on samples 924 and 1054, and the curves shown in figures 36 and 37 illustrate this point. The cut is varied by adjusting the reject flow. Separation data were taken over a range of cuts to determine if there were any losses in separation efficiency due to a concentration gradient in front of the sample. These data were plotted and extrapolated to zero cut. At zero cut no concentration gradient should exist. When the measurements $c$ an be made at a low enough cut so that there is no discernable difference between the measured value and the extrapolated value, then cut curves are not needed for each test. Measurements at pressures above $5 \mathrm{~mm} \mathrm{Hg}$ showed that the cut effect could properly be accounted for by the correction given on page 13 for cuts existing below approximately $\theta=0.05$. Most measurements were made at cuts of 0.001 or less where a 
DWG. NO. G-72-893

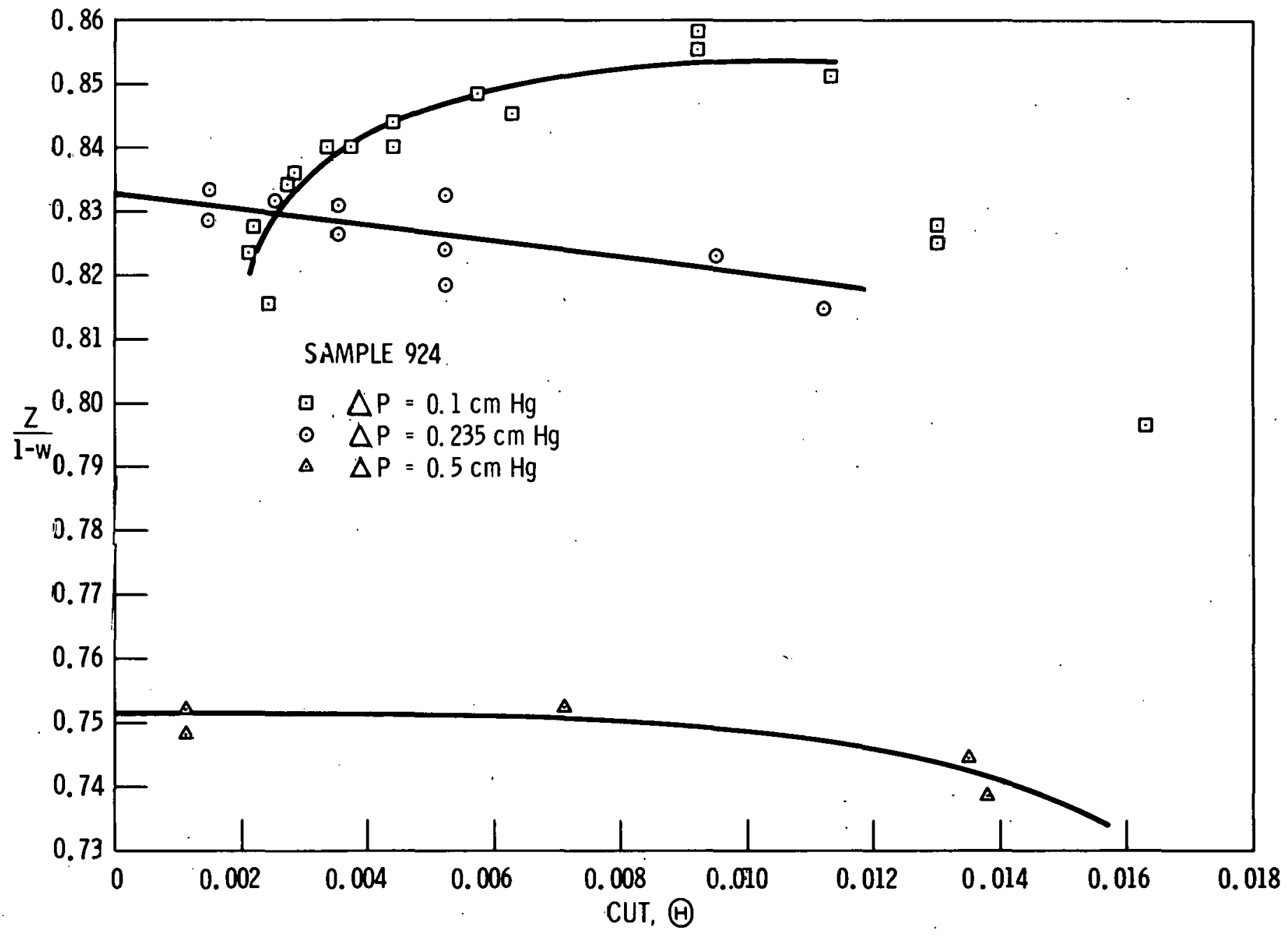

Figure 36

CUT CURIEES FOR A 12.65-MICRON-RADIUS PLASTIC CAPILLARY SAMPLE 


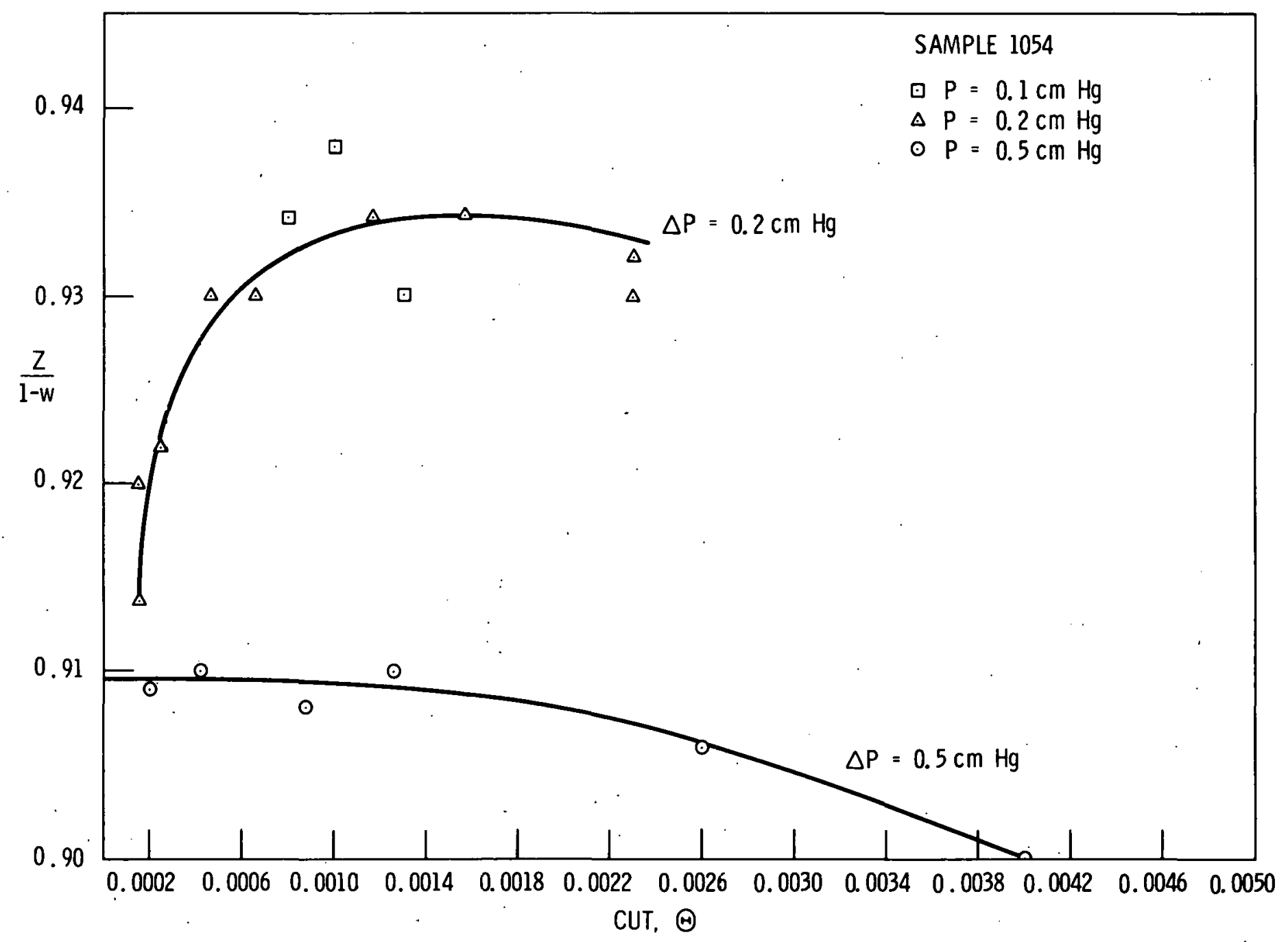

Figure 37

CUT CURVES FOR A' 4. 907-MICRON GLASS CAPILLARY SAMPLE 
correction was unnecessary. A very unusual cut effect was observed at pressures of $2 \mathrm{~mm} \mathrm{Hg}$ and lower. A decrease in separation efficiency. is observed as the cut is decreased. This occurs when the velocity of the feed gas is about 0.01 or greater times that of sound. It is possible that the high velocity of the feed gas produces a perturbation in the velocity distribution function which causes this effect. From experience, it is concluded that the highest measured separation efficiencies at these pressure' levels are the most representative of the sample, and that generally'all of these lower pressure data are biased low.

Figures 38 and 39 show the lowest pressure data obtained with samples 1054 and 924. As indicated above, the data at pressures of $2 \mathrm{~mm} \mathrm{Hg}$ or lower are less reliable and tend to be' low because of the cut effect. These two figures also show the three model calculations and more accurately indicate how they compare at these lower pressures.

Comparison of the experimental data obtained on a long glass capillary, an orifice, and a parallel plate is shown in figures 40 and 41 . The radius of the capillary samples and the helght of the parallel plate samples are not identical, but they are close enough to make a good comparison of the separation efficiency obtained on the different geometries. These two figures emphasize the small differences in experimental data which can result in significant differences in the parameters required by the PBFM to obtain a good fit of the data.

A large difference in the initial slope of the separation curve between the long capillary and the parallel plate having the same radius and plate spacing is predicted by $P B M$ when the appropriate Clausing factors are used. As is seen in figures 40 and 41 , this is not experimentally observed. The length-to-plate spacing ratio for the parallel plate and, to a lesser extent, the length-to-radius ratio for a capillary have an effect on the initial slope of the separation curves. Table 10 shows the calculated effect for the test samples used in this study. The data may not be accurate enough to make a definite conclusion, but the data are more consistent with the hypothesis that the length-to-spacing ratio for parallel plates does not affect the initial, slope of the separation curve to the extent predicted and that it should be proportional only to the plate spacing. As seen in table 9, the ratio of the initial slope of the separation curves for the two parallel plate samples tested is different from the ratio of the plate spacing, but not as predicted by the Clausing correction to the Present and deBethune theory. There is an indication from the flow data that there is more specular reflection with test sample 1 than with test sample 5, which would account for this deviation in the separation slope. Again, this is an important point because this also implies that the clausing factor is not the appropriate coefficient to indicate the correct momentum transfer to the wall. Howevcr, additional data are needed for confirmation.

Figure 42 shows the separation data for the short capillary test sample 2 compared with the calculated curves. In this case the PBM, using the appropriate C1.ausing factor with the capillary radius and the appropriate 


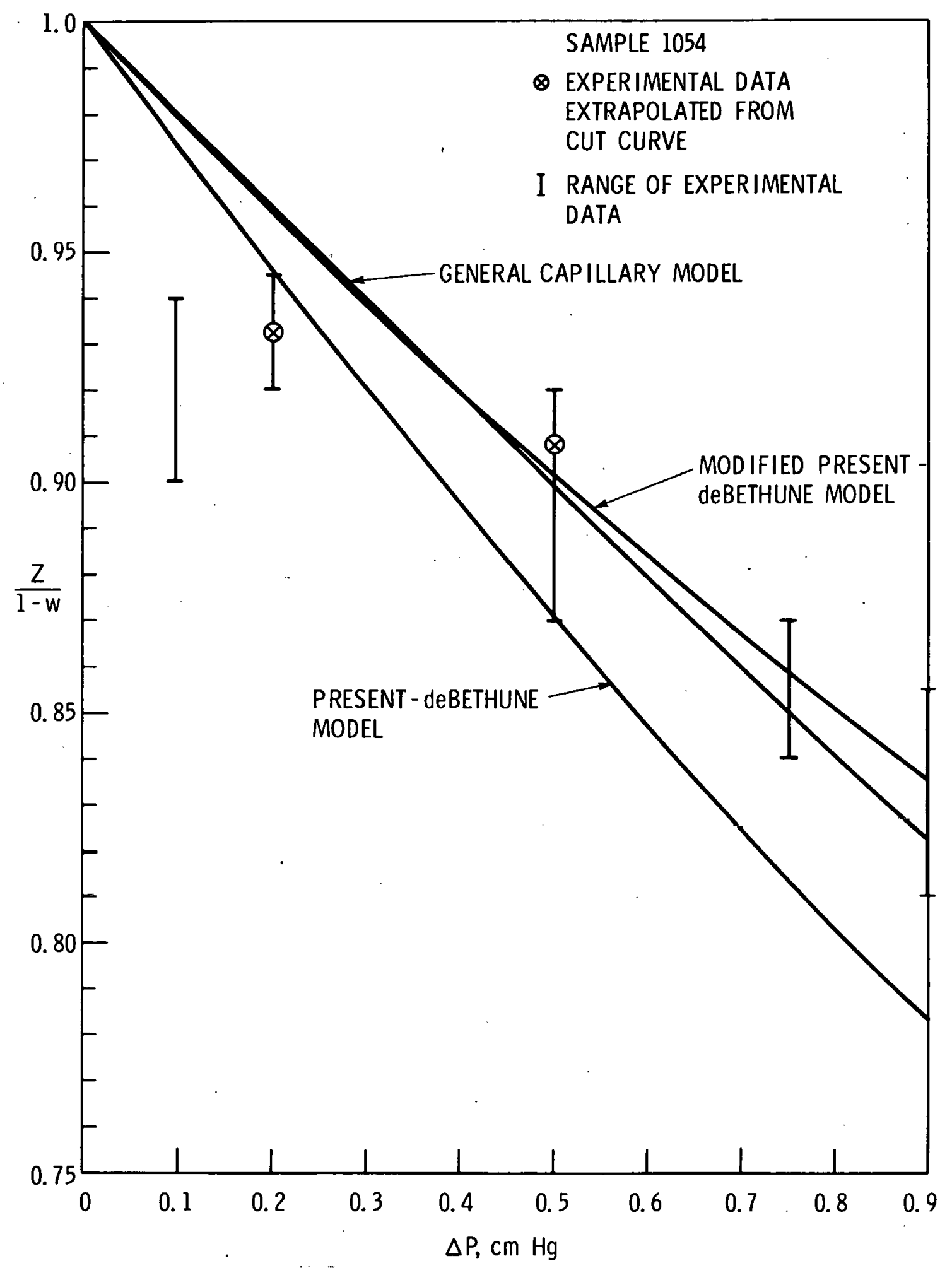

F1gure 38

LOW PRESSURE SEPARATION EFFICIENCY DATA FOR 4. 907-MICRON-RADIUS GLASS CAPILLARY SAMPLE 


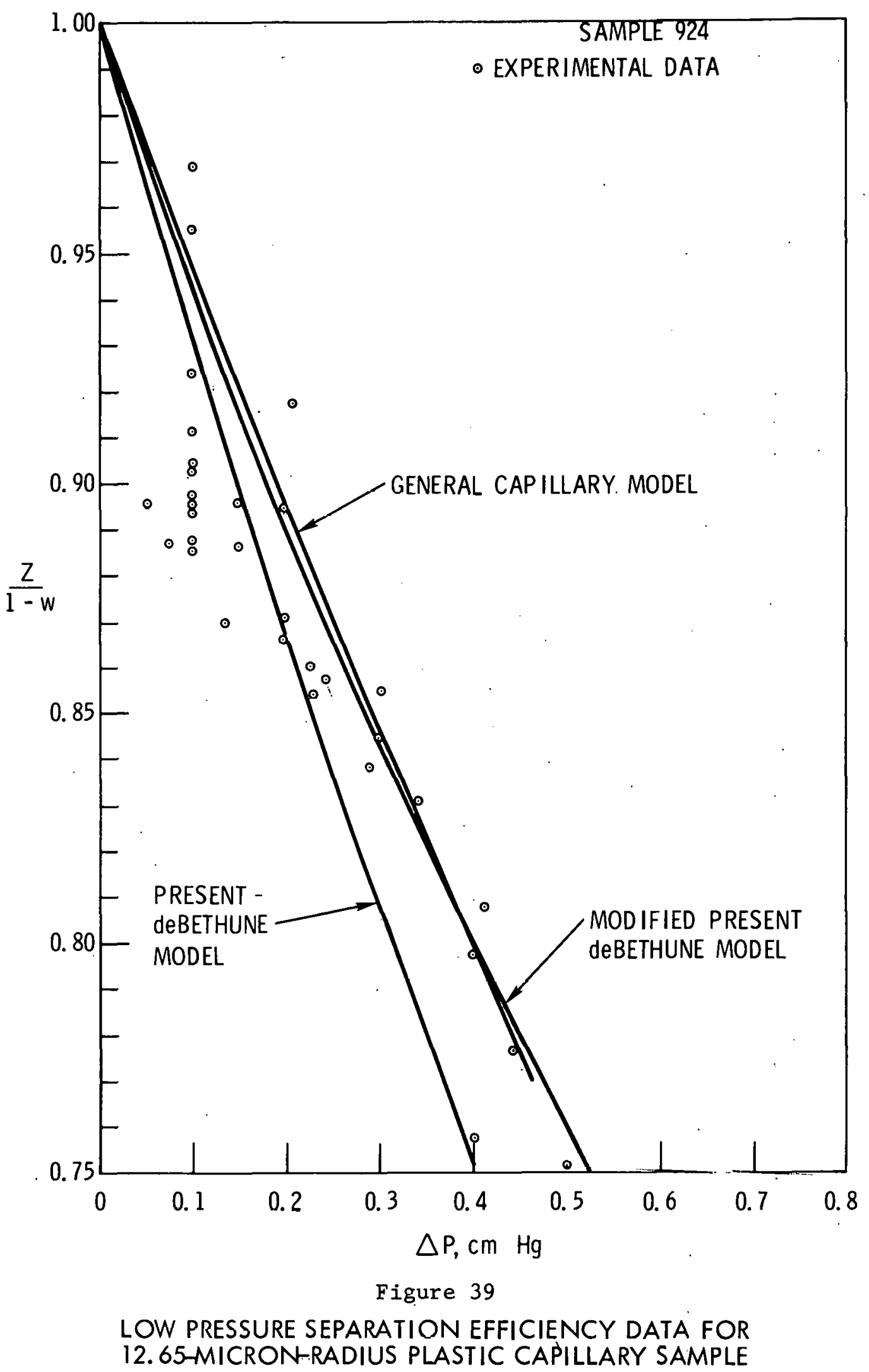




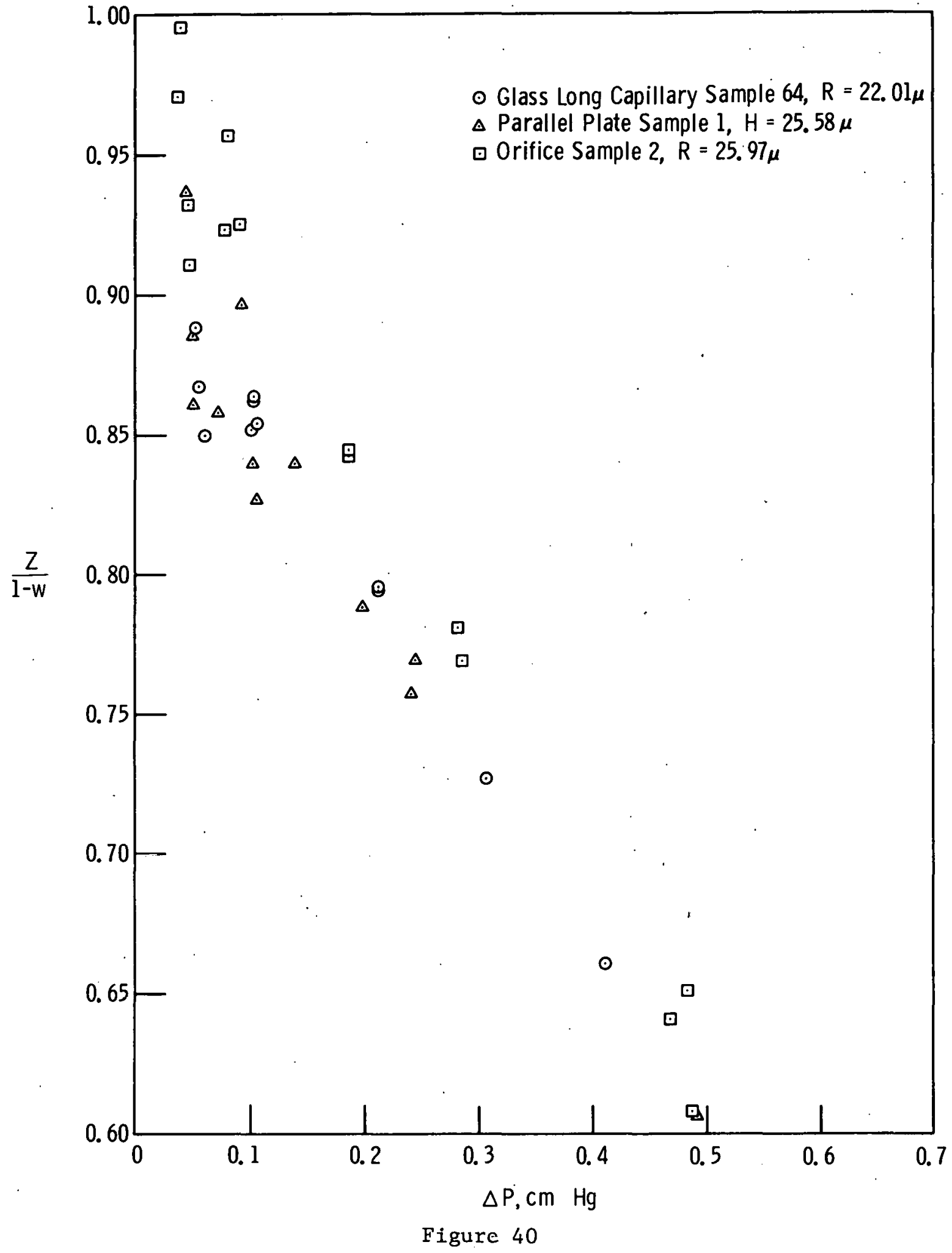
AND PARALLEL PLATE DATA IN LOW PRESSURE REGION 
DWG. NO. G-70-952

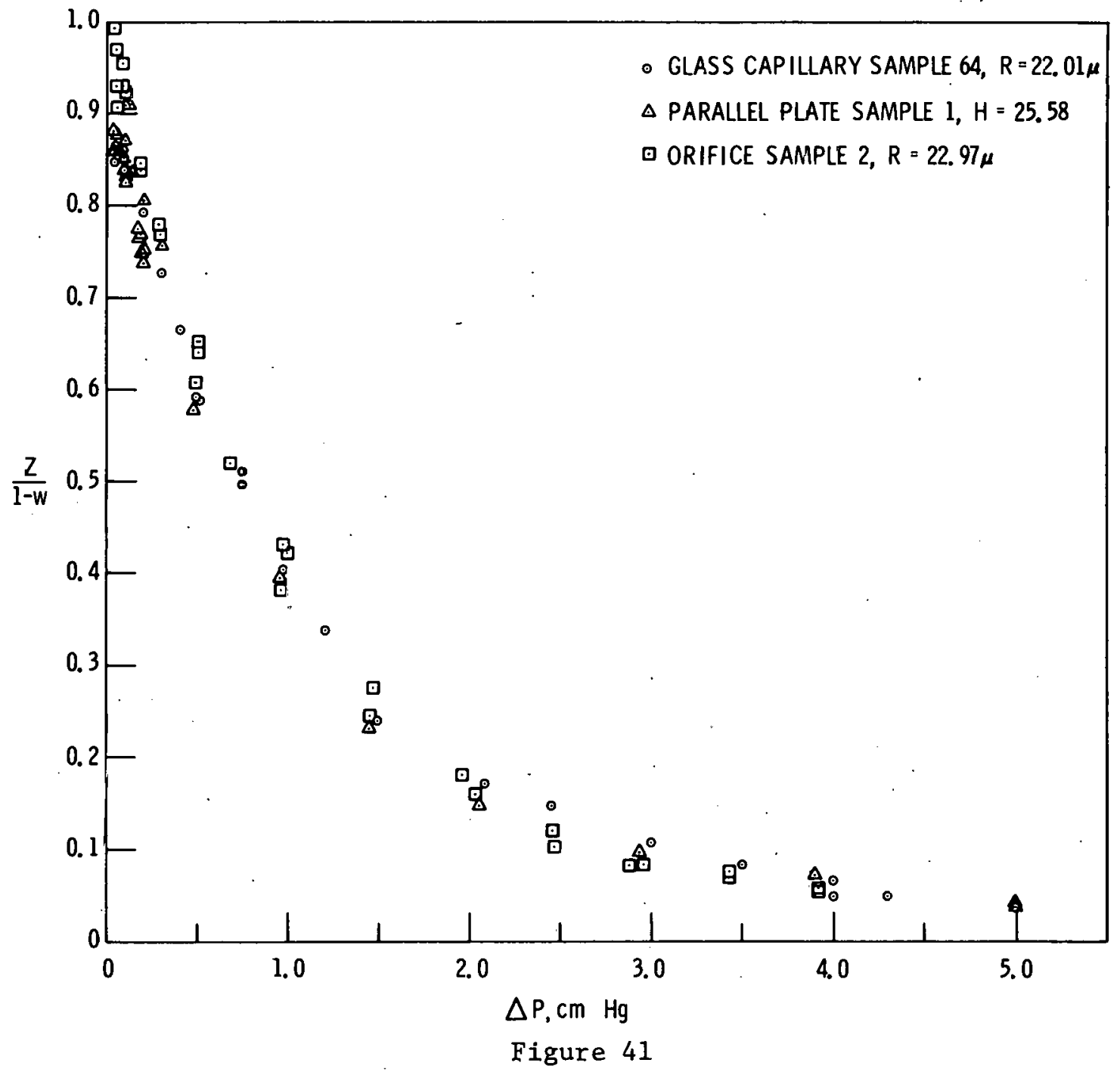

COMPARISON OF SEPARATION EFFICIENCY OF LONG CAPILLARY, ORIFICE, AND PARALLEL PLATE 
DWG. NO. G-72-1261

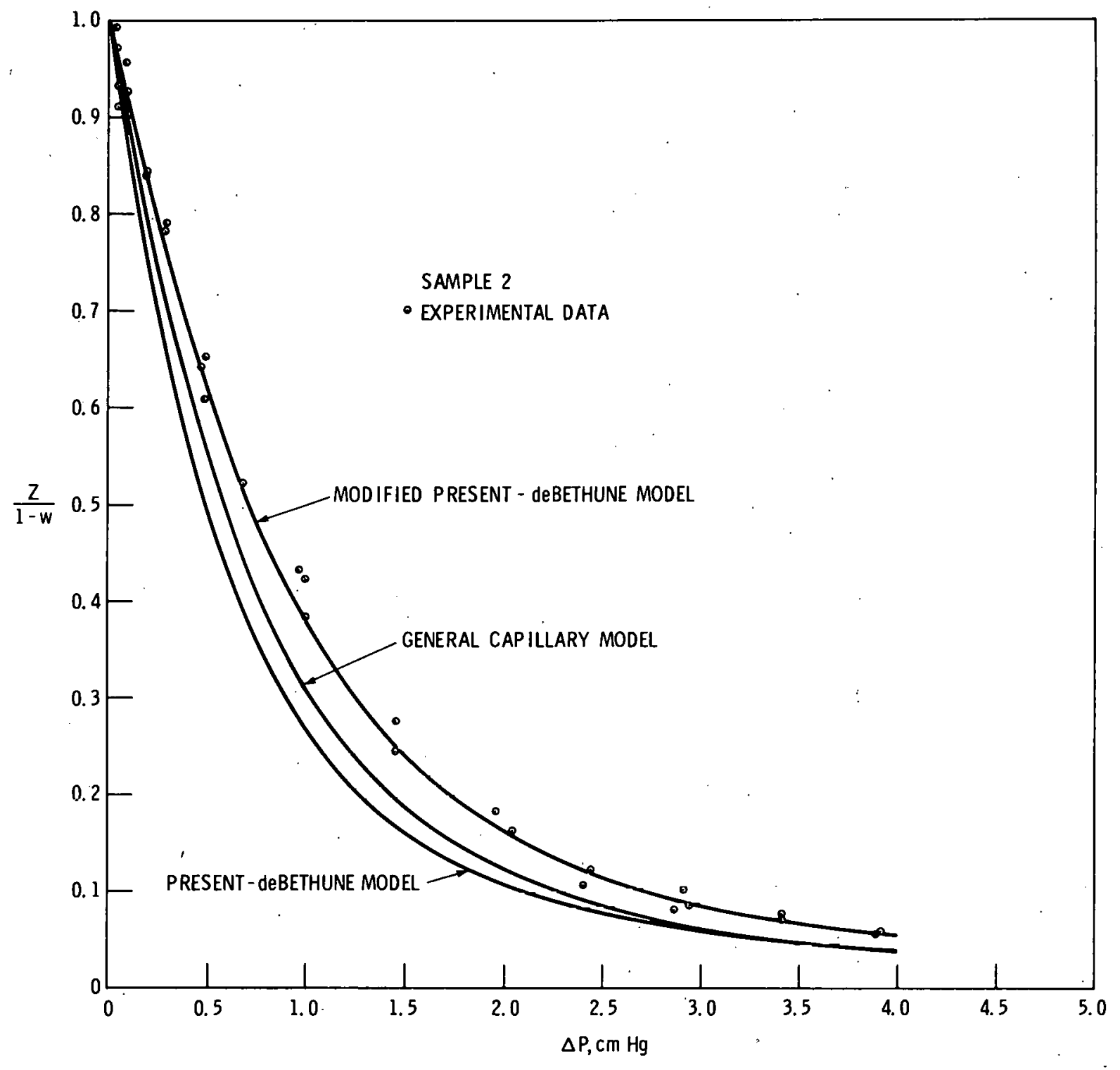

Figure 42

SEPARATION EFFICIENCY OF 25: 97-MICRONRADIUS GOLD ORIFICE SAMPLE 
Table 10

THE MODIFICATION CONSTANT $K$ FOR THE PRESENT AND deBETHUNE MODEL FOR DIFFERENT GEOMETRIES AND CALCULATION METHODS

\begin{tabular}{|c|c|c|c|c|}
\hline \multirow{2}{*}{$\begin{array}{l}\text { Sample } \\
\text { Number }\end{array}$} & Clausing Free & \multirow{2}{*}{$\frac{\text { Molecule Flow }}{\text { Finite Length }}$} & S1ip Flow & $\begin{array}{l}\text { Momentum } \\
\text { Transfer }\end{array}$ \\
\hline & Infinite Length & & Infinite Length & Infinite Length \\
\hline 212 & 1 & 0.974 & 0.76 & 1.178 \\
\hline 838 & 1 & 0.989 & 0.76 & 1.178 \\
\hline 924 & 1 & 0.986 & 0.76 & 1.178 \\
\hline 1054 & 1 & 0.992 & 0.76 & 1.178 \\
\hline 64 & $\therefore$ & 0.986 & 0.76 & 1.178 \\
\hline 2 & 1 & 0.550 & 0.76 & -- \\
\hline 1 & 2.203 & - & 0.76 & 1.178 \\
\hline 5 & 2.544 & - & 0.76 & 1.178 \\
\hline
\end{tabular}

$K^{\prime}$ constant taking proper account of viscous flow for the short capillary, represents the data better than the GCM' with nominal values of $C$ and $\sigma$. This result perhaps should not be too surprising since the transmission ratio for this test sample is linear with average pressures as was assumed in the Present and deBethune theory. A somewhat better fit is obtained with the PBFM using an arbitrary value of the constant $K$ which is again smaller than that calculated from the clausing factor. The best fit with PBFM was obtained with a value of $\mathrm{w}_{\mathrm{m}} / \mathrm{W}_{\mathrm{K}}=1$ corresponding to a transmission ratio, linear with average pressure, which is consistent with the intent of the modification of the PBM. A good fit is obtained with the GCM when a smaller than nominal value of $\sigma$ is used.

Figures 43 and 44 show the separation data for the parallel plate test sample 1 and 5 compared with the model calculations. In this case, the calculation for PBM using the Clausing factor was so poor that a calculation using the spacing itself as the dimension parameter was made. This calculation corresponds to using the hydraulic radius as was suggested by Present and deBethune. However, this suggestion is inconsistent with the change to the Clausing factor which was made by Present and deBethune for the capillary. The use of the hydraulic radius in the PBM produced calculated values of the separation efficiency ratio which were much higher, but still lower than the experimental data. The GCM using nominal $C$ and $\sigma$ gives results significantly higher than the data in the low pressure region and significantly lower than the data in the high pressure region. The calculated slope-to-spacing ratio for the GCM is about 50\% less than the measured slope-to-spacing ratio. Again, both the PBM and GCM give poor representation of the experimental data for the parallel plate data. 
DWG. NO. G-72-1259

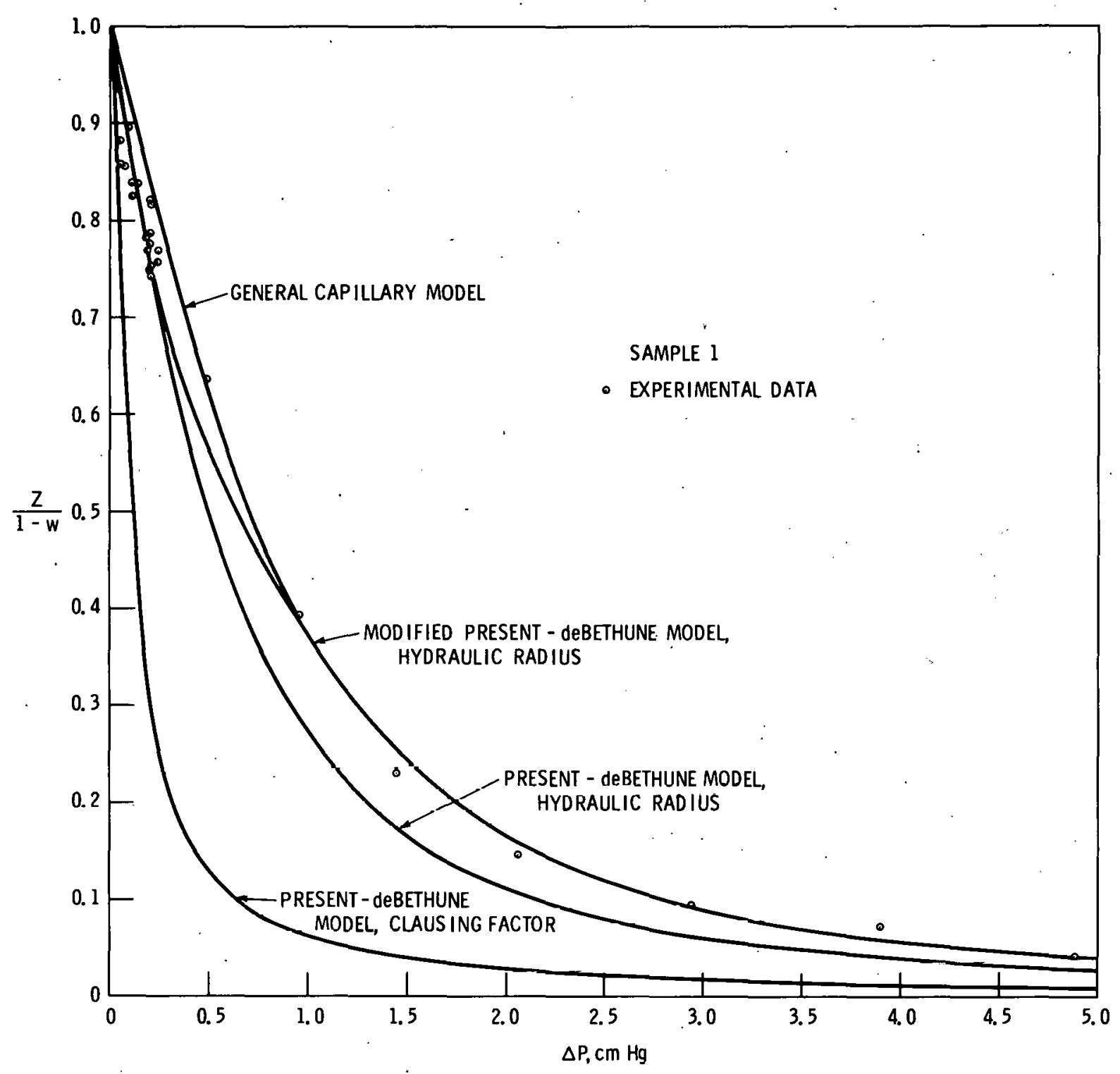

Figure 43

SEPARATION EFFICIENCY OF STEEL PARALLEL PLATE SAMPLE

WITH PLATE SPACING OF 25.58 MICRONS 


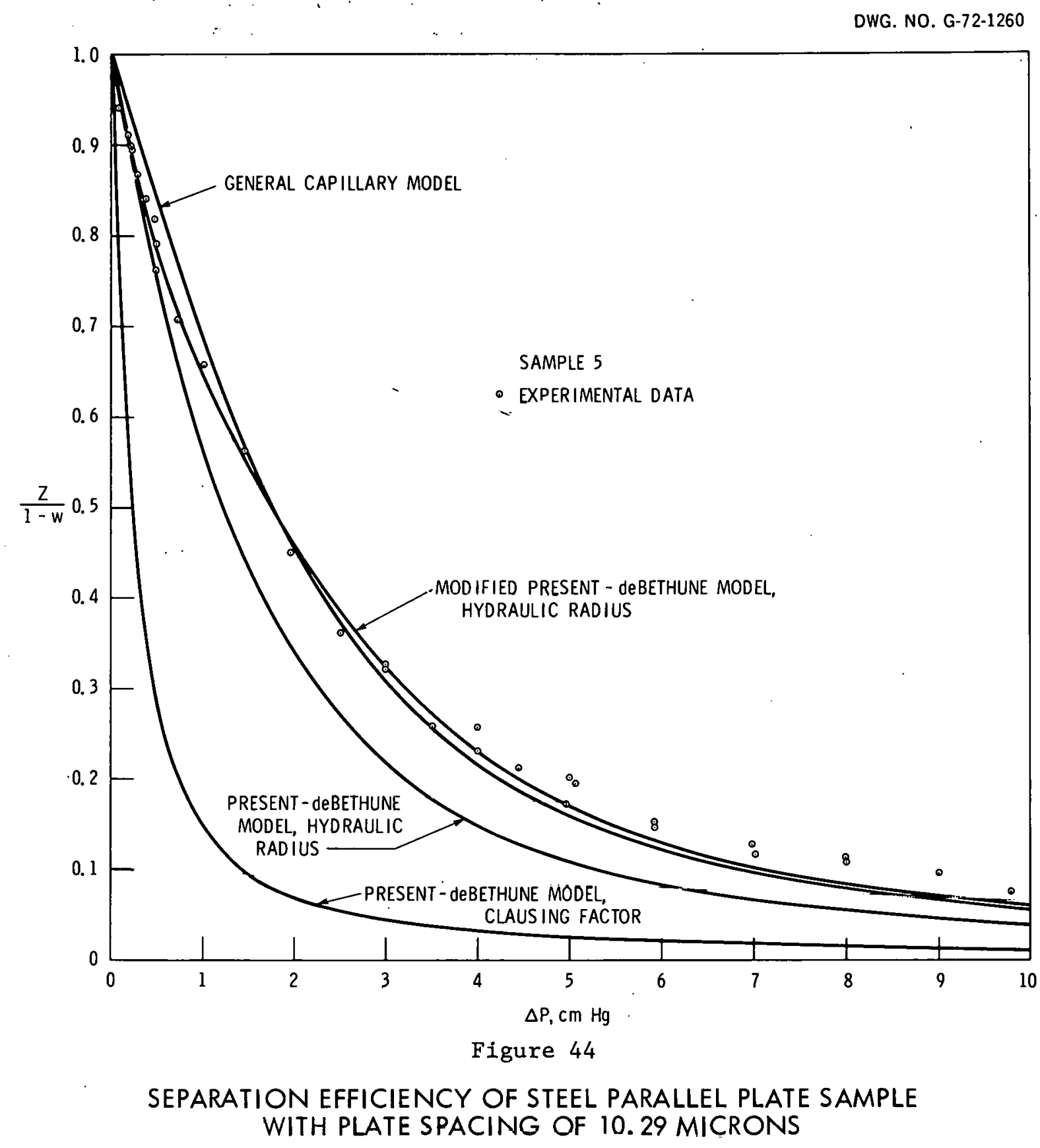


Because of the pattern of deviations from the experimental data, it would be particularly difficult to fit the experimental data with the GCM even with completely unreasonable $C$ and $\sigma$. The PBFM fits the experimental data fairly well with parameters consistent with the intent of the model when the hydraulic radius is used to represent the free molecule flow component, but not when the clausing factor is used for that purpose. 


\section{CONCLUSIONS}

A large body of accurate data showing the pressure dependence of the separation of neon isotopes by diffusion with a pressure gradient through different regular geometries is presented. The geometries investigated include long and short capillaries and parallel flat plates. The test samples were prepared with different materials such as glass, plastic, and metals. Consistent differences in the separation data were observed. Some of the differences in the separation data can be attributed to the geometric differences among the test samples and others can be attributed to the differences in the material used to prepare the test samples. The differences in the separation data produced by the materials used to prepare the test samples are presumably due to differences in the law of scattering of the molecules from these surfaces. Such deviations in the scattering law have been well documented as previously indicated.

Isotopes were chosen for this study to try to avoid discrepancies which would result if the anomaly produced by variations in the surface scattering law were different for the two gas species in the binary mixture. This appears to have been a fortunate choice, since both the flow and separation data show large anomalies presumably due to variations in the surface scattering law. However, as expected, the separation data show the anomaly to be the same for both isotopes, since the separation efficiency approaches that for ideal free molecule flow in every case. The variation in the anomaly due to surface scattering law deviations as indicated by both flow and separation measurements was about $30 \%$. This variation is only slightly larger than that which was reported by Lund and Berman [3].

There was very good correspondence between the capillary radii and the plate spacings as determined by optical measurements and by flow measurements. In general, the flow measurements were more precise than the optical measurements. The best agreement between flow and optical measurements was obtained when a similar sample was metallographically polished before the optical measurements were made. Most of the optical measurements were obtained on the as-made samples with their rough, poorly defined edges. For this reason, the capillary radii and plate spacings determined from the flow measurements were considered to be the more accurate.

Even though the approaches to a theory for separation are grossly different in character, the theory of Present and deBethune, PBM, and the result obtained by Malling using the Lund and Berman flow equations, GCM, are quite similar in character and calculation. The GCM should be more accurate because it specifically provides for variations in free molecule flow as well as for slip flow. Also, the pressure weighting is slightly different because of the independent variation in slip and free molecule flow. However, the coefficients of free molecule and slip flow required to fit the separation data are quite different from those measured by Lund and Berman or those indicated by the flow measurements on the test samples used in this study. The pattern of changes in the initial slope of the 
separation curves between test samples also scems contrary to the flow measurements. This discrepancy appears to be caused by the way the free molecule and slip flow anomalies are introduced into the theory. In the GCM there are only separative and nonseparative terms which are influenced independently by the anomalies. There is no interaction term. In the PBM the whole problem is an interaction term through the momentum exchange calculation. The momentum exchange is proportional to the free molecule flow level which is constant. The PBFM allows the interaction term to be scaled to vary from the free molecule flow level to the slip flow level with appropriate influence from the flow anomalies in both cases. This approach appears to have a particularly favorable effect in allowing fits of the data for all geometries. This is most clearly demonstrated in the case of the parallel plates which exhibit such large variations between the free molecule and slip flow levels. The PBFM is purely an interpolation equation and seems to represent the data exceptionally well. It was derived from physical arguments and therefore can be given a physical interpretation, but only in a qualitative sense. The PBFM approach gives the PBM the same kind of flexibility that the Lund and Berman equations gives to the GCM. It should be clear that the refinements required to represent the separation data do not have to be nearly as accurate as those required to fit the flow data. However, they must account for the interaction between molecules.

In their theory, Present and deBethune derived equations for a capillary only. Initially, they calculated the free molecule flow for a capillary using the calculation technique of momentum transfer to the wall. However, this did not agree with the free molecule flow calculation of Knudsen, Clausing and others, so they introduced a correction factor to make their calculation agree with the Knudsen and Clausing value. In their paper, they indicated that the capillary radius should be replaced with the hydraulic radius (ratin of rrese-occtional ared to perimeter) for other geometries. However, to be consistent, it should be concluded that the appropriate Clausing factor which would define the free molecule transmission probability, for whatever geometry is considered, would be the appropriate value to use in the equations.

The GCM does use the appropriate clausing factor with the capillary radius for capillaries and fairly well approximates that value at finite pressures for the parallel plate. The Hiby and Pahl interpolation is used for the parallel plate.

In the PBFM, the hydraulic radius is used and an appropriate constant is determined to fit the data. The constant which is determined should provide some implication as to what value is correct. The constants determined for the PBFM and the arbitrary constants used with the GCM to obtain the best fits indicate that the clausing factor is not the best value to indicate the relative amount of momentum transferred to the walls. Both sets of constants imply that there is a smaller amount of momentum loss to the walls per unit of drift velocity than is indicated by the Clausing factor for the transmission probability. For the capillaries, this might be interpreted as being due to scattering law deviations which 
result in a preponderance of backscattering. For test sample 1054, this would require 15 to $20 \%$ backscattering, which seems to be a rather large amount for what should be a smooth glass surface. An alternative explanation would be that the constant of proportionality for momentum exchange between molecules is not correct. A decrease of about 25 to $30 \%$ in the constant of proportionality could change. the inferred backscattering to specular reflection, with near perfect diffuse reflection for sample 1054 and 15 to $20 \%$ specular reflection for sample 64 . However, this does not correct the discrepancy observed for the short capillary and the parallel plates.

The constants obtained with the parallel plate data are simply too small to be accounted for by scattering law deviation. The constants are, however, compatible with the original calculation of momentum loss to the wall by Present and deBethune or to the use of the hydraulic radius. Since the capillary data are not consistent with the original calculation of momentum loss to the walls, and neither the capillary nor the parallel plate is completely compatible with the clausing factor, there is at present no satisfactory explanation for the experimental variation of the separation data with geometry.

The effects produced by surface scattering law variations are well represented with the long capillaries. The large plastic capillaries, 212, and the small plastic capillaries, 838 and 924, showed approximately the same constants with both flow and separation measurements. The small glass capillarles, 1054, showed constants significantly lower than the plastic capillaries and the larger glass capillaries, 64, showed constants slgnificantly larger than the plastic capillaries. The flow measurements implied specular reflection in varying degrees for all of the capillaries, but the separation measurements implied backscattering for all samples except 64 when the Clausing factor, as suggested by Present and deBethune, is used in the separation equations. If the characteristic constant relating the momentum loss to the wall to the average drift velocity were about 0.75 times the Clausing factor, then the constants determined from the separation measurements would all imply about the same amount of specular reflection as is indicated by the flow measurements.

Regardless of what the appropriate constant of proportionality is, the variation in the initial slope of the separation curve with surface scattering law deviations is more consistent with the PBFM than with the GCM. This is true not only in connection with the initial slope, but also in terms of the resulting fit patterns. Since the representation of the separation data by the GCM with arbitrary constants is better over the full range of pressure and requires smaller changes in $C$ and $\sigma$, it might be concluded that the scattering law is more nearly diffuse for sample 1054 than for. any of the other samples. As has already been indicated, this conclusion is consistent with the results of the flow measurements. This conclusion is also supported by the fits obtained with the PBM by changing the apparent capillary radius. Sample 1054 gives the best fit from this simple change in the PBM.

The same sort of fit pattern vartance is shown to an even larger extent with the parallel plate data, where the large Clausing factor relative 
to the capillary Clausing factor produces a large increase in the initial slope of the separation curve for the PBFM, but a large decrease in slope for the GCM. It would seem to be indicated that while the GCM might be modified to account accurately for separation data in capillaries when only diffuse wall reflections are present, it is doubtful that in its present form it can properly account for anomalies due to scattering law variation or for extremes in geometry such as parallel plates.

The PBFM generally does an excellent job of fitting all the experimental data; however, even it shows some small fit pattern variances in the range of separation efficiencies below $40 \%$ for the short capillary and for the parallel plates. While the pattern variances are small, they serve to emphasize that the PBFM is an empirical modification and that a better theory is needed for a complete description.

There is at least an implication from this study that the theoretical equations for free molecule flow predict flow ratios which are too large for both the capillary and the parallel plate. The $\mathrm{K}$-factors obtained from the PBFM and the $C$ values from the GCM suggest that the flow rate for long capillaries should be perhaps as much as 0.75 times that predicted by Clausing and for a parallel plate as much as 0.5 times that predicted by Clausing. This study also implies that most calculations of the slip coefficient could also be too large. Both PBFM and GCM suggest that the ratio of the slip coefficient, as interpreted from these data, to the slip coefficient calculated from most other methods is about 0.6 .

This work has shown that separation data can be obtained with sufficient accuracy to allow significant interpretations regarding geometry, surface scattering law deviations, and possibly constants relative to the ratio of the average drift velocity to the momentum loss to the wall. It has been shown that when real gas flow chararteristico arc taken lulu account in a logical way, the Present. and deBethune separation theory can accurately represent separation produced by gaseous diffusion of a binary mixture of isotopes. It has raised some important and serious questions relative to the momentum transfer to the walls or mean flow velocity under free molecule conditions for all geometries, but especially for the parallel plate. Further work with parallel plate geometries with different length-to-spacing ratios and with different surfaces such as fire-polished glass and metal could be helpful in answering some of the questions raised by this work. Flow data only should be sufficient to answer the question concerning the dependence of the free molecule transmission ratio on length-tospacing ratio. 'l'his type of measurement represents a significant means of studying the relative interaction of different molecules with surfaces as well as molecule-molecule scattering. Thus, further measurements should be made with other isotopes and nonisotopic gas pairs. 


\section{ACKNOWLEDGMENTS}

A study of this magnitude would have been very difficult without the variety of comprehensive services which are available at the Oak Ridge Gaseous Diffusion Plant. Numerous physical and analytical services of the Gaseous Diffusion Development Division, the Laboratory Division, and the Computer Sciences Division are gratefully acknowledged. In particular, the mass spectrometer analyses provided by the Isotopic Analysis Department and the metallurgical and analytical services provided by the Metallurgical Services Section were invaluable.

Special credit should go to $W$. H. Harber who made all of the flow measurements with the special volumetric flow measurement system. The consultation and calculations provided by G. F. Malling have also contributed much to the study. Thanks also to R. D. Bundy, L. M. Lund, and particularly R. M. McGill for their review and discussion of the report. 


\section{BIBLIOGRAPHY}

1. Present, R. D., and deBethune, A. J., Phys. Rev., 75, 1050 (1949).

2. Malling, G. F., Union Carbide Corporation, Nuclear Division, Oak Ridge Gaseous Diffusion Plant, Prịate Communication.

3. Lund, L. M., and Berman, A. S., J. App1. Phys., 37, 2489 and 2496 (1966).

4. Clausius, R., Die Kinetische Theorie der Gase, F. Vieweg und Sohn, Braunschweig (1889).

5. Maxwe11, J. C., Scientific Papers, W. D. Niven, ed., Cambridge University Press, Cambridge (1890).

6. Boltzmann, L., Vorlesungen über die Gase Theorie, Johann Ambrosius Barth, Leipzig (1910).

7. Graham, T., Phil. Mag., 2, 175, 269, 351 (1833). Reprinted in Graham, T., Chemical and Physical Researches, Edinburgh University Press, pp. 44-70 (1876).

8. Aston, J. G., Phil. Mag., 39, 449 (1920).

9. Kundt and Warburg, Phil. Mag., 50, 53 (1875); Pogg. Ann., 155, 337, 525 (1875).

10. Knudsen, M., Ann. Physik, 28, 75 (1909).

11. Gacde, W., Ann. Physik, 41, 289 (1913).

12. Adzumi, H., Bul1. Chem. Soc. Japan, 12, 292; 14, 343 (1939).

13. Pollard, W. G., and Present, R. D., Phys. Rev., 73, 762 (1948).

14. Visner, S., Gaseous Self-Diffusion and Flow in Capillaries at Low Pressures (U), Union Carbide Corporation, Nuclear Division, Oak Ridge Gaseous Diffusion Plant, May 9, 1951 (K-688). Phys. Rev., 82, 297 (1951).

15. Hiby, J. W., and Pahl, M., Z. Naturforsch., 7A, 542 (1952).

16. Weber, S., "Kgl. Danske Videnskab. Selskab," Mat. Fys. Medd., 28, No. 2 (1954).

17. Albertoni, S., Cercignani, C., and Gotusso, L., Phys. Fluids, 6, 993 (1963)'.

18. Berman, A. S., and Maegley, W. J., Phys. Fluids, 15, 780 (1972). 
19. Scott, D. S., and Dullien, F. A. L., AIChE Journal, 8, 293 (1962).

20. Fryer, G. M., Proc. Roy. Soc., A293, 329 (1966).

21. Barrer, R. M., and Nicholsen, D., Brit. J. App1. Phys., 17, 1091 (1966).

22. Hertz, G. L., Z. Phys., 79, 108 (1932).

23. Woolridge, D. E., and Smythe, W. R., Phys. Rev., 50, 233 (1936).

24. Bosanquet, C. H., British. TA Report Br-507, September 27, 1944.

25. Huggill, J. A. W., Proc. Roy. Soc. (London), A212, 123 (1952).

26. Kennard, E. H., Kinetic Theory of Gases, McGraw Hill Book Co., Inc., New York, p. 294ff (19.38).

27. Hanks, R. W., and Weissberg, H. L., J. App1. Phys., 35, 142 (1964).

28. Berman, A. S., Internal Rarefied Gas Flows with Backscattering Part 1: The Backscattering Boundary Condition and Free Molecule Flow in a Long Capillary; Part 3: Kramer's Problem--The Effect of Backscattering on Slip (U), Union Carbide Corporation, Nuclear Division, Oak Ridge Gaseous Diffusion Plant, June 16; 1971 (K-1798, Parts 1 and 3 ).

29. Von Smoluchowski, M., Ann. Physik, 33, 1559 (1910).

30. Clausing, P., Ann. Physik, 12, 961 (1932).

31. DeMarcus, W. C., The Problem of Knudsen Flow - Part 3: Solutions for One-Dimensional Systems (U), Union Carbide Corporation, Nuclear Division, Oak Ridge Gaseous Diffusion Plant, March 19, 1957 (K-1302, Part 3).

32. Berman, A. S., J. App1. Phys., 36, 3356 (1965). 
APPENDIX A - NOMENCLATURE

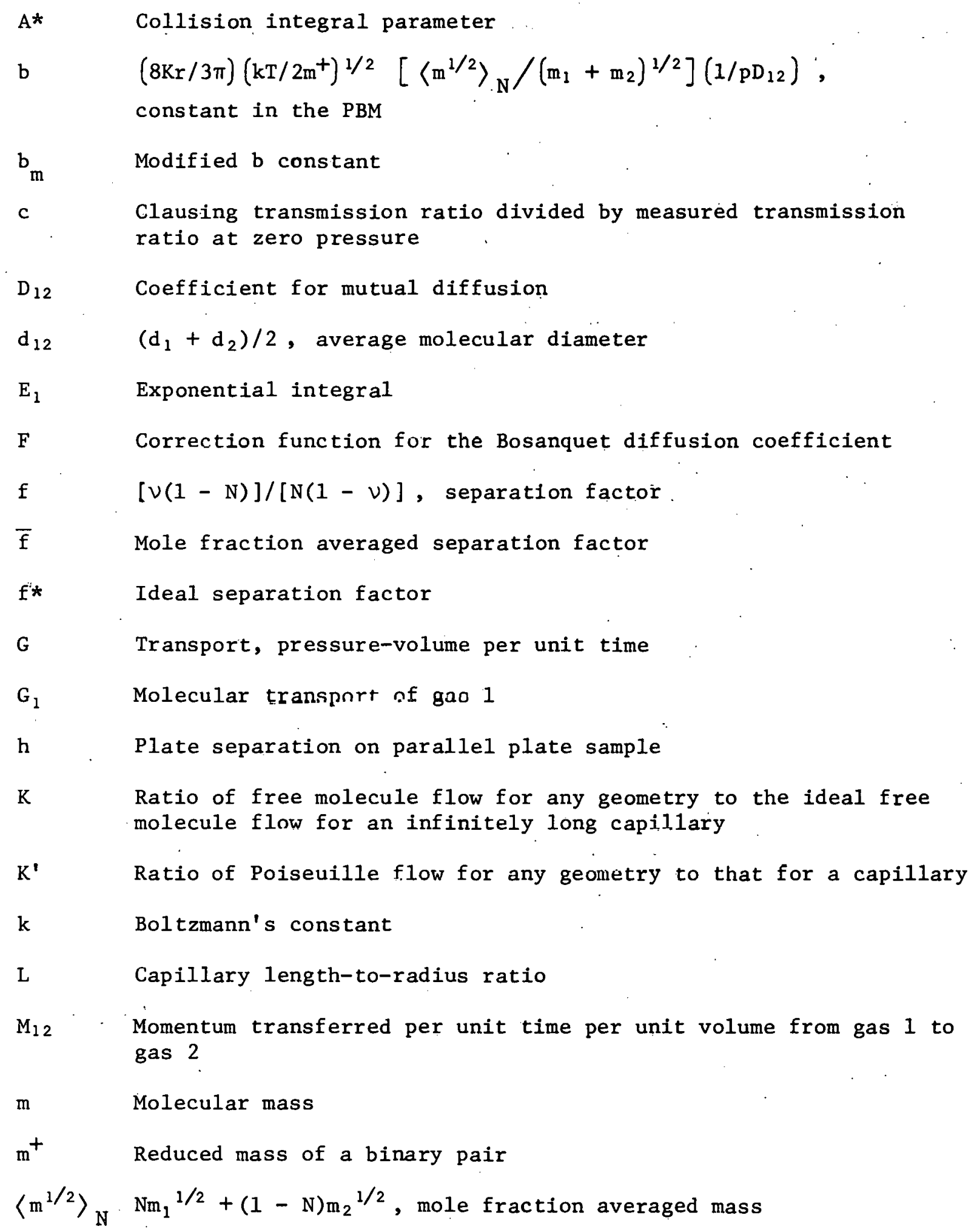




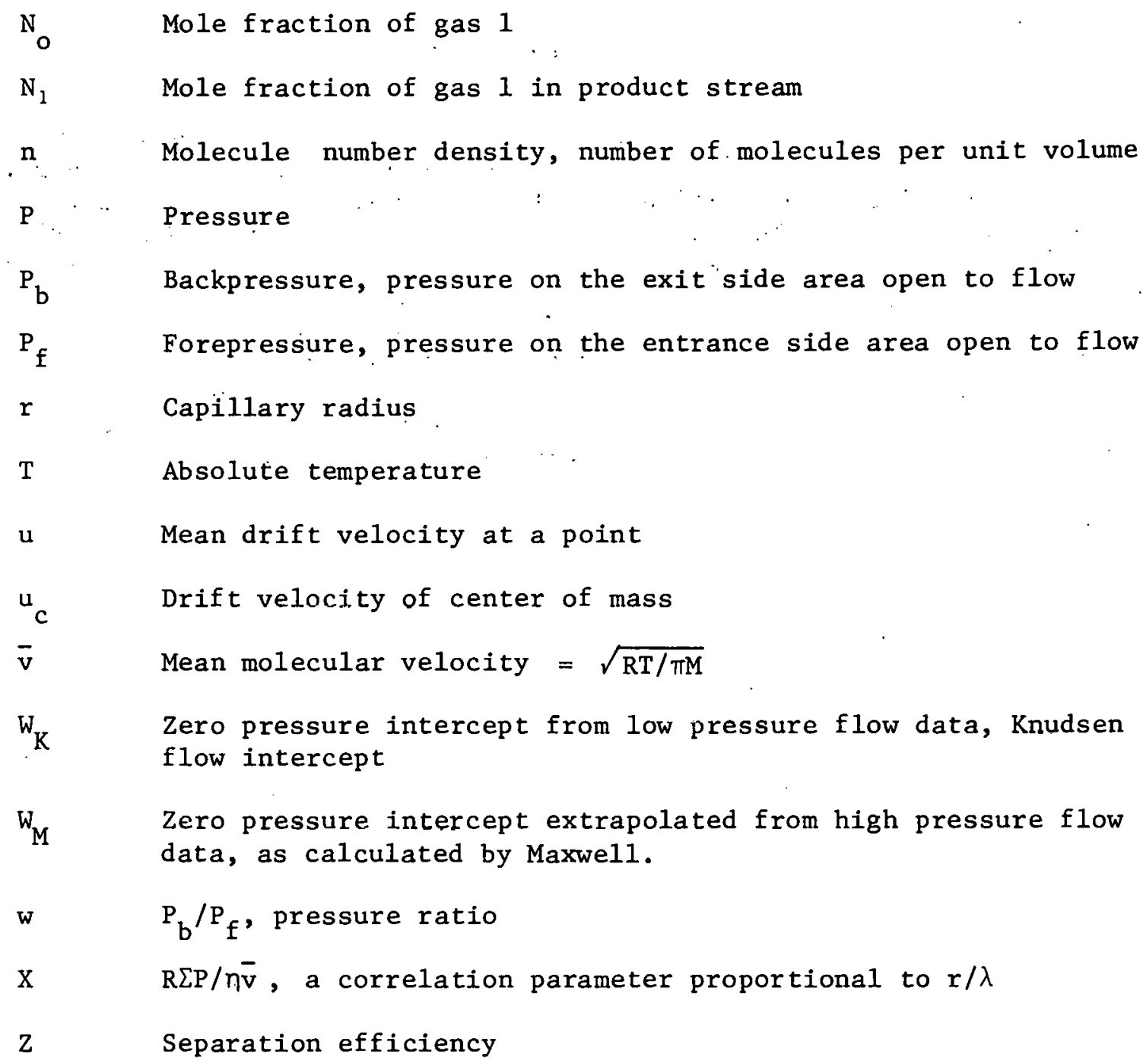

\section{Greek Symbols}

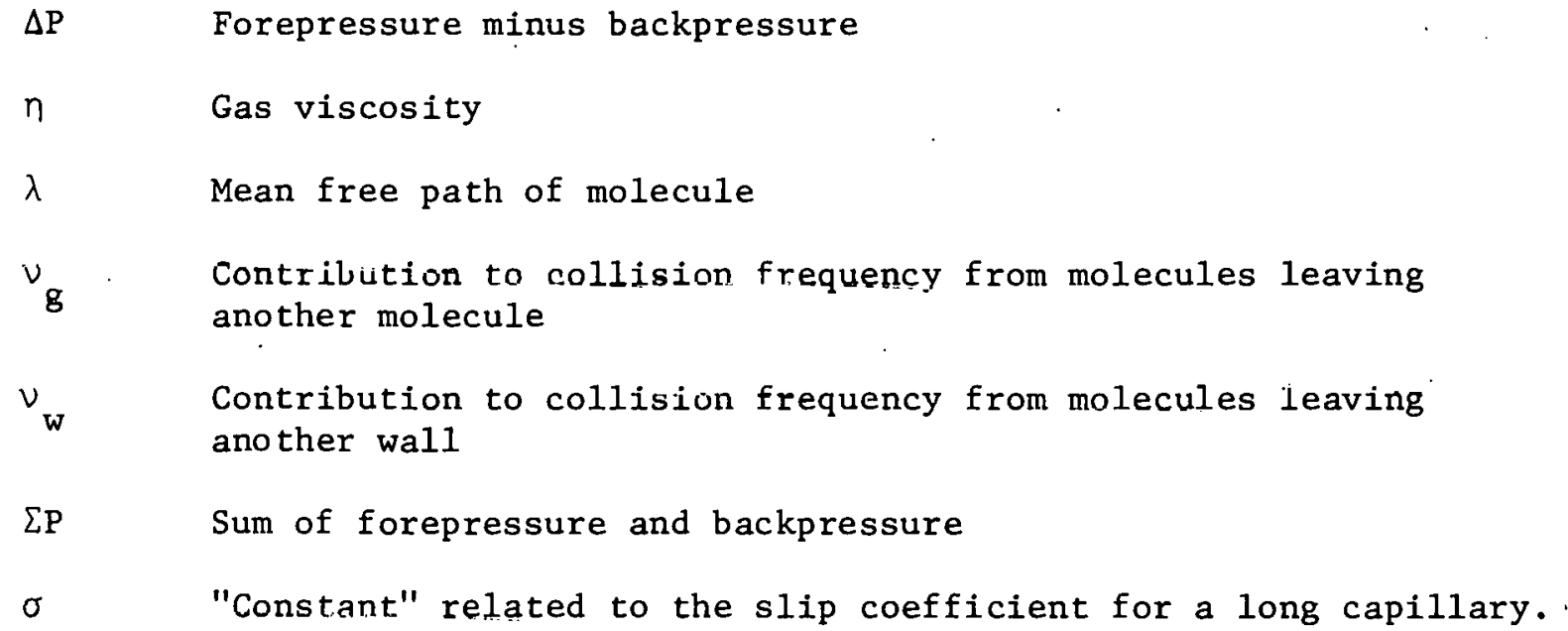


The following table lists all of the data which were obtained on all of the test samples. The test sample number is given at the top of the page. The first column lists an individual test point identification number. The second column lists the high side pressure, PF, in $\mathrm{cm} \mathrm{Hg}$. The third column lists the low side pressure, $\mathrm{PB}$, in $\mathrm{cm} \mathrm{Hg}$. The fourth column lists the ratio of the mole fraction ratio in the product stream to the mole fraction ratio feed stream as measured by the mass spectrometer. The fifth column lists the cut. The sixth column lists the pressure ratio, $\mathrm{PB} / \mathrm{PF}$. The seventh column lists the pressure difference across the test sample. The eighth column lists the separation efficiency, $Z$; and the ninth column lists the separation efficiency ratio, $Z /(1-w)$. 
NEON SEPARATION CATA SAMPLE NUMBER 212

\begin{tabular}{|c|c|c|c|c|c|c|c|c|}
\hline RUN & PF & $P B$. & RATIO & CUT & R & DELTA $P$ & 2 & $2 / 1-w$ \\
\hline 1005 & 4.6370 & 0.28000 & 1.00250 & 0.0684 & 0.06038 & 4.357 & 0.05308 & 0.05649 \\
\hline 1006 & 2.5040 & 0.15900 & 1.00600 & 0.0748 & 0.06350 & 2.345 & 0.12783 & 0.13650 \\
\hline 1007 & 1.1650 & 0.09300 & 1.31100 & 0.0819 & 0.07983 & 1.072 & 0.23527 & 0.25568 \\
\hline 1010 & 1.7020 & 0.08500 & 1.01390 & 0.0785 & 0.07072 & 1.117 & 0.29674 & 0.31932 \\
\hline 1011 & 1.1660 & 0.08200 & 1.01470 & 0.0827 & 0.07033 & 1.084 & 0.31455 & 0.33834 \\
\hline 1012 & 2.2130 & 0.12500 & 1.00710 & 0.0724 & 0.05643 & 2.088 & 0.15107 & 0.16011 \\
\hline 1013 & 3.3740 & 0.19100 & 1.00380 & 0.0672 & 0.05661 & 3.183 & 0.09062 & 0.08546 \\
\hline 1014 & 4.6510 & 0.25100 & 1.00210 & 0.0689 & 0.05397 & 4.400 & 0.04460 & 0.04714 \\
\hline 1015 & 2.0140 & 0.03001 & 1.00760 & 0.0731 & 0.01490 & 1.984 & 0.16176 & 0.16421 \\
\hline 1022 & $1 . \$ 350$ & 0.10600 & 1.01010 & 0.0791 & 0.06483 & 1.529 & 0.21569 & 0.23064 \\
\hline 1023 & 3.9420 & 0.21600 & 1.00430 & 0.0761 & 0.05479 & 3.726 & 0.09168 & 0.09699 \\
\hline 1024 & 2.8880 & .16750 & 1.00450 & 0.0786 & 0.05800 & 2.720 & 0.09607 & 10199 \\
\hline 1025 & 1.8660 & 0.11850 & 1.00890 & 0.0786 & 0.06350 & 1.747 & 0.19002 & 20290 \\
\hline 1026 & 1.2260 & .08750 & 1.01390 & 0.0791 & 0.07137 & 138 & 0.29684 & 31965 \\
\hline 1027 & 0.7320 & 07050 & 1.01660 & 0.0770 & 07564 & .861 & 35410 & 3307 \\
\hline 1029 & 1.1410 & 0.07650 & 1.01190 & 0.1312 & 0.06705 & 064 & 26178 & 8059 \\
\hline 1031 & 0.9759 & 0.07040 & 1.01640 & 0.0795 & 0.07214 & 906 & 35031 & 37754 \\
\hline 1787 & 1.9000 & 0.02970 & 1.02580 & 0.0121 & 0.02970 & .970 & 0.53181 & 0.54809 \\
\hline 1788 & 0.5020 & 0.01610 & 1.03140 & 0.0124 & 0.03207 & .486 & 0.64733 & 0.66877 \\
\hline 1789 & 0.3030 & 0.01100 & 1.03580 & 0.0118 & 0.03630 & .292 & 0.73782 & 0.76561 \\
\hline 1790 & 0.2000 & 0.00776 & 1.03870 & 0.0113 & 0.03880 & 0.192 & 0.79737 & 0.82956 \\
\hline 1791 & $0 . ก 880$ & 0.01020 & 1.03940 & 0.0037 & 0.11591 & 0.078 & 0.80870 & 0.91472 \\
\hline 1792 & 0.1100 & 0.01132 & .04000 & 0.0036 & 0.10291 & 0.099 & 0.82097 & 0.91515 \\
\hline
\end{tabular}


NEON SEPARATION DATA

SAMPLE NUMBER 838

\begin{tabular}{|c|c|c|c|c|c|c|c|c|}
\hline RUN & PF & P B & RATIO & CUT & $\mathbf{R}$ & DELTA $P$ & $z$ & $2 / 1-H$ \\
\hline 1032 & 5.0794 & 0.10300 & 1.00510 & 0.0006 & 0.02028 & 4.976 & 0.10451 & 0.10668 \\
\hline 1033 & 7.1031 & 0.13670 & 1.00280 & 0.0006 & 0.01925 & 6.966 & 0.05738 & $0.0585 . !$ \\
\hline 1034. & 10.2530 & 0.18460 & $1.00220^{\circ}$ & $\$ 0.0007$ & 0.01800 & 10.068 & 0.04509 & 0.04591 \\
\hline 1035 & 4.2107 & 0.091 .70 & 1.00540 & 0.0005 & 0.02178 & 4.119 & 0.11066 & $0.1131,3$ \\
\hline 1036 & 3.1280 & 0.07200 & 1.00910 & 0.0005 & 0.02302 & 3.056 & 0.18649 & 0.19088 \\
\hline 1039 & 4.8476 & 0.09540 & 1.00480 & 0.0539 & 0.01968 & 4.752 & 0.10112 & 0.10315 \\
\hline 1040 & 4.8650 & 0.09840 & $1: 00460$ & 0.0102 & 0.02023 & 4.767 & 0.09473 & 0.09668 \\
\hline 1041 & 4.7930 & 0.09540 & 1.00460 & 0.0010 & 0.01990 & 4.698 & 0.09429 & 0.09621 \\
\hline 1042. & 1.0130 & 0.02690 & 1.01970 & 0.0010 & 0.02655 & 0.986 & 0.40381 & 0.41482 \\
\hline 1043 & 1.0130 & 0.02690 & 1.02340 & 0.0096 & 0.02655 & 0.986 & 0.48173 & 0.49487 \\
\hline 1044 & 1.0830 & 0.02850 & 1.02560 & 0.0551 & 0.02632 & 054 & 0.53964 & 0.55423 \\
\hline 1045 & 2.4938 & 0.05770 & 1.00970 & 0.0005 & 0.02314 & 2.436 & 0.19878 & 0.20349 \\
\hline 1046 & 1.9690 & 0.04770 & .01410 & 0.0005 & 0.02423 & 921 & 0.28896 & 0.29613 \\
\hline 1047 & 1.4990 & 0.03850 & 1.01810 & 0.0006 & 0.02568 & 1.460 & 0.37093 & 0.38071. \\
\hline 1048 & 4.7404 & $0: 09540$ & 1.00480 & 0.0 .213 & $0: 02012$ & 645 & 0.09941 & 0.10145 \\
\hline 1049 & 1.0085 & $0: 03420$ & 1.02410 & 0.0095 & 0.03391 & 0.974 & 0.49612 & 0.51353 \\
\hline 1050 & 2.5038 & 0.06000 & 1.01210 & 0.0005 & 0.02396 & .444 & 0.24797 & 0.25405 \\
\hline 1051 & 1.0415 & 0.02650 & 1.02280 & 0.0122 & 0.02544 & 1.015 & 0.46999 & 0.48226 \\
\hline 1052 & 0.4800 & $0.01690:$ & 1.03060 & 0.0019 & 0.03521 & 0.463 & 0.62753 & 0.65043 \\
\hline 1053 & 1.0100 & 0.02920 & 1.02550 & 0.0008. & 0.02891 & .981 & 0.52264 & 0.53820 \\
\hline 1055 & 1.0138 & 0.02920 & 2520 & 0.0048. & 0.02880 & 985 & 0.51753. & 0.53288 \\
\hline 1056 & 1.0446 & 0.02770 & 1.02460 & 0.0244 & 0.02652 & 1.017 & 0.51026 & 0.52416 \\
\hline 1057 & 0.7661 & 0.02070 & 1.02910 & 0.0013 & 0.02702 & 0.745 & 0.59657 & 0.61314 \\
\hline 1058 & 2.5200 & 0.05850 & 1.01230 & 0.0005 & 0.02321 & 2.461 & 5206 & 0.25805 \\
\hline
\end{tabular}




\begin{tabular}{|c|c|c|c|c|c|c|c|c|}
\hline RUN & PF & PB & RATIO & CUT & $\mathbf{R}$ & DELTA P & 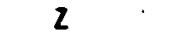 & $2 / 1-N$ \\
\hline 1059 & 3.5540 & 0.07540 & 1.00970 & 0.0005 & 0.02122 & 3.479 & .19878 & 0.20309 \\
\hline 1060 & 6.0176 & 0.11850 & 1.00400 & 0.0005 & 0.01969 & 5.899 & 0.08197 & .088362 \\
\hline 1061 & 8.0800 & 0.15000 & 1.00240 & 0.0006 & 0.01856 & 7.930 & 0.04919 & .05012 \\
\hline 1062 & 9.1000 & 0.16600 & $1.00250^{\circ}$ & 0.0007 & 0.01824 & 8.934 & .05124 & .05219 \\
\hline 1063 & .10 .1000 & 0.17920 & 1.00250 & $\$ 0.0007$ & 0.01774 & 9.921 & .05124 & .05216 \\
\hline 1064 & 0.5400 & 0.02000 & 1.03480 & 0.0017 & 0.03704 & 0.520 & .71357 & .74102 \\
\hline 1067 & 0.2485 & .01000 & 110 & 0.0049 & 0.04024 & 238 & 84412 & 87952 \\
\hline 1069 & 461 & 00 & 750 & 190 & 063 & 36 & 98258 & 19 \\
\hline 1071 & .0800 & 14 & so & 106 & 790 & 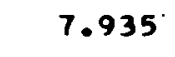 & 28 & 426 \\
\hline 1072 & 80 & 13 & 6 & 6 & 01846 & 49 & 06968 & 99 \\
\hline 1073 & 00 & & & 06 & 5 & & 18607 & 75 \\
\hline 1074 & 5 & & & & & & 2 & 15 \\
\hline 075 & & & & & 31 & & 5 & \\
\hline 1078 & 14. & $c$ & 0 & $*$ & 45 & 5 & 20 & 34 \\
\hline 1080 & 13 & 0 & 0 & 6 & 2 & & 8 & 00 \\
\hline 108 & & & & & 16 & & 37 & \\
\hline 1082 & & & & & & & 0 & 146 \\
\hline 1083 & I & & & & 42 & & & 13 \\
\hline 1084 & & & & 8 & 16 & & 69 & 15 \\
\hline 1085 & 17 & 10 & 50 & 11 & 2892 & 0 & 8423 & 05 \\
\hline 1087 & 2.2807 & 800 & 1540 & pon & 9 & $r$ & 560 & 23 \\
\hline 1088 & 3.8100 & 10 & 190 & 006 & 0.02178 & 727 & 0.16190 & 0.16551 \\
\hline 1089 & 12.2200 & 200 & 00170 & 008 & 0.01817 & 11.998 & 0.03484 & 0.03549 \\
\hline 1090 & .9350 & .10080 & .00420 & 0.0006 & 0.02043 & 4.834 & .08607 & .0878 \\
\hline
\end{tabular}




$\begin{array}{ccccccccc}\text { RUN } & \text { PF } & \text { PB } & \text { RATIO } & \text { CUT } & R & \text { OELTA P } & Z & Z / 1-W \\ 1091 & 10.0200 & 0.18080 & 1.00220 & 0.0007 & 0.01804 & 9.839 & 0.04509 & 0.04592 \\ 1092 & 6.4900 & 0.12620 & 1.00410 & 0.0006 & 0.01945 & 6.364 & 0.08403 & 0.08569 \\ 1093 & 1.4890 & 0.04150 & 1.02140 & 0.0006 & 0.02787 & 1.447 & 0.43856 & 0.45113 \\ 1094 & 0.4862 & 0.01690 & 1.03530 & 0.0027 & 0.03476 & 0.469 & 0.72420 & 0.75028 \\ 1095 & 0.6800 & 0.02150 & 1.03170 & 0.0012 & 0.03162 & 0.658 & 0.64986 & 0.67108 \\ 1096 & 2.4177 & 0.06000 & 1.01350 & 0.0005 & 0.02482 & 2.358 & 0.27666 & 0.28370 \\ 1098 & 2.4615 & 0.05540 & 1.01320 & 0.0005 & 0.02251 & 2.406 & 0.27051 & 0.27674 \\ 1099 & 2.7630 & 0.06380 & 1.01320 & 0.0005 & 0.02309 & 2.699 & 0.27051 & 0.27691 \\ 1100 & 3.0880 & 0.06770 & 1.01120 & 0.0005 & 0.02192 & 3.020 & 0.22952 & 0.23467\end{array}$


NEON SEPARATION DATA

SAMPLE NUMBER 924

\begin{tabular}{|c|c|c|c|c|c|c|c|c|}
\hline RUN & PF & PB & RATIO & CUT & $\mathbf{R}$ & DELTA P & 2 & $2 / 1-H$ \\
\hline 1101 & 5.0690 & $0: 12300$ & 1.00680 & 0.0007 & 0.02427 & 4.946 & 0.13937 & 0.14284 \\
\hline 1102 & 6.0400 & 0.14230 & 1.00520 & 0.0008 & 0.02356 & 5.898 & 0.10658 & 0.10915 \\
\hline 1103 & 2.9869 & 0.08153 & 1.01200 & 0.0007 & 0.02730 & 2.905 & 0.24594 & 0.25285 \\
\hline 1104 & 4.0676 & 0.10307 & 1.00860 & 0.0007 & $0: 02534$ & 3.965 & 0.17626 & 0.18084 \\
\hline 1105 & 7.1200 & 0.16077 & 1.00450 & 0.0008 & 0.02258 & 6.959 & 0.09223 & 0.09436 \\
\hline 1106 & 8.1200 & 0.17846 & 1.00360 & 0.0009 & 0.02198 & 7.942 & 0.07379 & 0.07545 \\
\hline 1107 & 9.2400 & 0.19769 & 1.00310 & 0.0009 & 0.02140 & 9.042 & 0.06354 & 0.06493 \\
\hline 1108 & 10.0100 & 0.21923 & 1.00290 & 0.0010 & 0.02190 & 9.791 & 0.05944 & 0.06077 \\
\hline 1110 & 1.0092 & 0.03615 & 1.02660 & 0.0011 & 0.03582 & 0.973 & 0.54527 & 0.56553 \\
\hline 1119 & 2.0077 & 0.05923 & 1.01670 & 0.0007 & 0.02950 & 1.948 & 0.34227 & 0.35267 \\
\hline 1120 & 3.4777 & 0.09153 & 1.00960 & 0.0010 & 0.02632 & 3.386 & 0.19678 & 0.20210 \\
\hline 1121 & 4.6169 & 0.11460 & 1.00450 & 0.0009 & 0.02482 & 4.502 & 0.09223 & 0.09458 \\
\hline 1122 & 5.6460 & 0.13230 & 1.00450 & 0.0008 & 0.02343 & 5.514 & 0.09223 & 0.09445 \\
\hline 1123 & 6.6230 & 0.15000 & 1.00360 & 0.0008 & 0.02265 & 6.473 & 0.07379 & 0.07550 \\
\hline 1124 & 7.6200 & 0.17080 & 1.00300 & 0.0009 & 0.02241 & 7.449 & 0.06149 & 0.06290 \\
\hline 1125 & 8.6500 & 0.18846 & 1.00250 & 0.0009 & 0.02179 & 8.462 & 0.05124 & 0.05238 \\
\hline 1126 & 12.2200 & 0.24300 & 1.00020 & 0.0 .011 & 0.01989 & 11.977 & 0.00410 & 0.00418 \\
\hline 1127 & 15.1000 & 0.30540 & 1.00040 & $\$ 0.0 .012$ & 0.02023 & 14.795 & 0.00820 & 0.00837 \\
\hline 1128 & 1.4554 & 0.04846 & 1.02240 & 0.0008 & 0.03330 & 1.407 & 0.45912 & 0.47493 \\
\hline 1129 & 0.2992 & 0.01461 & 1.03670 & 0.0046 & 0.04883 & 0.285 & 0.75362 & 0.79231 \\
\hline 1130 & 0.2654 & 0.01307 & 1.03850 & 0.0080 & 0.04925 & 0.252 & 0.79195 & 0.83297 \\
\hline 1131 & 0.4954 & 0.03000 & 1.03460 & 0.0019 & 0.06056 & 0.465 & 0.70956 & 0.75530 \\
\hline 1132 & 2.0277 & 0.05923 & 1.01640 & 0.0007 & 0.02921 & 1.968 & 0.33612 & 0.34624 \\
\hline 1167 & 6.0500 & 0.13900 & 1.00440 & 0.0009 & 0.02298 & 5.911 & 0.09019 & 0.09231 \\
\hline
\end{tabular}




\begin{tabular}{lllllllll} 
RUN & PF & PB & $R A T 10$ & CUT & $R$ & DELTA $P$ & 2 & $Z$ II-W \\
1168 & 7.9100 & 0.17900 & 1.00280 & 0.0010 & 0.02263 & 7.731 & 0.05739 & 0.05872 \\
1169 & 4.8800 & 0.10700 & 1.00670 & 0.0010 & 0.02193 & 4.773 & 0.13733 & 0.14041 \\
1170 & 8.9600 & 0.19300 & 1.00240 & 0.0010 & 0.02154 & 8.767 & 0.04920 & 0.05028 \\
1171 & 6.9200 & 0.15700 & 1.00340 & 0.0009 & 0.02269 & 6.763 & 0.06969 & 0.07131 \\
1172 & 4.0000 & 0.09900 & 1.00700 & 0.0009 & 0.02475 & 3.901 & 0.14348 & 0.14712 \\
1174 & 3.0100 & 0.06900 & 1.00920 & 0.0008 & 0.02292 & 2.941 & 0.18856 & 0.19298 \\
1175 & 2.0200 & 0.05300 & 1.01680 & 0.0008 & 0.02624 & 1.967 & 0.34433 & 0.35360 \\
1177 & 3.0900 & 0.08200 & 1.01090 & 0.0007 & 0.02654 & 3.008 & 0.22339 & 0.22948 \\
\hline 1178 & 2.5200 & 0.07200 & 1.01370 & 0.0007 & 0.02857 & 2.448 & 0.28078 & 0.28904 \\
1181 & 10.1400 & 0.20800 & 1.00180 & 0.0010 & 0.02051 & 9.932 & 0.03690 & 0.03767 \\
1182 & 8.0400 & 0.17800 & 1.00270 & 0.0009 & 0.02214 & 7.862 & 0.05534 & 0.05659 \\
1183 & 3.9900 & 0.09900 & 1.00720 & 0.0007 & 0.02481 & 3.891 & 0.14756 & 0.15132 \\
1184 & 1.5100 & 0.04800 & 1.02190 & 0.0008 & 0.03179 & 1.462 & 0.44886 & 0.46359 \\
1185 & 3.0000 & 0.07800 & 1.01100 & 0.0007 & 0.02600 & 2.922 & 0.22545 & 0.23146 \\
1187 & 1.4400 & 0.04600 & 1.02180 & 0.0008 & 0.03194 & 1.394 & 0.44682 & 0.46156 \\
1188 & 0.9931 & 0.03538 & 1.02690 & 0.0010 & 0.03563 & 0.958 & 0.55140 & 0.57176 \\
1189 & 0.4300 & 0.01923 & 1.03770 & 0.0032 & 0.04472 & 0.411 & 0.77364 & 0.80986 \\
1190 & 0.7780 & 0.02980 & 1.03090 & 0.0012 & 0.03830 & 0.748 & 0.63344 & 0.65867 \\
1191 & 0.2392 & 0.01080 & 1.03980 & 0.0062 & 0.04515 & 0.228 & 0.81794 & 0.85662 \\
1194 & 3.4920 & 0.09100 & 1.00920 & 0.0007 & 0.02606 & 3.401 & 0.18855 & 0.19360 \\
1195 & 4.5000 & 0.11100 & 1.00530 & 0.0007 & 0.02467 & 4.389 & 0.10862 & 0.11137 \\
1196 & 5.1800 & 0.12400 & 1.00540 & 0.0007 & 0.02394 & 5.056 & 0.11067 & 0.11339 \\
1197 & 5.6880 & 0.13120 & 1.00470 & 0.0008 & 0.02307 & 5.557 & 0.09633 & 0.09860 \\
1198 & 0.6220 & 0.02360 & 1.03370 & 0.0014 & 0.03794 & 0.598 & 0.69093 & 0.71818
\end{tabular}




$\begin{array}{llllllllll}\text { RUN } & \text { PF } & \text { PB } & \text { RATIO } & \text { CUT } & R & \text { DELTA } P & Z & Z \text { II-W } \\ 1199 & 0.4168 & 0.01780 & 1.03540 & 0.0025 & 0.04271 & 0.399 & 0.72616 & 0.75855 \\ 11200 & 0.5172 & 0.02140 & 1.03510 & 0.0017 & 0.04138 & 0.496 & 0.71974 & 0.75081 \\ 1201 & 0.3152 & 0.01370 & 1.03990 & 0.0041 & 0.04346 & 0.302 & 0.81914 & 0.85636 \\ 1203 & 0.2124 & 0.01028 & 1.04260 & 0.0079 & 0.04840 & 0.202 & 0.87622 & 0.92079 \\ 1204 & 0.3120 & 0.01400 & 1.03940 & 0.0039 & 0.04487 & 0.298 & 0.80878 & 0.84678 \\ 1205 & 0.2072 & 0.00980 & 1.04160 & 0.0072 & 0.04730 & 0.197 & 0.85538 & 0.89785 \\ 1206 & 0.1520 & 0.00732 & 1.04160 & 0.0060 & 0.04816 & 0.145 & 0.85485 & 0.89810 \\ 1207 & 0.0980 & 0.00488 & 1.04430 & 0.0058 & 0.04980 & 0.093 & 0.91026 & 0.95797 \\ 1419 & 0.1010 & 0.00232 & 1.04280 & 0.0015 & 0.02297 & 0.099 & 0.87753 & 0.89816 \\ 1420 & 0.2020 & 0.00428 & 1.04160 & 0.0012 & 0.02119 & 0.198 & 0.85279 & 0.87125 \\ 1421 & 0.0520 & 0.00120 & 1.04270 & 0.0019 & 0.02308 & 0.051 & 0.87566 & 0.89634 \\ 1422 & 0.0772 & 0.00160 & 1.04240 & 0.0019 & 0.02073 & 0.076 & 0.86948 & 0.88788 \\ 1423 & 0.1010 & 0.00236 & 1.04260 & 0.0016 & 0.02337 & 0.099 & 0.87348 & 0.89438 \\ 1424 & 0.2000 & 0.00460 & 1.04130 & 0.0012 & 0.02300 & 0.195 & 0.84666 & 0.86659 \\ 1425 & 0.2940 & 0.00680 & 1.04000 & 0.0011 & 0.02313 & 0.287 & 0.81994 & 0.83935 \\ 1426 & 0.4020 & 0.00540 & 1.03840 & 0.0009 & 0.01343 & 0.397 & 0.78709 & 0.79781 \\ 1427 & 0.1500 & 0.00300 & 1.04240 & 0.0014 & 0.02000 & 0.147 & 0.86929 & 0.88703 \\ 1428 & 0.2500 & 0.00570 & 1.04090 & 0.0011 & 0.02280 & 0.244 & 0.83841 & 0.85797 \\ 1429 & 0.3480 & 0.00800 & 1.03970 & 0.001 .0 & 0.02299 & 0.340 & 0.81376 & 0.83290 \\ 1430 & 0.4500 & 0.00960 & 1.03710 & 0.0009 & 0.02133 & 0.440 & 0.76043 & 0.77701 \\ 1467 & 0.1008 & 0.00792 & 1.04100 & 0.0021 & 0.07857 & 0.093 & 0.84088 & 0.91258 \\ 1468 & 0.1000 & 0.00258 & 1.04220 & 0.0064 & 0.02580 & 0.097 & 0.86736 & 0.89033 \\ 1470 & 0.1020 & 0.00707 & 1.04100 & 0.0019 & 0.06931 & 0.095 & 0.84077 & 0.90339\end{array}$




\begin{tabular}{|c|c|c|c|c|c|c|c|c|}
\hline UN. & PF & PB & RATIO & CUT & $\mathbf{R}$ & DELTA $P$ & 2 & $2 / 1-H$ \\
\hline 1472 & 0.1020 & 0.00702 & 1.04110 & 0.0031 & 0.06882 & 0.095 & 0.84336 & 0.90569 \\
\hline 1473 & 0.1020 & 0.00703 & 1.04070 & 0.0018 & 0.06892 & 0.095 & 0.83459 & 0.89637 \\
\hline 1.474 & 0.1020 & 0.00700 & 1.04160 & 0.0078 & 0.06863 & 0.095 & 0.85562 & 0.91867 \\
\hline 1475 & 0.1020 & 0.00700 & 1.04120 & 0.0050 & 0.06863 & 0.095 & 0.84620 & 0.90855 \\
\hline 1477 & 0.0990 & 0.00690 & 1.04060 & 0.0019 & 0.06970 & .092 & 0.83258 & 0.89495 \\
\hline 1478 & 0.1020 & 0.00744 & 1.04180 & 0.0071 & 0.07294 & 0.095 & 0.85943 & .92705 \\
\hline 1479 & 0.1020 & 0.00708 & 1.04090 & 0.0065 & 0.06941 & 0.095 & 0.84070 & 0.90341 \\
\hline 1488 & 0.1020 & 0.00700 & 1.04080 & 0.0069 & 0.06863 & $0: 095$ & 0.83880 & 0.90061 \\
\hline 1489 & 0.1020 & 0.00680 & 1.04 & 0.0020 & 06667 & 0.095 & 12442 & 8331 \\
\hline 1490 & 0.1020 & 0.00690 & 1.04100 & 36 & 0.06765 & 095 & 0.84149 & 255 \\
\hline 1491. & 0.1050 & 0.00240 & 1.04140 & 0.0058 & 0.02286 & 0.103 & 0.85067 & 0.87057 \\
\hline 1492 & 0.1020 & 0.00690 & 1.04180 & 0.0083 & 0.06765 & 0.095 & 0.85996 & 0.92236 \\
\hline 96 & 0.1 & 0.00708 & 1.04040 & 0.0021 & 0.06941 & 0.095 & 32858 & 0.89038 \\
\hline 707 & 0 & 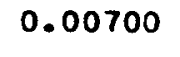 & & & 3 & 5 & & 71 \\
\hline 1498 & 0.1 & 0.00240 & 1.04100 & 0. & 3 & & 0 & \\
\hline 149 & 0. & 0.0 & . & 0 & 9 & 5 & 5 & \\
\hline 1500 & 0.1020 & 0.00 & 1.04130 & 0.0059 & 0.06765 & 0.095 & 0.84866 & 0.91023 \\
\hline 1 & 0.1030 & $0 . n n 366$ & 1.04100 & 0.0083 & 3 & 0.098 & 0.85584 & 0.91380 \\
\hline 150 & 0 & 0.00 & 1.03980 & 0 & 9 & 0.094 & 32 & 79 \\
\hline 1 & & 0 & 1.04070 & 0.0029 & 6 & 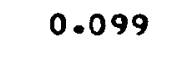 & 5 & 28 \\
\hline 150 & & 0 & 0 & & & & 4 & \\
\hline 1 & 0 & 0 & & 0124 & & & 1 & 70 \\
\hline 151 & 0 & 0.02 & 1.03830 & 0 & 80 & 0.230 & 0.78524 & 0.85426 \\
\hline 152 & 0.2500 & 0.00480 & 1.03970 & 0.0055 & 0.01920 & 0.245 & 0.81561 & 0.83158 \\
\hline
\end{tabular}




\begin{tabular}{|c|c|c|c|c|c|c|c|c|}
\hline RUN & PF & PB & RATIO & CUT & $\mathbf{R}$ & DELTA P & 2 & $2 / 1-H$ \\
\hline 1524 & 0.2500 & 0.01480 & 1.03820 & 0.0 .115 & .05920 & 0.235 & 0.78717 & 0.83670 \\
\hline 526 & 0.2500 & 0.00460 & 1.04010 & 0.0029 & 0.01840 & 0.245 & 0.82274 & 0.83816 \\
\hline 1527 & 0.2500 & 0.00440 & 1.04020 & 0.0014 & .01760 & 0.246 & 0.82420 & 0.83897 \\
\hline 1528 & 0.1020 & 0.00198 & 1.04160 & 0.0114 & 0.01941 & 0.100 & 0.85718 & 0.87415 \\
\hline 1529 & 0.1020 & 0.00180 & $1.04190^{\circ}$ & 0.0087 & 0.01765 & 0.100 & 0.86221 & 0.87770 \\
\hline 530 & 0.5100 & 0.00840 & .03580 & 138 & 1647 & 0.502 & 0.73858 & 0.75094 \\
\hline 1531 & 0.5000 & 0.00840 & 1.03660 & 0.0072 & 0.01680 & 0.492 & 0.75258 & 0.76544 \\
\hline 1533 & 0.5000 & 0.01260 & 1.03610 & 0.0135 & 0.02520 & 0.487 & 0.74466 & 0.76391 \\
\hline 1534 & 0.5060 & 0.01260 & 1.03650 & 0.0011 & 0.02490 & 0.493 & 0.74821 & 0. \\
\hline 1535 & 0 & 840 & 1.03 & 2011 & 0.01660 & 498 & 75231 & 6501 \\
\hline 153 & & 40 & 1.04040 & 0 & 5 & 95 & 38 & 13 \\
\hline 153 & 60 & 0.0 & & 0 & :0 & 0.481 & 33 & 15 \\
\hline 1539 & 0 & 0.0 & 1.03890 & 0 & 1 & 35 & & \\
\hline (1) & 1.02 .00 & 0.01520 & 950 & 0.0013 & 0.01490 & 05 & 0.60479 & 0.6 \\
\hline 1542 & & 0 & $1.0<700$ & .0017 & & & 4 & 32 \\
\hline 1543 & 1.0200 & 0 & & & & & & 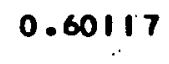 \\
\hline 1 & 1.02 .00 & 0 & & & & & & \\
\hline 1 & 0 & 0 & & & & & & \\
\hline 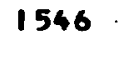 & 1.0200 & 0 & & 8 & & & & 31 \\
\hline 15 & 1.0200 & o & 1.02950 & & 98 & & 17 & 0.62452 \\
\hline 1 & 0200 & 0 & 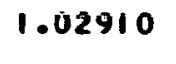 & & & & 99 & 99 \\
\hline 154 & 2 & 0 & 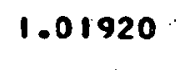 & 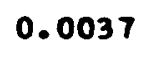 & 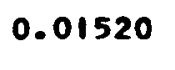 & & & \\
\hline 1550 & 2.00 & 0.0 .3 & 1.01860 & 0.0062 & 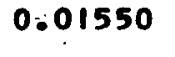 & 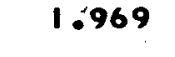 & $6{ }^{\circ}$ & 0.38828 \\
\hline 55 & 0000 & .03040 & 0189 & .0015 & 01520 & 1.970 & .38750 & 393 \\
\hline
\end{tabular}




$\begin{array}{llllllllll}\text { RUN } & \text { PF } & \text { PB } & \text { RATIO } & \text { CUT } & R & \text { DELTA P } & 2 & 2 I 1-H \\ 1.552 & 4.0400 & 0.05180 & 1.00910 & 0.0028 & 0.01282 & 3.988 & 0.18670 & 0.18913 \\ 1553 & 0.1000 & 0.07500 & 1.00480 & 0.0010 & 0.01230 & 6.025 & 0.09839 & 0.09962 \\ 1554 & 8.1600 & 0.06500 & 1.00450 & 0.0010 & 0.00797 & 8.095 & 0.09224 & 0.09298 \\ 1555 & 3.0400 & 0.02820 & 1.01280 & 0.0015 & 0.00928 & 3.012 & 0.26245 & 0.26490 \\ 1556 & 5.0800 & 0.04400 & 1.00620 & 0.0011 & 0.00866 & 5.036 & 0.12709 & 0.12820 \\ 1557 & 4.1000 & 0.05200 & 1.00860 & 0.0012 & 0.01268 & 4.048 & 0.17630 & 0.17856 \\ 1558 & 7.1200 & 0.05800 & 1.00480 & 0.0010 & 0.00815 & 7.062 & 0.09839 & 0.09920 \\ 1559 & 3.0400 & 0.04400 & 1.01240 & 0.0015 & 0.01447 & 2.996 & 0.25423 & 0.25797 \\ 1560 & 9.2000 & 0.10200 & 1.00320 & 0.0010 & 0.01109 & 9.098 & 0.06559 & 0.06633 \\ 1561 & 8.2000 & 0.06600 & 1.00270 & 0.0010 & 0.00805 & 8.134 & 0.05534 & 0.05579\end{array}$


NEON SEPARATION DATA

SAMPLE NUMBERI 054

\begin{tabular}{|c|c|c|c|c|c|c|c|c|}
\hline & & & & & & ELTA & 2 & $11-w$ \\
\hline 211 & 2.0360 & .01000 & 03210 & .0001 & 0.00491 & 2.026 & 0.65765 & 0.6605 \\
\hline 2.12 & 3.0040 & 1400 & 02760 & 0.0001 & 0.00466 & 2.990 & .565 .51 & 568 \\
\hline 213 & 4.0180 & 01812 & $.02190^{\circ}$ & .0001 & 0.00451 & 4.000 & .44868 & $450^{\circ}$ \\
\hline $214^{\circ}$ & 10.1400 & 0.04130 & .00770 & .0001 & 407 & 10.099 & 776 & 58 \\
\hline 21 & 0 & 0 & 90 & 1 & & 98 & 4 & \\
\hline 217 & 15.0800 & 0.05780 & 1.00470 & $* 0.0001$ & 0.00383 & 15.022 & 0.09631 & 0.096 \\
\hline 21 & .9570 & .03720 & 0 & .0001 & 5 & 20 & 874 & 0 \\
\hline 21 & 7.0500 & 0 & 0 & 1 & 7 & 1 & 4 & 0.259 \\
\hline 228 & 1 & & & & & & & \\
\hline 2 & & & & & & & & \\
\hline & & & & & & & & \\
\hline 3 & sen & & & & & & & \\
\hline - & & & & & & & & \\
\hline & & & & & & & & \\
\hline & & & & & & & & \\
\hline 24 & & & & & & & & \\
\hline 243 & & & & & & & & \\
\hline 270 & & & & & & & & \\
\hline . & & & & & & & & \\
\hline-0 & & & & & & & & \\
\hline 2 & & & & & & & & \\
\hline 1250 & & & & & & & & \\
\hline & & & & & & & & 0.3742 \\
\hline & .200 & .0022 & 1.04610 & - & 0.01087 & 0.204 & 0.94550 & 0.935 \\
\hline
\end{tabular}




\begin{tabular}{|c|c|c|c|c|c|c|c|c|}
\hline UN & $F$ & B & ATIO & CUT & $\boldsymbol{R}$ & DELTA $P$ & 2 & $2 / 1-H$ \\
\hline 1267 & .5044 & 00257 & .04150 & 0.0002 & 00510 & .502 & .85032 & 85467 \\
\hline 1268 & 0.2080 & 00246 & 50 & 0003 & 183 & 206 & 89138 & 0.90205 \\
\hline 1269 & 1.0060 & .00530 & .04000 & .0002 & 00527 & 0.01 & .81958 & 2 \\
\hline $1.271^{\circ}$ & 0.7632 & 00360 & 10 & 0.0002 & 0472 & 760 & 36 & 55 \\
\hline 1272 & 0.3152 & 00306 & 480 & 0.0003 & 9971 & 12 & 1797 & 97 \\
\hline 1276 & 0.5008 & 00246 & & 0.0002 & 0491 & & & 0.85658 \\
\hline 127 & 0.7536 & 00388 & 70 & 0.0001 & 1.00515 & 150 & & 0 \\
\hline 127 & 124 & 10 & 1.04410 & 0.0 & 463 & 301 & 6 & \\
\hline 128 & 0 & 08 & 0 . & 0.1 & 1012 & 9 & 0.90370 & 94 \\
\hline 128 & & & & & 3 & & & \\
\hline 128 & & & & & & & & \\
\hline 128 & & & & & & & & \\
\hline 128 & 0. & 00550 & 0 & 0. & 1.07 & 1 & & \\
\hline 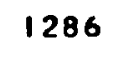 & 12 & & 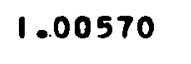 & & 5 & & & \\
\hline & & & & & & & & \\
\hline 128 & & & & & & & & \\
\hline 28 & & & & & & & & \\
\hline & & & & & & & & 51 \\
\hline 129 & & & & & & & & 84 \\
\hline 129 & & & & & & & & \\
\hline & & & & & & & & \\
\hline & & & & & & & & \\
\hline & & & & & & 4 & & 51 \\
\hline $1<90$ & .040 & 0.02400 & 1.01540 & 0.0001 & 0.00397 & 6.016 & 0.31552 & 0.31678 \\
\hline
\end{tabular}




\begin{tabular}{|c|c|c|c|c|c|c|c|c|}
\hline UN & PF & PB & AT IO & CUT & $\mathbf{R}$ & DELTA P & 2 & $2 / 1-W$ \\
\hline 1299 & 10.0300 & 0.03680 & 1.00770 & 0.0001 & 0.00367 & 9.993 & 0.15 .776 & .1583 \\
\hline 1.300 & .7512 & 0.00406 & .0 .4160 & .0001 & .00540 & .747 & .85236 & 85699 \\
\hline 1301 & 5024 & 00252 & 04120 & 0003 & 00502 & 500 & 4425 & $848 !$ \\
\hline 1302 & 488 & 0386 & 03990 & 0001 & 0515 & 45 & 755 & 17 \\
\hline 1303 & 0.5030 & .00266 & .04180 & .0003 & .00529 & 500 & 85653 & 86108 \\
\hline 1304 & 6.0400 & 0.02028 & 01550 & .0001 & 0.00336 & 020 & 1758 & 365 \\
\hline 1305 & 680 & 0 & 0 & .0001 & 0.00399 & 44 & 2578 & 09 \\
\hline 1306 & 10. & 0 & 0 & 1 & 4 & 88 & 8 & 73 \\
\hline I & 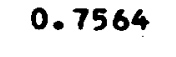 & 14 & & & & & 3 & 65 \\
\hline 130 & 1.0050 & 0.00 & 03940 & & 1 & & & 5 \\
\hline 130 & 2.01 & 0 & 0 & 1 & 6 & 07 & 200 & 14 \\
\hline 31 & 0 & 2 & 0 & & & & & \\
\hline 1311 & & & & & & & & \\
\hline 1.31 & & & & & & & & \\
\hline 1.31 & & & & & & & & \\
\hline 1314 & 4 & 0. & 0 & & & & 36 & 05 \\
\hline 31 & & & & & & & 5 & \\
\hline 1316 & 0040 & 0.0 & & & & & & 2 \\
\hline 1317 & & & & & & & & 721 \\
\hline & & & & & & & & \\
\hline 1 & & & 1 & & & & & 4 \\
\hline 132 & 0 & 0.003 & 1.09080 & & & & & \\
\hline 1321 & 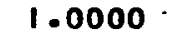 & 0.00464 & 1.0 & & 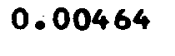 & & & \\
\hline 322 & מו & 00242 & 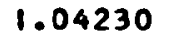 & 3 & .004 & 0.312 & .86677 & .87087 \\
\hline
\end{tabular}




\begin{tabular}{|c|c|c|c|c|c|c|c|c|}
\hline UN & PF & PB & RAT IO & CUT & $\mathbf{R}$ & DELTA $P$ & 2 & $2 / 1-4$ \\
\hline 1325 & 0.5000 & 0.00276 & 1.04240 & 0.0003 & 0.00552 & 0.497 & 0.86883 & 0.87365 \\
\hline 1326 & 0.61112 & .00296 & 1.04220 & 0.0002 & 0.00484 & .608 & 0.86463 & .86884 \\
\hline 1327 & 0.4020 & .00252 & 1.04360 & 0.0007 & 0.00627 & 399 & 0.89355 & .89919 \\
\hline 1328 & 0.4460 & 0.00222 & 1.04340 & 0.0004 & 0.00498 & 0.444 & 0.88937 & 0.89382 \\
\hline 1329 & 0.3120 & 0.00168 & 1.04690 & 0.0023 & 0.00538 & 0.310 & 0.96198 & 0.96719 \\
\hline 1330 & 0.3460 & .00198 & 1.04380 & 0.0012 & .00572 & 0.344 & 0.89788 & 0.90305 \\
\hline 1562 & 0.5080 & .00300 & 1.04450 & 0.0002 & 0.00591 & 0.505 & 1180 & 91722 \\
\hline 1563 & 0.5100 & 0.00320 & 1.04470 & 0.0009 & 0.00627 & .507 & 0.91621 & 0.92199 \\
\hline 1564 & 0.5100 & 0.00090 & 1.04360 & 0.0018 & 0.00176 & 0.509 & 0.89406 & 0.89564 \\
\hline 1565 & 0.5000 & 0.00300 & 1.04350 & 0.0 & 0600 & 7 & 0.89318 & 857 \\
\hline 1567 & 100 & 300 & 10 & & 88 & 7 & 0.92443 & \\
\hline 156 & 0.5100 & 0.00300 & 1.04420 & & & & 674 & 10 \\
\hline 157 & 0.5000 & 0.00300 & 1.04440 & 0.0013 & 0.00600 & 0.497 & 22 & 0.91572 \\
\hline 157 & 0.5100 & 0.00300 & 1.04430 & 0.0009 & .00588 & .507 & 801 & 0.91338 \\
\hline 1572 & 0.5100 & 0 & .04440 & 0.0004 & 0588 & .507 & 90986 & 525 \\
\hline 1573 & 0 & 0 & & & & & & 7 \\
\hline 157 & 0.2000 & & & & & & & \\
\hline 157 & 200 & 0.00150 & 4560 & 2 & 50 & 8 & 78 & 94185 \\
\hline iste & 0.2000 & 0.00090 & 1.04540 & 0.0023 & 0450 & & 22 & 0.93543 \\
\hline I & 0 & 0 & .00 & & 40 & & 27 & 93834 \\
\hline 157 & 1.0 & 0 & .07 & & 54 & & 4 & 34 \\
\hline 158 & 0 & 0 & . & & 0 & & 96 & 66 \\
\hline 1582 & 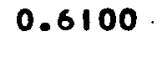 & 0 & 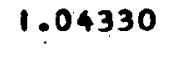 & 0.0007 & 0 & ${ }^{\circ}$ & 4 & 8 \\
\hline 1583 & 0.7500. & 0.00450 & 1,04230 & 0.0011 & 0.00600 & 0.745 & 0.86711 & 0.87234 \\
\hline
\end{tabular}




\begin{tabular}{|c|c|c|c|c|c|c|c|c|}
\hline RUN & PF & PB & RAT IO & CUT & $\mathbf{R}$ & DELTA $P$ & 2 & $2 / 1-H$ \\
\hline$! 585$ & 1.2000 & 0.00660 & 1.04030 & 0.0010 & 0.00550 & 1.193 & 0.82605 & 0.83062 \\
\hline$! 586$ & 0.9060 & 0.00600 & 1.04140 & 0.0010 & 0.00662 & 0.900 & 0.84862 & 0.85428 \\
\hline 1587 & 1.2000 & 0.00660 & 1.03920 & 0.0010 & 0.00550 & 1.193 & 0.80350 & 0.80795 \\
\hline 1588 & 1.5000 & 0.00840 & 1.03790 & 0.0010 & 0.00560 & 1.492 & 0.77687 & 0.78125 \\
\hline 1589 & 0.1000 & 0.00042 & 1.04560 & 0.0008 & 0.00420 & 0.100 & 0.93461 & 0.93856 \\
\hline 1590 & 0.1000 & 0.00055 & 1.04580 & 0.0010 & 0.00550 & 0.099 & 0.93881 & 0.94400 \\
\hline 1591 & 0.1000 & 0.00060 & 1.04540 & 0.0013 & 0.006 .00 & 0.099 & 0.93074 & 0.93636 \\
\hline 1711 & 986 & 0.00379 & .04340 & 006 & 0.00760 & 95 & 0.88943 & 89624 \\
\hline 171 & 0.2030 & 0.00157 & 1.04520 & 13 & 0773 & 0.201 & 92665 & 0.93387 \\
\hline 1713 & 0.7508 & 0.00187 & 1.04080 & 0.0018 & 0.00249 & 49 & 0.83664 & 0.83873 \\
\hline 171 & 994 & 0.00228 & 1.03950 & 0.0010 & 0.00228 & & 0.80967 & 0.81152 \\
\hline 171 & 012 & 0.00086 & .04450 & 1012 & 0.00850 & & 225 & 92 \\
\hline 171 & 1 & 0 & & & & & & \\
\hline 171 & 0 & & .04580 & & 5 & & 4 & 8. \\
\hline 171 & 010 & 00341 & 1.04390 & 0. & 81 & 98 & 0.89969 & 0.90585 \\
\hline 171 & 0.2026 & 0.00155 & $! .04540$ & 0.0013 & 0.00765 & 01 & 0.93074 & 0.93792 \\
\hline 172 & 1004 & 0 & 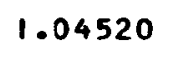 & 2 & 37 & 00 & 2659 & 0.93347 \\
\hline 172 & & 0 & 1.02850 & & & & 9 & 40 \\
\hline $17 \%$ & & & & & & & & \\
\hline 172 & 4 & 0 & 0 & & 2 & & 35 & 4 \\
\hline 1724 & 4.9900 & 38 & 1.0 & 0 & 98 & 4.980 & 26 & 0.42309 \\
\hline 172 & 7.5340 & 800 & 1.01340 & .0010 & 83 & 7.520 & 67 & 0.27518 \\
\hline 172 & 9 & 0 & 0 & 0 & & 88 & 8448 & 0.18470 \\
\hline 727 & 9720 & 0.00346 & 02780 & .0010 & 0.00116 & 2.969 & 0.56985 & 0.57051 \\
\hline
\end{tabular}




$\begin{array}{llllllllll}\text { RUN } & \text { PF } & \text { PB } & \text { RATIO } & \text { CUT } & R & \text { DELTA P } & 2 & Z \text { II-W } \\ 1803 & 1.0000 & 0.00889 & 1.03980 & 0.0004 & 0.00889 & 0.991 & 0.81557 & 0.82289 \\ 1804 & 0.7500 & 0.00656 & 1.04060 & 0.0010 & 0.00875 & 0.743 & 0.83221 & 0.83955 \\ 1805 & 0.5100 & 0.00413 & 1.04300 & 0.0010 & 0.00810 & 0.506 & 0.88142 & 0.88861 \\ 1806 & 0.2000 & 0.00205 & 1.04600 & 0.0008 & 0.01025 & 0.198 & 0.94281 & 0.95257 \\ 1807 & 0.5000 & 0.00428 & 1.04280 & 0.0010 & 0.00856 & 0.496 & 0.87731 & 0.88488 \\ 1808 & 0.2000 & 0.00192 & 1.04530 & 0.0008 & 0.00960 & 0.198 & 0.92845 & 0.93745 \\ 1809 & 0.7500 & 0.00563 & 1.04140 & 0.0010 & 0.00751 & 0.744 & 0.84862 & 0.85503 \\ 1810 & 1.0000 & 0.00755 & 1.04100 & 0.0010 & 0.00755 & 0.992 & 0.84042 & 0.84681 \\ 1811 & 0.1000 & 0.00120 & 1.04610 & 0.0010 & 0.01200 & 0.099 & 0.94495 & 0.95643 \\ 1812 & 1.0000 & 0.00776 & 1.04070 & 0.0010 & 0.00776 & 0.992 & 0.83426 & 0.84078 \\ 1813 & 2.2000 & 0.01370 & 1.03360 & 0.0010 & 0.00623 & 2.186 & 0.68874 & 0.69306 \\ 1814 & 3.0000 & 0.01850 & 1.02800 & 0.0010 & 0.00617 & 2.981 & 0.57394 & 0.57750 \\ 1815 & 0.7560 & 0.00580 & 1.04190 & 0.0010 & 0.00767 & 0.750 & 0.85887 & 0.86551 \\ 1816 & 0.5100 & 0.00429 & 1.04320 & 0.0010 & 0.00841 & 0.506 & 0.88552 & 0.89303 \\ 1817 & 0.5000 & 0.00411 & 1.04420 & 0.0010 & 0.00822 & 0.496 & 0.90601 & 0.91352 \\ 1818 & 0.2000 & 0.00186 & 1.04650 & 0.0008 & 0.00930 & 0.198 & 0.95304 & 0.96199 \\ 1819 & 1.0000 & 0.00755 & 1.04050 & 0.0010 & 0.00755 & 0.9 .92 & 0.83017 & 0.83648 \\ 1820 & 1.0000 & 0.01755 & 1.04020 & 0.0010 & 0.00755 & 0.992 & 0.82402 & 0.83029\end{array}$


NEON SEPARATION DATA

SAMPLE NUMBER 64

$\begin{array}{lccccccccc}\text { RUN } & \text { PF } & \text { PB } & \text { RATIO } & \text { CUT } & R & \text { DELTA } & 2 & 211-W \\ 1384 & 0.9840 & 0.00600 & 1.01960 & 0.0006 & 0.00610 & 0.978 & 0.40168 & 0.40415 \\ 1385 & 2.1000 & 0.00740 & 1.00830 & 0.0003 & 0.00352 & 2.093 & 0.17008 & 0.17068 \\ 1386 & 0.5008 & 0.00400 & 1.02870 & 0.0012 & 0.00799 & 0.497 & 0.58836 & 0.59309 \\ 1387 & 0.5150 & 0.00320 & 1.02860 & 0.0012 & 0.00621 & 0.512 & 0.58629 & 0.58995 \\ 1388 & 0.2120 & 0.00138 & 1.03850 & 0.0005 & 0.00651 & 0.211 & 0.78898 & 0.79415 \\ 1389 & 0.3080 & 0.00150 & 1.03530 & 0.0007 & 0.00487 & 0.306 & 0.72346 & 0.72700 \\ 1390 & 0.2120 & 0.00100 & 1.03860 & 0.0005 & 0.00472 & 0.211 & 0.79101 & 0.79476 \\ 1391 & 0.1000 & 0.00040 & 1.04140 & 0.0007 & 0.00400 & 0.100 & 0.84848 & 0.85189 \\ 1392 & 0.0600 & 0.00018 & 1.04130 & 0.0009 & 0.00300 & 0.060 & 0.84650 & 0.84905 \\ 1393 & 0.1060 & 0.00120 & 1.04120 & 0.0007 & 0.01132 & 0.105 & 0.84439 & 0.85406 \\ 1394 & 0.1040 & 0.00200 & 1.04130 & 0.0007 & 0.01923 & 0.102 & 0.84644 & 0.86304 \\ 1395 & 0.7624 & 0.00420 & 1.02480 & 0.0005 & 0.00551 & 0.758 & 0.50823 & 0.51105 \\ 1396 & 0.4140 & 0.00200 & 1.03230 & 0.0007 & 0.00483 & 0.412 & 0.66199 & 0.66520 \\ 1397 & 1.5000 & 0.00780 & 1.011170 & 0.0009 & 0.00520 & 1.492 & 0.23982 & 0.24107 \\ 1398 & 0.1020 & 0.00046 & 1.044190 & 0.0007 & 0.00451 & 0.102 & 0.85874 & 0.86263 \\ 1399 & 0.0552 & 0.00040 & 1.04200 & 0.0008 & 0.00725 & 0.055 & 0.86084 & 0.86712 \\ 1400 & 0.0520 & 0.00136 & 1.04220 & 0.0009 & 0.02615 & 0.051 & 0.86495 & 0.88818 \\ 1401 & 1.2100 & 0.00700 & 1.01640 & 0.0005 & 0.00579 & 1.203 & 0.33607 & 0.33803 \\ 1402 & 2.4700 & 0.01460 & 1.00720 & 0.0003 & 0.00591 & 2.455 & 0.14753 & 0.14841 \\ 1403 & 3.0200 & 0.01720 & 1.00520 & 0.0003 & 0.00570 & 3.003 & 0.10635 & 0.10716 \\ 1404 & 3.5600 & 0.02100 & 1.00400 & 0.0003 & 0.00590 & 3.539 & 0.08196 & 0.08245 \\ 1405 & 0.7500 & 0.00440 & 1.02410 & 0.0017 & 0.00587 & 0.746 & 0.49417 & 0.49709 \\ 1406 & 4.0000 & 0.02120 & 1.00240 & 0.0003 & 0.00530 & 3.979 & 0.04918 & 0.04944 \\ 1407 & 4.6100 & 0.02680 & 1.00240 & 0.0003 & 0.00581 & 4.583 & 0.04918 & 0.04947\end{array}$




$\begin{array}{lccccccccc}\text { RUN } & \text { PF } & \text { PB } & \text { RATIO } & \text { CUT } & R & \text { DELTA } P & 2 & 2 / 1-W \\ 1408 & 5.0300 & 0.02920 & 1.00190 & 0.0003 & 0.00581 & 5.001 & 0.03893 & 0.03916 \\ 1409 & 6.0400 & 0.02240 & 1.00140 & * 0.0003 & 0.00371 & 6.018 & 0.02869 & 0.02879 \\ 1410 & 7.0400 & 0.02660 & 1.00080 & * 0.0003 & 0.00378 & 7.013 & 0.01639 & 0.01645 \\ 1411 & 6.0900 & 0.03520 & 1.00160 & * 0.0003 & 0.00578 & 6.055 & 0.03278 & 0.03298 \\ 1412 & 8.0200 & 0.04580 & 1.00050 & * 0.0003 & 0.00571 & 7.974 & 0.01025 & 0.01030 \\ 1413 & 7.5200 & 0.04440 & 1.00010 & * 0.0003 & 0.00590 & 7.476 & 0.00205 & 0.00206 \\ 1414 & 5.4800 & 0.03160 & 1.00140 & * 0.0003 & 0.00577 & 5.448 & 0.02869 & 0.02885 \\ 1415 & 10.0000 & 0.03860 & 1.00005 & * 0.0004 & 0.00386 & 9.961 & 0.00102 & 0.00103 \\ 1416 & 4.0000 & 0.02240 & 1.00320 & 0.0003 & 0.00560 & 3.978 & 0.06557 & 0.06594 \\ 1417 & 7.5200 & 0.04320 & 1.00050 & * 0.0003 & 0.00574 & 7.477 & 0.01025 & 0.01030 \\ 1800 & 0.2120 & 0.00493 & 1.03850 & 0.0005 & 0.02325 & 0.207 & 0.78898 & 0.80776 \\ 1801 & 0.1020 & 0.00220 & 1.04170 & 0.0007 & 0.02157 & 0.100 & 0.85465 & 0.87349 \\ 1802 & 0.3000 & 0.00574 & 1.03640 & 0.0004 & 0.01913 & 0.294 & 0.74591 & 0.76046\end{array}$


NEON SEPARATION DATA

SAMPLE NUMBER 2

\begin{tabular}{lccccccccc} 
RUN & PF & PB & RAT10 & CUT & $R$ & DELTA & $Z$ & $Z 11-W$ \\
\hline 1598 & 0.5000 & 0.03160 & 1.02930 & 0.0011 & 0.06320 & 0.468 & 0.60061 & 0.64113 \\
1599 & 0.1000 & 0.00960 & 1.04080 & 0.0010 & 0.09600 & 0.090 & 0.83629 & 0.92510 \\
1600 & 0.0500 & 0.00500 & 1.04090 & 0.0013 & 0.10000 & 0.045 & 0.83847 & 0.93164 \\
1601 & 0.0508 & 0.00400 & 1.04090 & 0.0013 & 0.07874 & 0.047 & 0.83848 & 0.91014 \\
1602 & 2.1000 & 0.06520 & 1.00770 & 0.0020 & 0.03105 & 2.035 & 0.15791 & 0.16297 \\
1603 & 1.0200 & 0.04020 & 1.01980 & 0.0019 & 0.03941 & 0.980 & 0.40604 & 0.42270 \\
1605 & 2.4600 & 0.06080 & 1.00510 & 0.0017 & 0.02472 & 2.399 & 0.10458 & 0.10723 \\
1606 & 3.0200 & 0.07340 & 1.00410 & 0.0018 & 0.02430 & 2.947 & 0.08407 & 0.08617 \\
1607 & 1.5000 & 0.04200 & 1.01310 & 0.0018 & 0.02800 & 1.458 & 0.26862 & 0.27636 \\
1669 & 0.5020 & 0.02188 & 1.02840 & 0.0017 & 0.04359 & 0.480 & 0.58234 & 0.60888 \\
1670 & 0.7000 & 0.02787 & 1.02440 & 0.0017 & 0.03981 & 0.672 & 0.50033 & 0.52107 \\
1671 & 1.0010 & 0.03998 & 1.01800 & 0.0017 & 0.03994 & 0.9 .61 & 0.36910 & 0.38445 \\
1672 & 1.5000 & 0.05415 & 1.01150 & 0.0017 & 0.03610 & 1.446 & 0.23581 & 0.24464 \\
1674 & 2.5040 & 0.07225 & 1.00580 & 0.0018 & 0.02885 & 2.432 & 0.11893 & 0.12247 \\
1675 & 0.1000 & 0.02160 & 1.03530 & 0.0014 & 0.21600 & 0.078 & 0.72372 & 0.92311 \\
1676 & 0.0502 & 0.01365 & 1.03540 & 0.0013 & 0.27191 & 0.037 & 0.72573 & 0.99676 \\
1677 & 0.2020 & 0.01701 & 1.03770 & 0.0016 & 0.08421 & 0.185 & 0.77302 & 0.84410 \\
1678 & 0.2988 & 0.01443 & 1.03570 & 0.0017 & 0.04829 & 0.284 & 0.73203 & 0.76918 \\
1679 & 2.9900 & 0.12975 & 1.00380 & 0.0017 & 0.04339 & 2.860 & 0.07792 & 0.08145 \\
1680 & 3.5000 & 0.08926 & 1.00340 & 0.0016 & 0.02550 & 3.411 & 0.06971 & 0.07154 \\
1681 & 4.0000 & 0.10322 & 1.00270 & 0.0015 & 0.02580 & 3.897 & 0.05536 & 0.05682 \\
1682 & 4.0280 & 0.12055 & 1.00280 & 0.0006 & 0.02993 & 3.907 & 0.05738 & 0.05915 \\
1683 & 3.5160 & 0.09847 & 1.00370 & 0.0006 & 0.02801 & 3.418 & 0.07583 & 0.07801 \\
1684 & 2.9940 & 0.07675 & 1.00490 & 0.0005 & 0.02563 & 2.917 & 0.10042 & 0.10306
\end{tabular}




$\begin{array}{llllllllll}\text { RUN } & \text { PF } & \text { PB } & \text { RAT10 } & \text { CUT } & \text { R } & \text { DELTA P } & Z & Z \text { II-H } \\ 1685 & 2.0080 & 0.05730 & 1.00870 & 0.0005 & 0.02854 & 1.951 & 0.17829 & 0.18353 \\ 1686 & 0.9960 & 0.03258 & 1.02040 & 0.0005 & 0.03271 & 0.963 & 0.41804 & 0.43218 \\ 1687 & 0.5048 & 0.02038 & 1.03050 & 0.0005 & 0.04037 & 0.484 & 0.62505 & 0.65134 \\ 1688 & 0.3014 & 0.02141 & 1.03540 & 0.0006 & 0.07104 & 0.280 & 0.72548 & 0.78096 \\ 1689 & 0.1996 & 0.01598 & 1.03780 & 0.0007 & 0.08006 & 0.184 & 0.77470 & 0.84212 \\ 1690 & 0.0996 & 0.02125 & 1.03670 & 0.0008 & 0.21335 & 0.078 & 0.75220 & 0.95621 \\ 1691 & 0.0502 & 0.01288 & 1.03520 & 0.0010 & 0.25657 & 0.037 & 0.72151 & 0.97052\end{array}$


NEON SEPARATIDN DATA

SAMPLE NUMBER I

\begin{tabular}{|c|c|c|c|c|c|c|c|c|}
\hline JN & & 8 & 800 & UT & R & LTA & $\mathbf{z}$ & II-H \\
\hline 338. & .0120 & 1.12200 & 210 & 015 & 2434 & 390 & 306 & 0401 \\
\hline $39:$ & .1260 & .06570 & 1.00700 & .0015 & 0.03090 & 060 & .14352 & 1481 \\
\hline 341 & 9968 & 03820 & 0 & 022 & 03832 & 959 & .37944 & 45 \\
\hline 342 & .5080 & .06000 & 1.01080 & 0017 & .03979 & 448 & .22146 & 30 \\
\hline 14 & 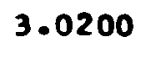 & $\$ 60$ & 60 & DI5. & 11 & 935 & 1431 & \\
\hline 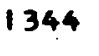 & .0040 & & & & & 900 & & \\
\hline 349 & 0.2160 & .01280 & 1.03720 & 258 & 26 & 03 & 218 & 0.8208 \\
\hline 15 & 2058 & 0 & 1.0 & 2 & 0 & & 0 & \\
\hline 35 & B & 0 & & & & & & \\
\hline 361 & & & & & & & & \\
\hline 362 & & & & & & & & \\
\hline 36 & & & & & & & & \\
\hline 367 & & 0 . & & & & & & \\
\hline 368 & & & & & & & & \\
\hline & & & & & & & & \\
\hline 17 & & & & & & & & \\
\hline . & & & & & & & & \\
\hline 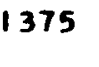 & 年 & & & & & & & \\
\hline- & & & & & & & & \\
\hline & & & & & & & & \\
\hline & & & & & & & & \\
\hline & & & & & & & & \\
\hline & & & & & & & & \\
\hline & 101 & 0.01039 & 1.03920 & .0031 & 0.1027 & 0.0 .91 & 0.80437 & 1.8904 \\
\hline
\end{tabular}




$\begin{array}{lllllllll}\text { RUN } & \text { PF } & \text { PB } & \text { RAT10 } & \text { CUT } & \text { R } & \text { DELTA P } & 2 & 211-W \\ 1759 & 0.0505 & 0.00610 & 1.04010 & 0.0038 & 0.12070 & 0.044 & 0.82312 & 0.93610 \\ 1760 & 0.5046 & 0.01489 & 1.02870 & 0.0017 & 0.02951 & 0.490 & 0.58849 & 0.60638 \\ 1761 & 0.2512 & 0.00869 & 1.03620 & 0.0022 & 0.03459 & 0.243 & 0.74247 & 0.76908\end{array}$


NEON SEPARATION DATA

SAMPLE NUMBER 5

\begin{tabular}{|c|c|c|c|c|c|c|c|c|}
\hline RUN & - PF & P. B & RATIO & CUT & R. & DELTA P & 2 & $2 / 1-H$ \\
\hline $1763^{\circ}$ & 0.4018 & 0.01065 & 1.03990 & 0.0019 & .0 .02651 & 0.391 & 0.81822 & 0.84050 \\
\hline 1764 & 2.5200 & $0.0 .1779^{\circ}$ & 1.01730 & 0.0237 & 0.00706 & 2.502 & 0.3587 .3 & 0.36128 \\
\hline 1765 & 1.0244 & 0.02089 & 1.03140 & 0.0021 & 0.02039 & .1 .004 & 0.64397 & 0.65738 \\
\hline $1766^{\circ}$ & 0.7566 & 0.01851 & 1.03370 & $0.0020^{\circ}$ & 0.02446 & .738 & 0.691 .11 & 0.70844 \\
\hline 767 & 0.4918 & 0.01262 & 1.03890 & $0: 0019$ & 0.02566 & 0.479 & 0.79771 & 0.818 .72 \\
\hline 768 & 3.0180 & 0.01815 & 1.01540 & 0.0259 & 0.00601 & 3.000 & 0.31969 & 0.32162 \\
\hline 769 & $3.5700^{\circ}$ & 0.02291 & 1.01240 & 0.0262 & 0.00642 & 547 & 0.25745 & 0.25912 \\
\hline 770 & 4.0440 & 0.01572 & 1.0 .1120 & 0.0 & 0.00389 & 28 & 23275 & 3365 \\
\hline 771 & 0.3058 & 0.00936 & 1.04100 & 0.0018 & 0.03061 & 96 & 0.84077 & 732 \\
\hline 772 & 0.2300 & .00662 & 1.04240 & 0.0019 & 0. & 3 & 51 & 28 \\
\hline 773 & 0.1004 & 0387 & 4410 & 0 & 0 & 7 & 418 & 043 \\
\hline 774 & 4.4780 & 02549 & 20 & 0.0294 & 569 & 53 & 21212 & 34 \\
\hline 1775 & 1.5008 & 02606 & 1. & 0.002 & 0 & 475 & 6 & 55 \\
\hline 776 & 2.0000 & $24+4+3$ & I & 0023 & 0 & 8 & 04 & 35 \\
\hline 1777 & 5.0180 & c & 1 & 0 & 1582 & & 69 & 69 \\
\hline 1778 & 5.9680 & 7 & 1 & 0 & 0 & 6 & 78 & 58 \\
\hline 779 & 7.0580 & 739 & $\mathbf{I}$ & 0 & 0 & 21 & 82 & 745 \\
\hline 1780 & 8.0360 & 0.02653 & 1.00510 & 0.0383 & 00330 & 109 & 0.10655 & 0.10691 \\
\hline 781 & 9.0380 & 0.02886 & 1.00460 & 0.0411 & 0.00319 & 109 & 0.09625 & 19656 \\
\hline 1782 & 9.8340 & 3360 & 0360 & 0434 & 0.00342 & no & 0.07542 & 17567 \\
\hline 783 & 0.4916 & 0.01240 & 03020 & 0091 & 02522 & 479 & 0.74506 & 0.76434 \\
\hline 1784 & 0.2086 & 0.00650 & 1.04220 & 049 & 0.03116 & 02 & 0.86669 & 0.89456 \\
\hline 785 & 0.1992 & 00060 & 1.04300 & 0008 & 0.03313 & 0.193 & 0.88128 & 0.91148 \\
\hline 786 & 0.5020 & 0.011157 & 1.03770 & 0.0008 & 0.02305 & 0.490 & 0.77270 & 0.79093 \\
\hline
\end{tabular}




$\begin{array}{lllllllll}\text { RUN } & \text { PF } & \text { PB } & \text { RATIO } & \text { CUT } & \text { R } & \text { DELTA P } & 2 & 2 / 1-W \\ 1793 & 5.1000 & 0.03361 & 1.00950 & 0.0006 & 0.00659 & 5.066 & 0.19470 & 0.19599 \\ 1794 & 5.1000 & 0.07290 & 1.00980 & 0.0031 & 0.01429 & 5.027 & 0.20109 & 0.20400 \\ 1795 & 6.0100 & 0.07400 & 1.00730 & 0.0032 & 0.01231 & 5.936 & 0.14980 & 0.15167 \\ 1796 & 7.0200 & 0.04110 & 1.00620 & 0.0033 & 0.00585 & 6.979 & 0.12723 & 0.12798 \\ 1797 & 8.0400 & 0.04628 & 1.00550 & 0.0038 & 0.00576 & 7.994 & 0.11290 & 0.11355 \\ 1798 & 3.0200 & 0.04788 & 1.01570 & 0.0025 & 0.01585 & 2.972 & 0.32206 & 0.32725 \\ 1799 & 4.0000 & 0.06407 & 1.01230 & 0.0028 & 0.01602 & 3.936 & 0.25235 & 0.25646\end{array}$


APPENDIX C - ACCURACY AND PRECISION

\section{MASS SPECTROMETER MEASUREMENTS}

A quality control test was conducted to monitor the performance of the mass spectrometer during the period of this study. Neon samples were prepared by collecting appropriately large samples from several of the separation tests. Ratios of the isotopic ratios were measured by the mass spectrometer by pairing together individual product samples with multiple feed samples and individual feed samples with multiple product samples. The ratio of the ${ }^{22} \mathrm{Ne} /\left(1-{ }^{22} \mathrm{Ne}\right)$ for the product sample to the ${ }^{22} \mathrm{Ne} /\left(1-{ }^{22} \mathrm{Ne}\right)$ for the feed sample was calculated to give a value, $R$, for the ratio of isotopic ratios.

Thirteen control samples with varying ${ }^{22} \mathrm{Ne} /\left(1-{ }^{22} \mathrm{Ne}\right)$ were prepared and paired together to form 19 ratio pairs with $R$ values ranging from 1.008 to 1.043. These paired control materials were analyzed from October 1967 to March 1970 for a total of 117 analyses. The following statistical estimates were obtained from the analyses:

$$
\begin{array}{lr}
\text { Variance per individual }(\mathrm{R}-1) \text { result: } & 0.19 \times 10^{-6} \\
\text { Standard deviation per individual }(\mathrm{R}-1) \text { result: } & \pm 0.44 \times 10^{-3} \\
95 \% \text { confidence level per individual }(\mathrm{R}-1) \text { result: } \cdot \pm 0.86 \times 10^{-3}
\end{array}
$$

There is no known bias associated with the measurements.

\section{FLOW MEASUREMENTS}

The flow measurements on all the test samples were made with the volumetric flow system described in the text. The precision of the volumetric system was checked by measuring flow rates through a jeweled orifice with a throat diameter of 0.001 in. Measurements were also made with the gravimetric flow system which was designed and constructed at ORGDP and has been compared with NBS standards.* Table C-1 shows a comparison between the weasurements made with the grávimetric system and the volumetric system. Table C-2 shows results of viscosity ratios and slip intercepts with standard deviations obtained from measurements with different gases on the test sample 1054 .

*Collins, W. T., and Selby, T. W., Gravimetric Mass Flow Standard. Part 1: Design and Construction, Union Carbide Corporation, Nuclear Division, Oak Ridge Gaseous Diffusion Plant, May 18, 1965 (K-1632, Part 1).

Collins, W. T., and Selby, T. W., Grovimetric Mass Flow Standard. Part 2: Performance and Evaluation, Union Carbide Corporation, Nuclear Division, Oak Ridge Gaseous Diffusion Plant, April 15, 1966 (K-1632, Part 2). 
Table C-1

COMPARISON OF FLOW MEASUREMENTS FROM A VOLUMETRIC

SYSTEM WITH THOSE FROM A GRAVIMETRIC SYSTEM

Gravimetric System

A fit of seven measurements gave:

$F($ std $c c / m i n)=0.07934 P_{f}-0.0992$

Standard deviation $=0.0179$

Percent deviation at midpoint of curve $=0.074 \%$

Volumetric System

A fit of 24 measurements gave:

$\mathrm{F}(\mathrm{std} \mathrm{cc} / \mathrm{min})=0.4710 \times 10^{-5} \mathrm{P}_{\mathrm{f}}{ }^{2}+0.07666 \mathrm{P}_{\mathrm{f}}-0.5865$

Standard deviation $=0.014$

Percent deviation at midpoint of curve $=0.083 \%$

Comparison of Two Systems

Pcreent dIfference in values calculated from the curves at the midpoint of the region where the two sets of data overlap: $0.12 \%$

Note: Standard conditions referred to are $76 \mathrm{~cm} \mathrm{Hg}$ at $25^{\circ} \mathrm{C}$. 
Table C-2

COMPARISON OF MEASURED AND

THEORETICAL VALUES FOR DIFFERENT GASES

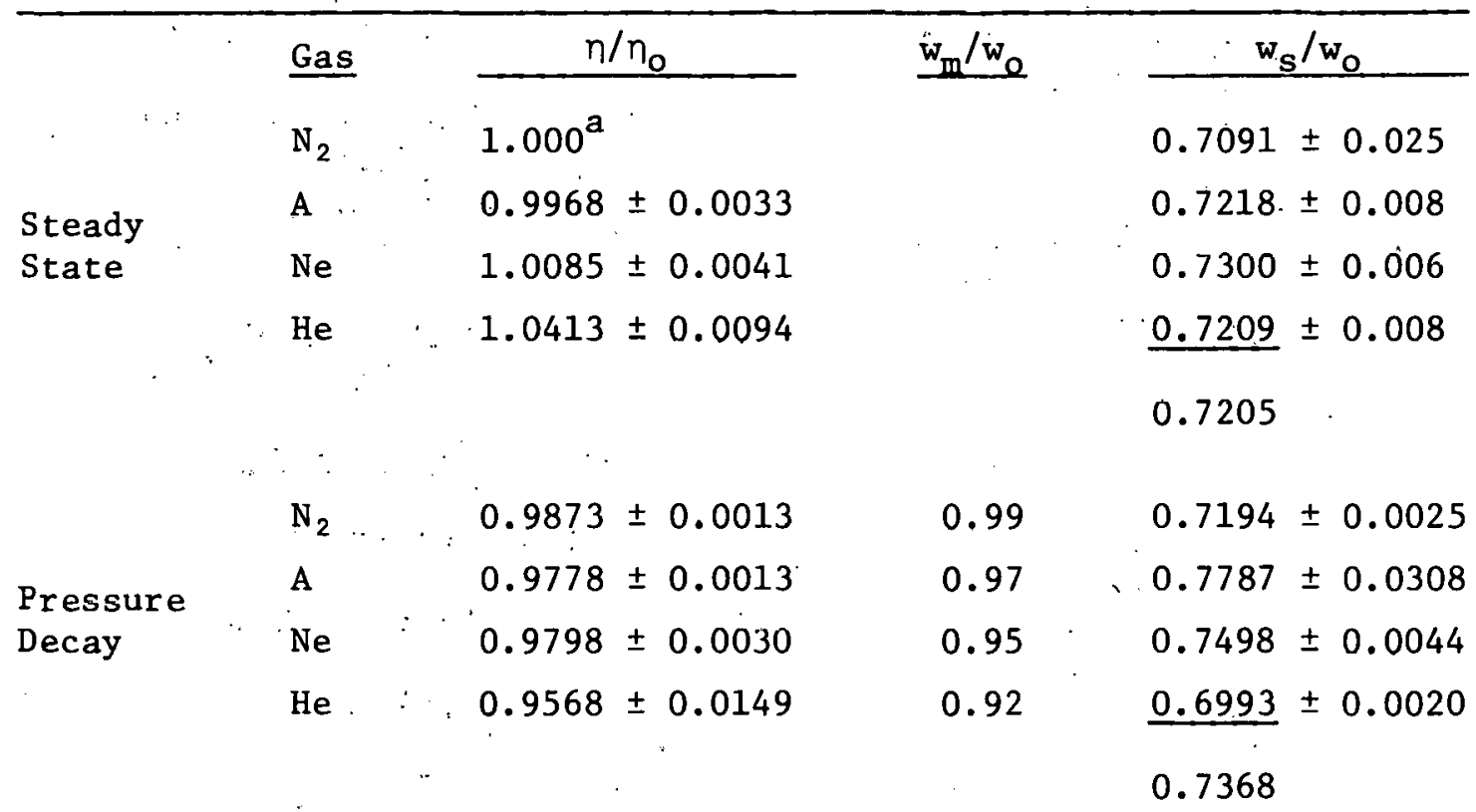

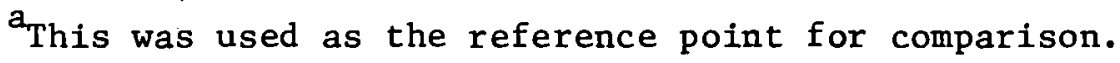




\section{INTERNAL DISTR IBUTION}

1. Barrier Manufacturing Division

Strang, F.

2- 3. Engineering Division Patton, F. S.

Rooks, W. E.

4-47. Gaseous Diffusion Development Division Brown, W. K. (4) Bundy; R. D. Burton, D. W. Collins, W. T. Fain, D. E. (25) Harris, E. B. Higgins, R. L. Kidd, G. J., Jr. King, C. J . Lund, L. M. Malling, G. F. McGill, R. M. Melroy, P. E. Pashley, J. H. Ritter, R. L. Sirreetman, K: D. Tramme11, H. E。
48-51. Laboratory Division Barton, J. C. Garber, J. W. Smith, L. A. Ziehlke, K. T.

52-53. Planning and Analysis Division Lang, D. M. Von Halle, E.

54. Plant Library Ferguson, J. B.

55-56. Plant Records (RC)

57. Sommerfeld, K. W.

58. W11cox, W. J., Jr .

59. Winkel, R. A.

60-61. Y-12 Plant

Googin, J. M.

Vanoerum, F: R:

EXTERNAL DISTRIBUTION

62-185. TIC-4500 